\title{
Analysis of the Relationship Between Vehicle Weight/Size and Safety, and Implications for Federal Fuel Economy Regulation
}

\begin{abstract}
Final Report prepared for the Office of Energy Efficiency and Renewable Energy, US Department of Energy
\end{abstract}

\author{
Prepared by \\ Tom Wenzel \\ Energy Analysis Department \\ Environmental Energy Technologies Division \\ Lawrence Berkeley National Laboratory \\ Berkeley, CA 94720
}

March 2010

This work was supported by the Assistant Secretary for Energy Efficiency and Renewable Energy, Director of Strategic Planning and Analysis, of the U.S. Department of Energy under Contract No. DE-AC02-05CH11231. 


\section{DISCLAIMER}

This document was prepared as an account of work sponsored by the United States Government. While this document is believed to contain correct information, neither the United States Government nor any agency thereof, nor The Regents of the University of California, nor any of their employees, makes any warranty, express or implied, or assumes any legal responsibility for the accuracy, completeness, or usefulness of any information, apparatus, product, or process disclosed, or represents that its use would not infringe privately owned rights. Reference herein to any specific commercial product, process, or service by its trade name, trademark, manufacturer, or otherwise, does not necessarily constitute or imply its endorsement, recommendation, or favoring by the United States Government or any agency thereof, or The Regents of the University of California. The views and opinions of authors expressed herein do not necessarily state or reflect those of the United States Government or any agency thereof, or The Regents of the University of California.

Ernest Orlando Lawrence Berkeley National Laboratory is an equal opportunity employer. 


\section{Table of Contents}

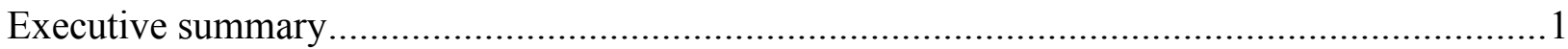

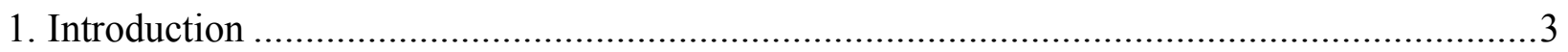

2. Relationship between vehicle weight and size .......................................................... 3

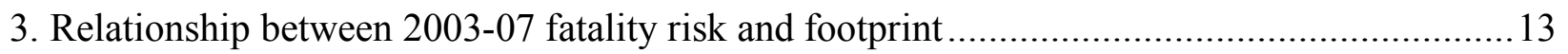

4. Relationship between 2000-04 casualty risk and footprint ..........................................20

5. Risks in truck-based and car-based SUVs................................................................... 42

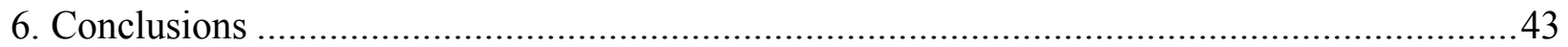

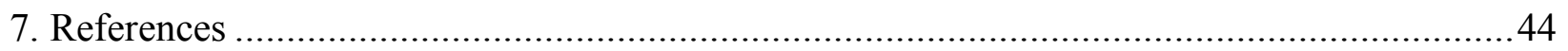

\section{List of Tables and Figures}

Figure 2-1. Sales-weighted average wheelbase by vehicle type, 2005 vehicles (diamonds represent range in wheelbase for models within each vehicle type) .................................5

Figure 2-2. Sales-weighted average track width by vehicle type, 2005 vehicles (diamonds represent range in track width for models within each vehicle type) .............................5

Figure 2-3. Sales-weighted average footprint by vehicle type, 2005 vehicles (diamonds represent range in footprint for models within each vehicle type)

Figure 2-4. Sales-weighted average curb weight by vehicle type, 2005 vehicles (diamonds

represent range in curb weight for models within each vehicle type).............................6

Figure 2-5. Vehicle footprint and curb weight by vehicle type, 2005 vehicle models ................7

Figure 2-6. Vehicle footprint and curb weight by car type, 2005 car models..........................8

Figure 2-7. Vehicle footprint and curb weight by light truck type, 2005 light truck models ........8

Figure 2-8. Range in vehicle curb weight for selected 2005 vehicle models............................9

Figure 2-9. Wheelbase and track width, 2005 vehicle models........................................ 10

Figure 2-10. Wheelbase and track width, 2005 car models .................................................. 10

Figure 2-11. Wheelbase and track width, 2005 light truck models ..................................... 11

Table 2-1. Summary results of relationship between model year 2005 vehicle weight and size,

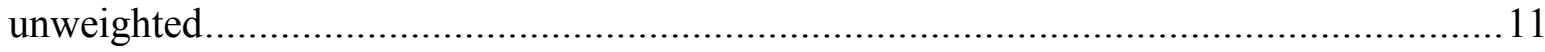

Table 2-2. Summary results of relationship between model year 2005 vehicle weight and size,

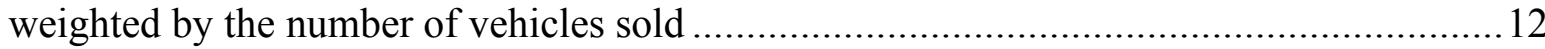

Figure 3-1. Relationship between 2003-07 US fatality risk to drivers and vehicle footprint, by

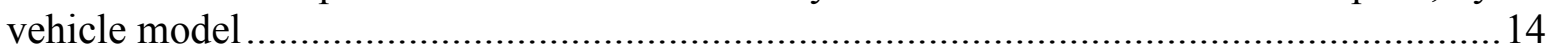

Figure 3-2. Relationship between 2003-07 US fatality risk to drivers and car footprint, by car

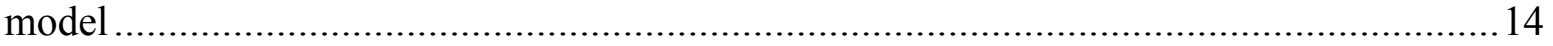

Figure 3-3. Relationship between 2003-07 US fatality risk to drivers and light truck footprint, by

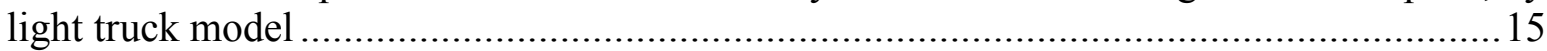

Figure 3-4. Relationship between 2003-07 US fatality risk to drivers of other vehicles and vehicle footprint, by vehicle model.................................................................. 16

Figure 3-5. Relationship between 2003-07 US fatality risk to drivers of other vehicles and car

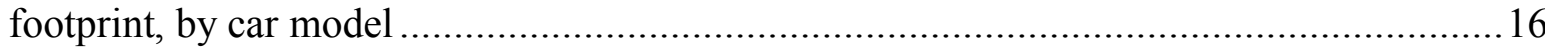


Figure 3-6. Relationship between 2003-07 US fatality risk to drivers of other vehicles and light truck footprint, by light truck model

Figure 3-7. Relationship between 2003-07 US fatality risk to drivers in frontal (non-rollover) crashes and vehicle wheelbase, by vehicle model

Figure 3-8. Relationship between 2003-07 US fatality risk to drivers in left side (non-rollover) crashes and vehicle track width, by vehicle model.

Table 3-1. Summary results of relationship between vehicle weight/size and casualty risk (excluding crashes involving young male or elderly drivers, and crashes in very rural or urban counties), by vehicle model, unweighted.

Table 3-2. Summary results of relationship between vehicle weight/size and casualty risk (excluding crashes involving young male or elderly drivers, and crashes in very rural or urban counties), by vehicle model, weighted by the number of MY05 vehicles sold.

Figure 4-1. Distribution of drivers of 2000-04 vehicles in state crash data, by population density of county in which crash occurred

Figure 4-2. Casualty risk for drivers (excluding young males and elderly drivers), by population density decile and vehicle type.....

Figure 4-3. Distribution of police-reported crashes, by population density decile and vehicle

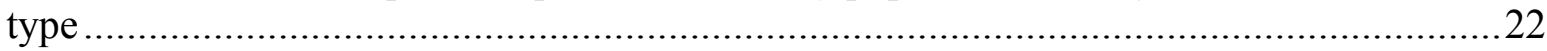

Figure 4-4. State casualty and US fatality risk for drivers, by vehicle type..........................23

Figure 4-5. State casualty and US fatality risk to drivers of other vehicles, by vehicle type ......24

Figure 4-6. Casualty risk for drivers accounting for driver age and crash location, by vehicle type

Figure 4-7. Casualty risk to others accounting for driver age and crash location, by vehicle type

Figure 4-8. Relationship between casualty risk to drivers and vehicle curb weight, by vehicle model (casualty risk is calculated excluding crashes involving young male or elderly drivers, and crashes in very rural or very urban counties) .....

Figure 4-9. Relationship between casualty risk to drivers and car curb weight, by car model (casualty risk is calculated excluding crashes involving young male or elderly drivers, and crashes in very rural or very urban counties).

Figure 4-10. Relationship between casualty risk to drivers and light truck curb weight, by light truck model (casualty risk is calculated excluding crashes involving young male or elderly drivers, and crashes in very rural or very urban counties)

Figure 4-11. Relationship between casualty risk to drivers and vehicle footprint, by vehicle model (casualty risk is calculated excluding crashes involving young male or elderly drivers, and crashes in very rural or very urban counties) ....

Figure 4-12. Relationship between casualty risk to drivers and car footprint, by car model (casualty risk is calculated excluding crashes involving young male or elderly drivers, and crashes in very rural or very urban counties).....

Figure 4-13. Relationship between casualty risk to drivers and light truck footprint, by light truck model (casualty risk is calculated excluding crashes involving young male or elderly drivers, and crashes in very rural or very urban counties) .....

Figure 4-14. Relationship between casualty risk to drivers in frontal crashes and vehicle wheelbase, by vehicle model (casualty risk is calculated excluding crashes involving young male or elderly drivers, and crashes in very rural or very urban counties) 
Figure 4-15. Relationship between casualty risk to drivers in left side crashes and vehicle track width, by vehicle model (casualty risk is calculated excluding crashes involving young male or elderly drivers, and crashes in very rural or very urban counties).

Figure 4-16. Relationship between casualty risk to drivers of other vehicles and vehicle wheelbase, by vehicle model (casualty risk is calculated excluding crashes involving young male or elderly drivers, and crashes in very rural or very urban counties).....

Figure 4-17. Relationship between casualty risk to drivers of other vehicles and car wheelbase, by car model (casualty risk is calculated excluding crashes involving young male or elderly drivers, and crashes in very rural or very urban counties)

Figure 4-18. Relationship between casualty risk to drivers of other vehicles and light truck wheelbase, by light truck model (casualty risk is calculated excluding crashes involving young male or elderly drivers, and crashes in very rural or very urban counties).

Figure 4-19. Relationship between casualty risk to drivers of other vehicles and vehicle footprint, by vehicle model (casualty risk is calculated excluding crashes involving young male or elderly drivers, and crashes in very rural or very urban counties) ...........................34

Figure 4-20. Relationship between casualty risk to drivers of other vehicles and car footprint, by car model (casualty risk is calculated excluding crashes involving young male or elderly drivers, and crashes in very rural or very urban counties)

Figure 4-21. Relationship between casualty risk to drivers of other vehicles and light truck footprint, by light truck model (casualty risk is calculated excluding crashes involving young male or elderly drivers, and crashes in very rural or very urban counties)................35

Table 4-1. Summary results of relationship between vehicle weight/size and casualty risk (excluding crashes involving young male or elderly drivers, and crashes in very rural or urban counties), by vehicle model, unweighted...................................................................36

Table 4-2. Summary results of relationship between vehicle weight/size and casualty risk (excluding crashes involving young male or elderly drivers, and crashes in very rural or urban counties), by vehicle model, weighted by the number of vehicles of each model involved in police-reported crashes

Table 4-3. Casualty risk to drivers by vehicle model (excluding crashes involving young male or elderly drivers, and crashes in very rural or urban counties)..............................................38

Figure 4-22. Actual and predicted casualty risk to drivers by vehicle model, based on vehicle curb weight, footprint, and type (excluding crashes involving young male or elderly drivers, and crashes in very rural or urban counties).

Figure 4-23. Predicted and residual casualty risk to drivers by vehicle model, based on vehicle curb weight, footprint, and type (excluding crashes involving young male or elderly drivers, and crashes in very rural or urban counties).

Table 4-4. Casualty risk to drivers of other vehicles by vehicle model (excluding crashes involving young male or elderly drivers, and crashes in very rural or urban counties)........41

Table 5-1. Comparison of footprint, curb weight and risk, for SUVs and crossover SUVs.........43 


\section{Executive summary}

This report analyzes the relationship between vehicle weight, size (wheelbase, track width, and their product, footprint), and safety, for individual vehicle makes and models. Vehicle weight and footprint are correlated with a correlation coefficient $\left(\mathrm{R}^{2}\right)$ of about 0.62 . The relationship is stronger for cars (0.69) than for light trucks (0.42); light trucks include minivans, fullsize vans, truck-based SUVs, crossover SUVs, and pickup trucks. The correlation between wheelbase and track width, the components of footprint, is about 0.61 for all light vehicles, 0.62 for cars and 0.48 for light trucks. However, the footprint data used in this analysis does not vary for different versions of the same vehicle model, as curb weight does; the analysis could be improved with more precise data on footprint for different versions of the same vehicle model.

Although US fatality risk to drivers (driver fatalities per million registered vehicles) decreases as vehicle footprint increases, there is very little correlation either for all light vehicles (0.01), or cars $(0.07)$ or trucks $(0.11)$. The correlation between footprint and fatality risks cars impose on drivers of other vehicles is also very low (0.01); for trucks the correlation is higher (0.30), with risk to others increasing as truck footprint increases. Fatality risks reported here do not account for differences in annual miles driven, driver age or gender, or crash location by vehicle type or model. It is difficult to account for these factors using data on national fatal crashes because the number of vehicles registered to, for instance, young males in urban areas is not readily available by vehicle type or model.

State data on all police-reported crashes can be used to estimate casualty risks that account for miles driven, driver age and gender, and crash location. The number of vehicles involved in a crash can act as a proxy of the number of miles a given vehicle type, or model, is driven per year, and is a preferable unit of exposure to a serious crash than the number of registered vehicles. However, because there are relatively few fatalities in the states providing crash data, we calculate casualty risks, which are the sum of fatalities and serious or incapacitating injuries, per vehicle involved in a crash reported to the police. We can account for driver age/gender and driving location effects by excluding from analysis crashes (and casualties) involving young males and the elderly, and occurring in very rural or very urban counties.

Using state data on all police-reported crashes in five states, we find that excluding crashes involving young male and elderly drivers has little effect on casualty risk; however, excluding crashes that occurred in the most rural and most urban counties (based on population density) increases casualty risk for all vehicle types except pickups. This suggests that risks for pickups are overstated unless they account for the population density of the county in which the crashes occur. After removing crashes involving young males and elderly drivers, and those occurring in the most rural and most urban counties, we find that casualty risk in all light-duty vehicles tends to increase with increasing weight or footprint; however, the correlation $\left(\mathrm{R}^{2}\right)$ between casualty risk and vehicle weight is 0.31 , while the correlation with footprint is 0.23 . These relationships are stronger for cars than for light trucks. The correlation between casualty risk in frontal crashes and light-duty vehicle wheelbase is 0.12 , while the correlation between casualty risk in left side crashes and track width is 0.36 . We calculated separately the casualty risks vehicles impose on drivers of the other vehicles with which they crash. The correlation between casualty risk imposed by light trucks on drivers of other vehicles and light truck footprint is 0.15 , while 
the correlation with light truck footprint is 0.33 ; risk imposed on others increases as light truck weight or footprint increases.

Our analysis indicates that, after excluding crashes involving young male and elderly drivers, and crashes in very rural and very urban counties, and accounting for vehicle weight and footprint, sports cars, pickup trucks and truck-based SUVs have higher risk to their drivers than cars, while import luxury cars and crossover SUVs have lower risk to their drivers than cars. Similarly, pickups and sports cars impose a large casualty risk on drivers of other vehicles, after accounting for vehicle weight and footprint. Our analysis suggests that excluding young male and elderly drivers, and crashes in very rural and urban counties, accounting for vehicle weight, footprint, and type explains only about half of the variability in casualty risk to drivers, and to drivers of other vehicles, by vehicle model.

Car-based crossover SUVs provide an example of how manufacturers have designed vehicles that are lighter, and have higher fuel economy, and safer than conventional truck-based SUVs. On average, CSUVs have the same footprint, but are about 10\% lighter than truck-based SUVs. CSUVs also tend to have lower risks than SUVs, both for their drivers and to drivers of other vehicles. The safety record of crossover SUVs suggests that manufacturers are capable of designing vehicles that are lighter and have higher fuel economy, without sacrificing safety. 


\section{Introduction}

In 2007 the Energy Independence and Security Act (EISA) called on the National Highway Traffic Safety Administration (NHTSA) to adopt new fuel economy standards for light-duty trucks (minivans, SUVs, and pickup trucks) and cars. The new standards were to be "attributebased", in which the standards would vary according to a specific vehicle attribute. Based on analyses done previously, NHTSA selected the attribute of vehicle footprint (i.e. length, or wheelbase, times width, or track width) on which to base the new standard. NHTSA's rationale for selecting the footprint attribute was: 1) light trucks with larger footprint are safer for their occupants than light trucks with smaller footprint; and 2) wheelbase and track width, which are measured from the interior of the vehicle's tires, are more difficult to change, and thus circumvent the intent of the regulation, than a vehicle's overall length or width.

Wenzel and Ross (2005) analyzed fatality risk by vehicle model, using national driver fatalities and vehicle registrations. NHTSA criticized this analysis because it did not account for differences in driver age and gender, and crash location, across vehicle models. The Wenzel and Ross analysis used national vehicle registrations by model as its measure of exposure to calculate fatality risk; national registrations by owner age, gender, or zip code are not readily available, so the analysis could not account for driver or crash location variables. This report uses a new approach, casualty risks from state data on all police-reported crashes, to analyze the effect of driver and crash location on risk.

This report addresses three issues surrounding the relationship between vehicle weight, size and safety:

- how strong the correlation is between vehicle weight and size; and

- how accounting for driver age and gender and crash location affects casualty risk by vehicle model; and

- car-based "crossover" SUVs have lower risks to both their drivers and to others than conventional truck-based SUVs, while maintaining footprint and reducing weight by $10 \%$.

\section{Relationship between vehicle weight and size}

In its analysis of the relationship between vehicle weight and fatality risk, NHTSA argued that the weight and size of vehicles are so strongly correlated that their individual effects on fatality risk cannot be estimated (Kahane, 2003). Dynamic Research, Inc. (DRI) analyses (Van Auken and Zellner, 2002; Van Auken et al, 2003; Van Auken and Zellner, 2005a; Van Auken and Zellner, 2005b) replicated the NHTSA analyses using the same data and methods. DRI accounted for the separate effects of vehicle size (wheelbase and track width) and weight, and found that reducing weight in all vehicles, while maintaining their size, would result in a net decrease in fatalities. However, NHTSA still maintains that the independent effects of vehicle weight and size on fatality risk cannot be estimated (Kahane, 2004).

In this section we examine the relationship between vehicle weight and size, using the two variables that comprise vehicle footprint, wheelbase and track width. These data by vehicle 
model were provided by the US Department of Energy (DOE), from CAFE compliance data for model year 2005 (and later) vehicles. ${ }^{1}$ DOE also provided curb weight and vehicle sales by vehicle model. A vehicle's track width is the average of track width at its front and rear axle. For the most part, different versions of the same vehicle model nameplate have the same footprint; however, because of differences in engine size, transmission type, body style, and other factors, curb weight often varies for different versions of the same model. For models with a range of footprints and curb weights, sales-weighted values for each model were calculated by weighting the values for the different versions by the total sales of each version. Because the footprint and weight data come from CAFE compliance records, data are not available for light trucks larger than 8,500 lbs gross vehicle weight that are exempt from CAFE standards (most 3/4ton pickups, and all 1-ton pickups and vans; a small number of $3 / 4$-ton pickups are included in the CAFE compliance data provided us).

Figures 2-1 through 2-4 show model year 2005 sales-weighted wheelbase, track width, footprint, and curb weight, by vehicle type. Which vehicle type individual models are assigned to is somewhat arbitrary, based on definitions used in consumer literature such as the Consumer Guide. Conventional truck-based SUVs are treated separately from car-based crossover SUVs (the Jeep Cherokee and Grand Cherokee, which were the first to adopt some of the features of crossover SUVs, are included as truck-based SUVs in our categorization). In addition, because of vehicle design changes over time, some models have migrated to larger vehicle types (e.g. from a subcompact car to a compact or midsize car). The drop lines on the figures represent the range in vehicle dimensions for specific models within each vehicle type.

The figures indicate that size and mass tend to increase with increasing vehicle class; however, there is substantial range in size and mass within each vehicle class. Note that small and midsize crossover SUVs are roughly the same average size as their truck-based SUV counterparts, but weigh substantially less ( $9 \%$ and $18 \%$ less, respectively). Also note that, because most $3 / 4$-ton pickups are exempt from CAFE standards, they are not included in the figures; neither are 1-ton pickups and the larger fullsize vans.

\footnotetext{
1 The model year 2008 data provided were mid-model year data.
} 
Figure 2-1. Sales-weighted average wheelbase by vehicle type, 2005 vehicles (diamonds represent range in wheelbase for models within each vehicle type)

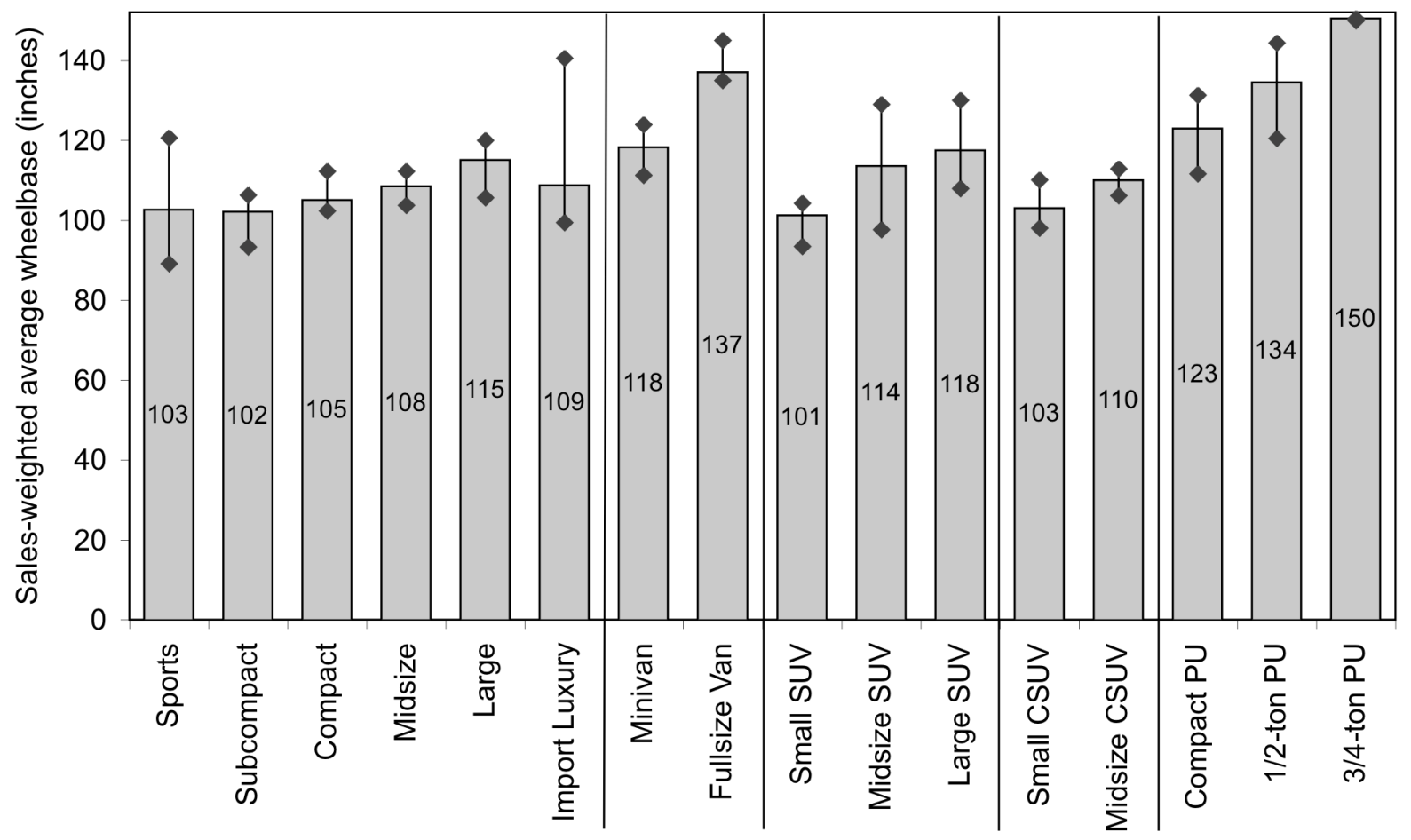

Figure 2-2. Sales-weighted average track width by vehicle type, 2005 vehicles (diamonds represent range in track width for models within each vehicle type)

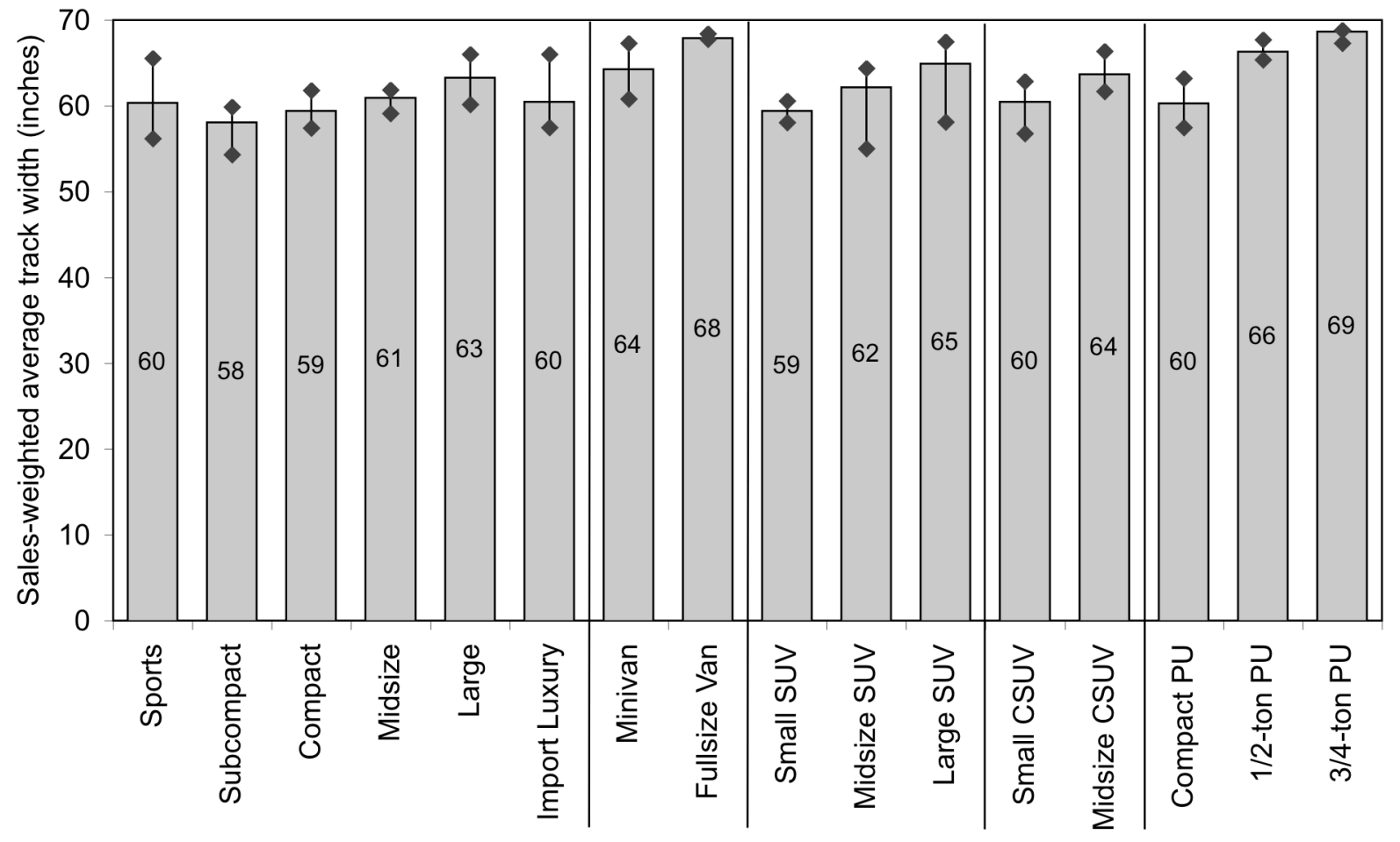


Figure 2-3. Sales-weighted average footprint by vehicle type, 2005 vehicles (diamonds represent range in footprint for models within each vehicle type)

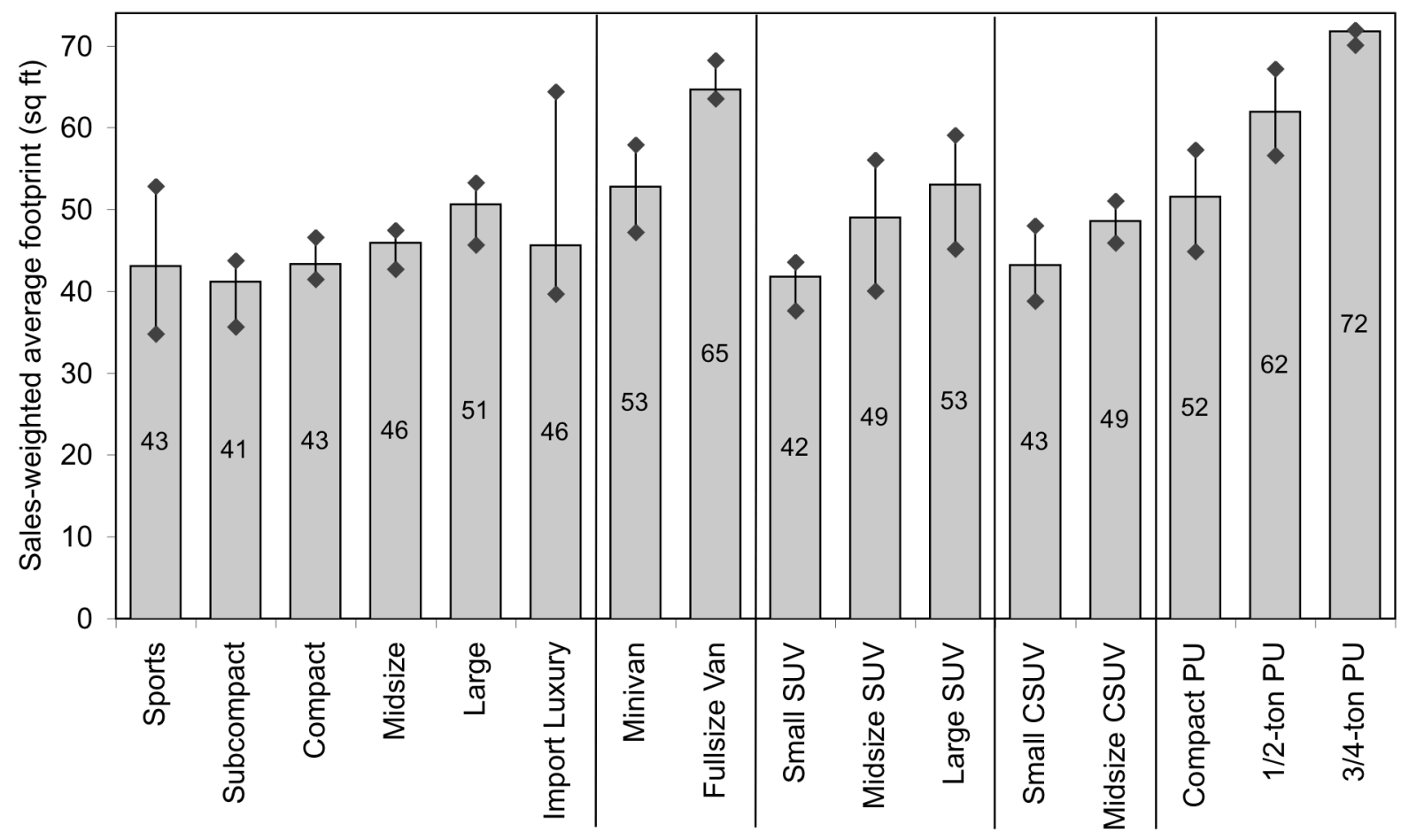

Figure 2-4. Sales-weighted average curb weight by vehicle type, 2005 vehicles (diamonds represent range in curb weight for models within each vehicle type)

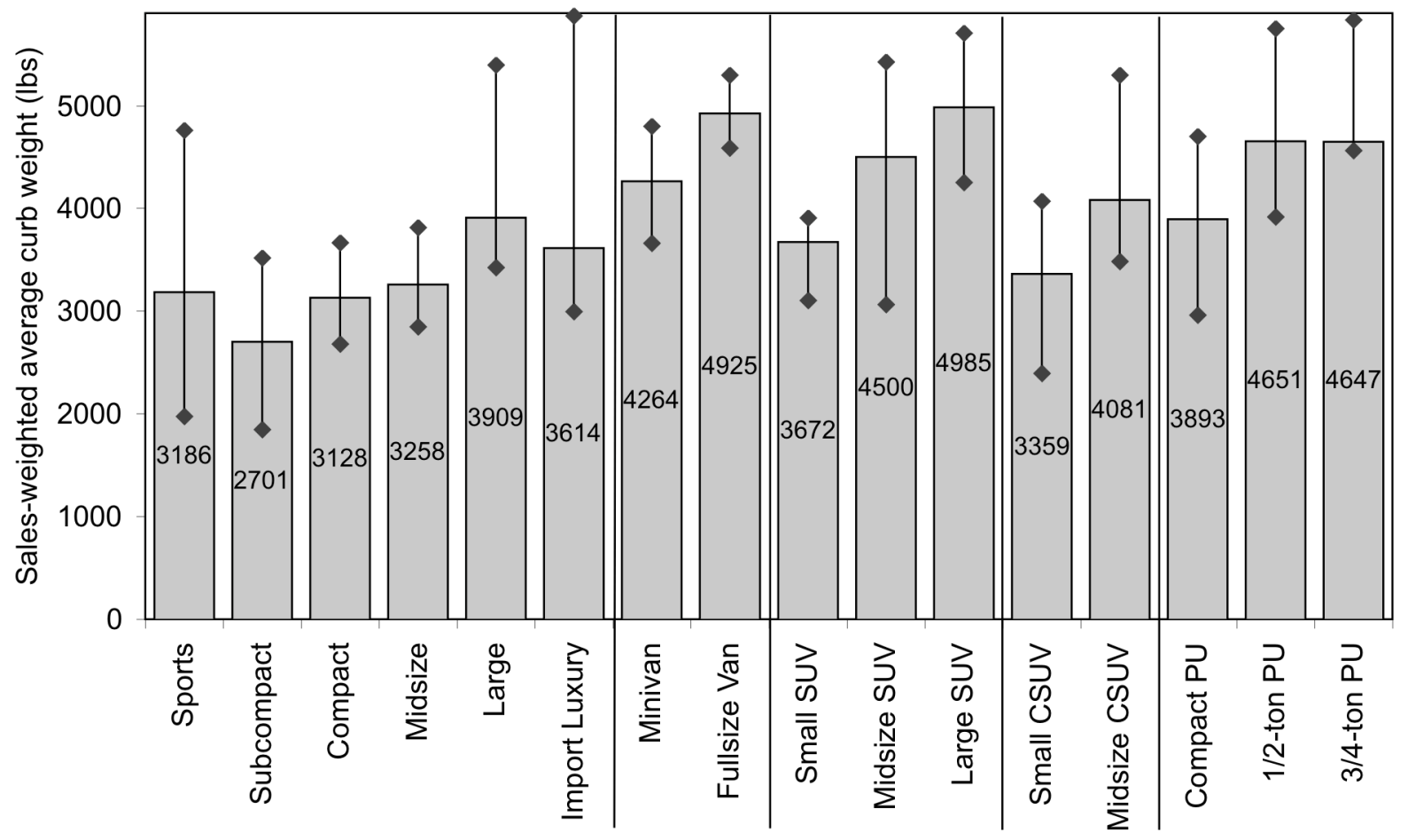


Figures 2-5 through 2-7 present the relationship between vehicle footprint and curb weight for unique vehicle models, by vehicle type. In these figures, different versions of individual models are treated as separate data points. There is a fairly strong linear relationship between footprint and weight, for all light-duty vehicle models $\left(\mathrm{R}^{2}=0.63\right)$, as well as for cars $\left(\mathrm{R}^{2}=0.60\right)$, but less so for light trucks $\left(\mathrm{R}^{2}=0.45\right)$. Figures 2-5 through 2-7 treat each vehicle model the same regardless of the number of vehicles of that model that were sold in 2005. When we weight each point in Figures 2-5 through 2-7 by the sales of each version of each vehicle model, the correlation coefficient for cars improves from 0.60 to 0.69 , but is somewhat lower for all vehicles $(0.63$ to $0.62)$ and for trucks $(0.45$ to 0.42$)$.

Figure 2-5. Vehicle footprint and curb weight by vehicle type, 2005 vehicle models

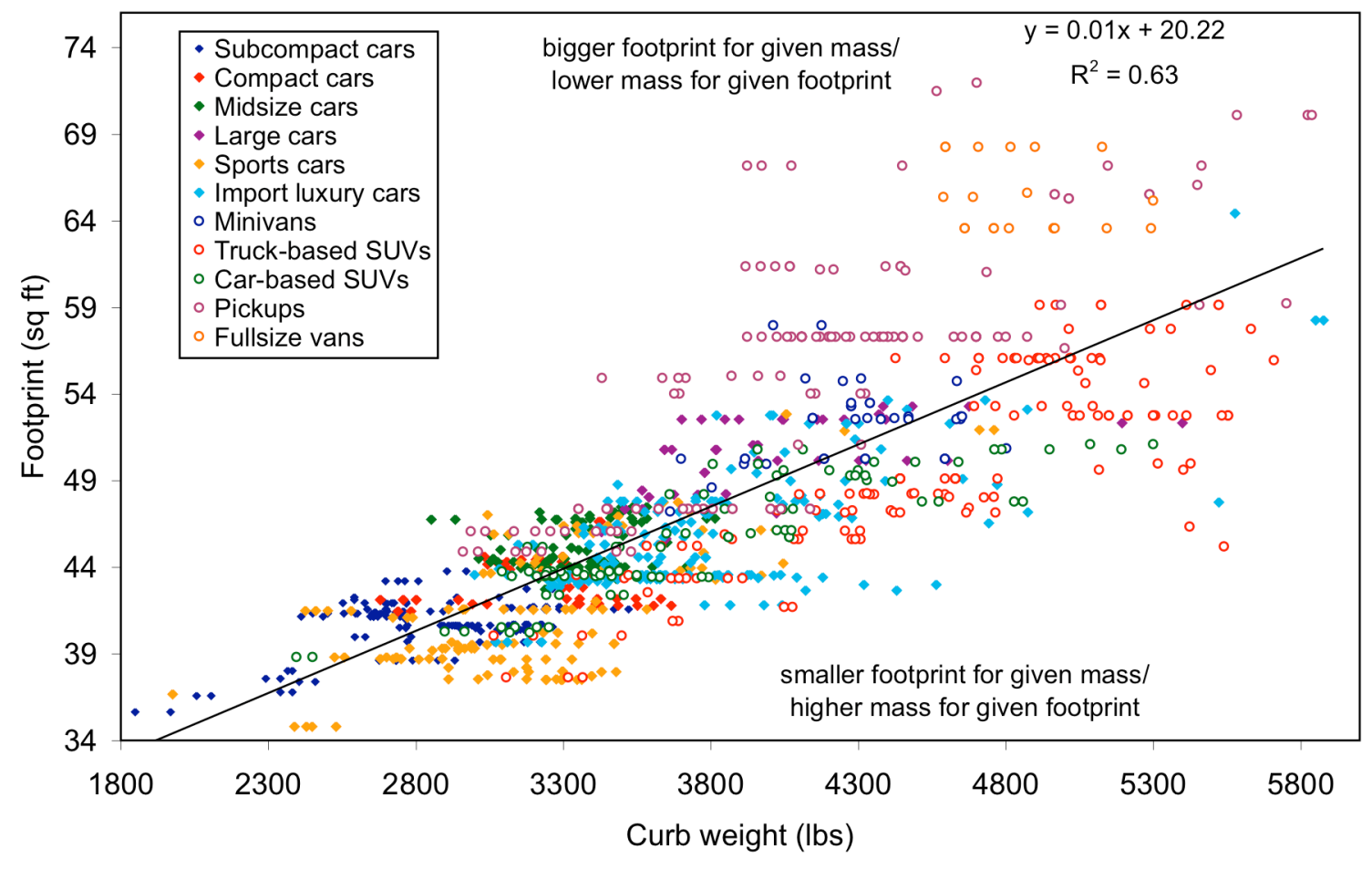


Figure 2-6. Vehicle footprint and curb weight by car type, 2005 car models

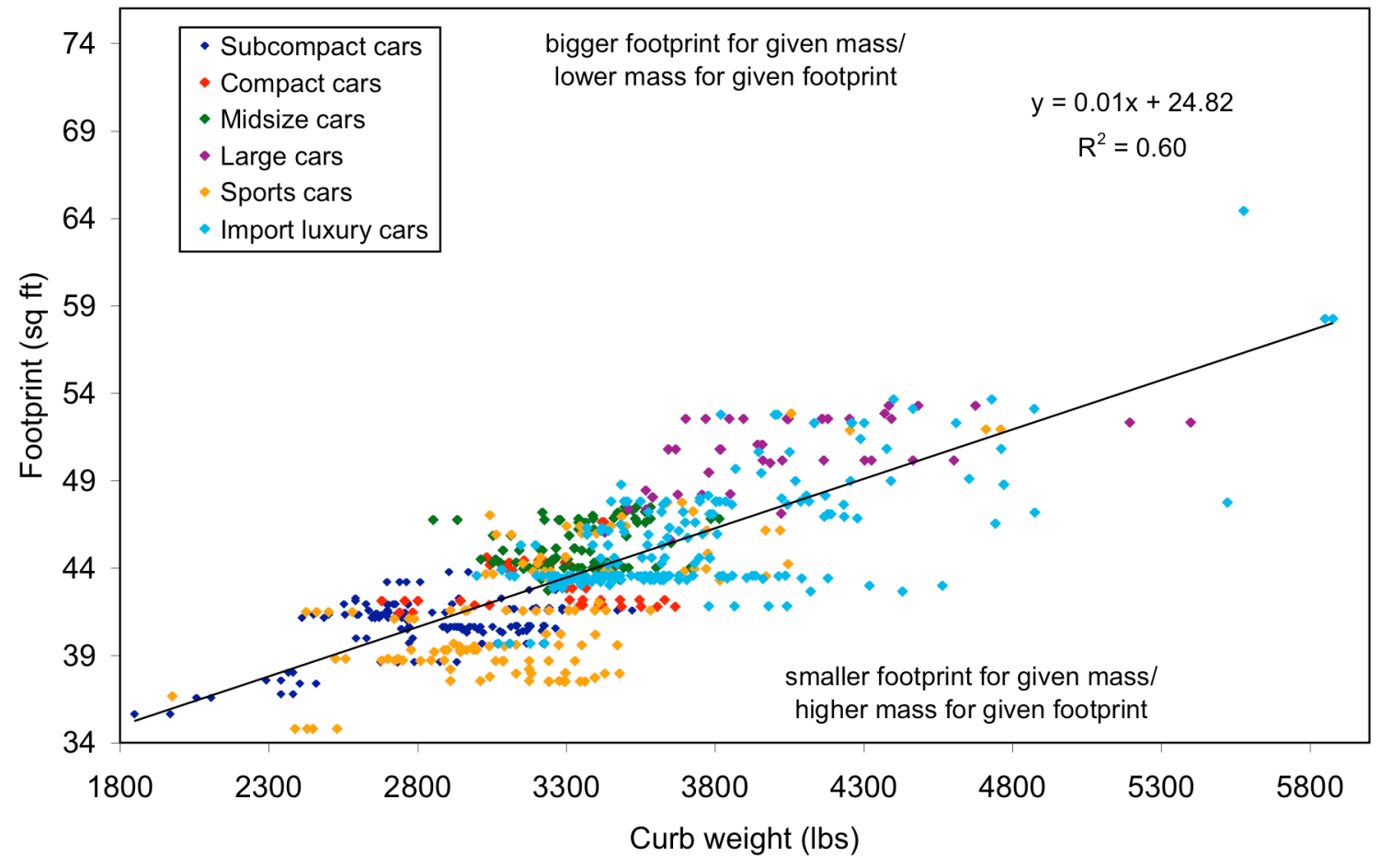

Figure 2-7. Vehicle footprint and curb weight by light truck type, 2005 light truck models

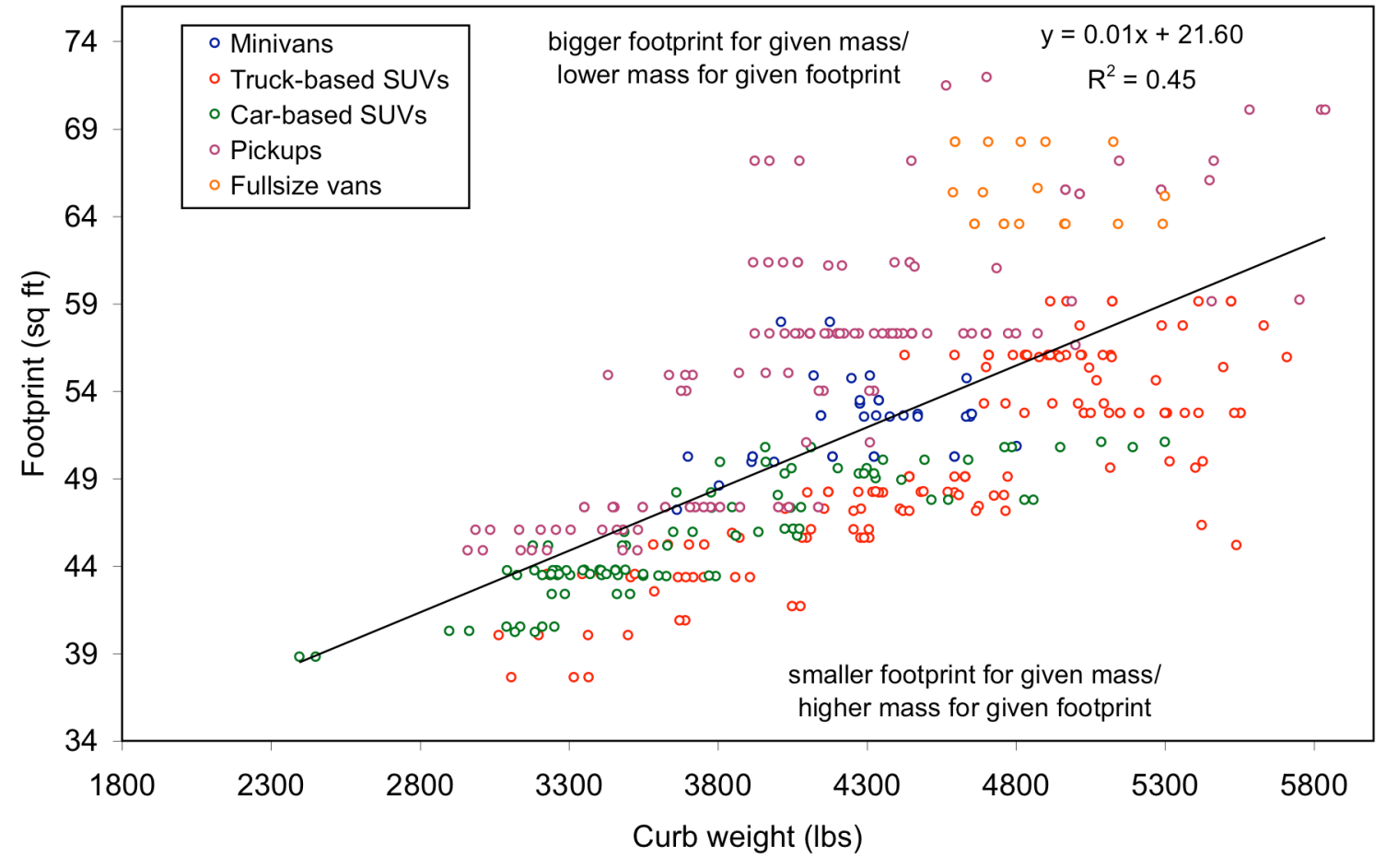


As mentioned above, in the CAFE compliance data provided us, different versions of a model nameplate have the same footprint; however, there often is a large range in curb weight for different versions of a given model. Figure 2-8 shows some examples of vehicles with a large range in curb weight within the same model nameplate. The range in curb weights is especially large for pickup trucks; pickup truck curb weight can vary based on drive configuration (two- or four-wheel drive), cab size (standard, extended/super, or crew/dual/quad), and bed length (short or long), among other factors. However, pickup curb weight also should vary depending on these variables. The CAFE compliance data provided us includes the variation in vehicle weight across different versions of the same vehicle model, but not the variation in vehicle footprint. For future analyses we hope to obtain data that provides detailed information on wheelbase and track width, as well as curb weight, for different versions of the same vehicle model. More detailed footprint data may reveal a stronger correlation between curb weight and footprint than we have shown here.

Figure 2-8. Range in vehicle curb weight for selected 2005 vehicle models

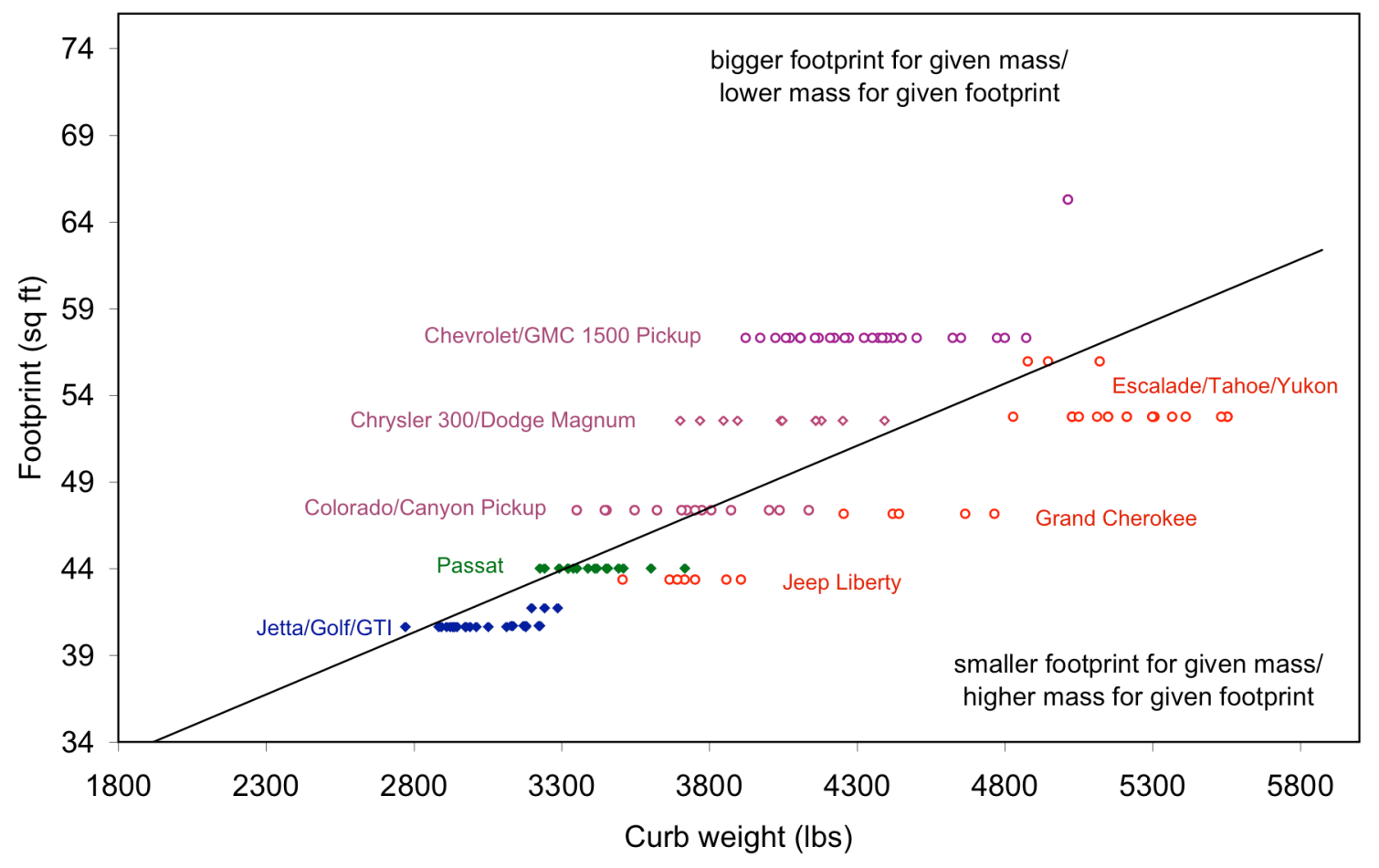

Using the sales-weighted average footprint and curb weight for vehicle models, rather than the individual values for different versions of the same vehicle model, increases the correlation coefficient between footprint and weight slightly for all light vehicles (from 0.62 to 0.65 ) and light trucks (from 0.42 to 0.48 ), but not for cars (0.69 in both).

Figures 2-9 through 2-11 show the relationship between the two components of footprint, wheelbase and track width. Again, there is a relatively weak correlation between these two measures of size, for all light vehicles $\left(R^{2}=0.54\right)$, passenger cars $\left(R^{2}=0.43\right)$, and light trucks $\left(\mathrm{R}^{2}=0.41\right)$. Using sales-weighted values increases the correlations to 0.61 for all light-duty vehicles, and to 0.62 for cars and to 0.48 for light trucks. Points above the diagonal line in the figures represent models that are wider or shorter than average (Pacifica and Pilot/MDX are 
examples), points below the line are models that are narrower or longer than average (Insight, Blazer, Canyon/Colorado, and Explorer Sport Trac are examples).

Figure 2-9. Wheelbase and track width, 2005 vehicle models

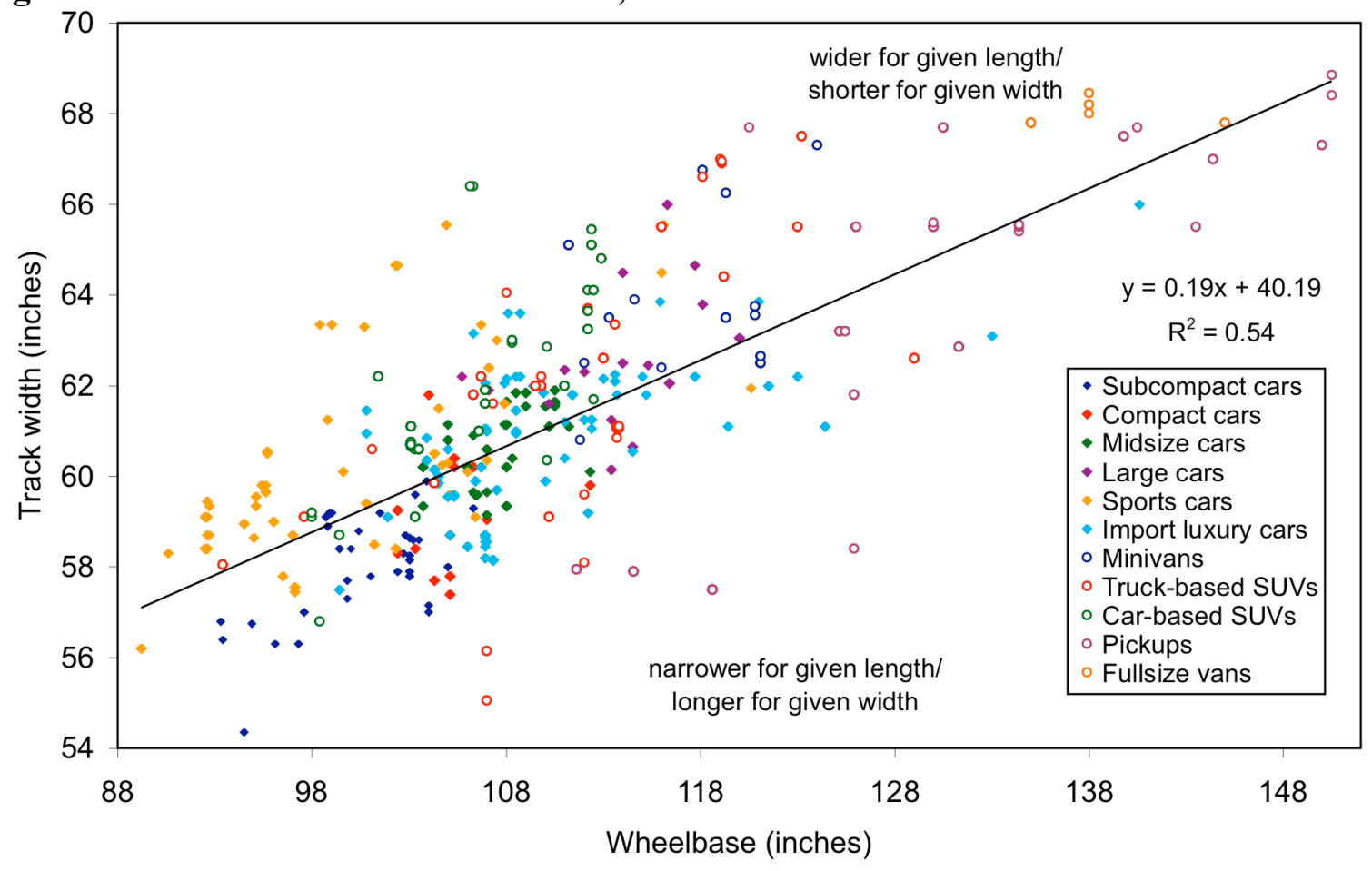

Figure 2-10. Wheelbase and track width, 2005 car models

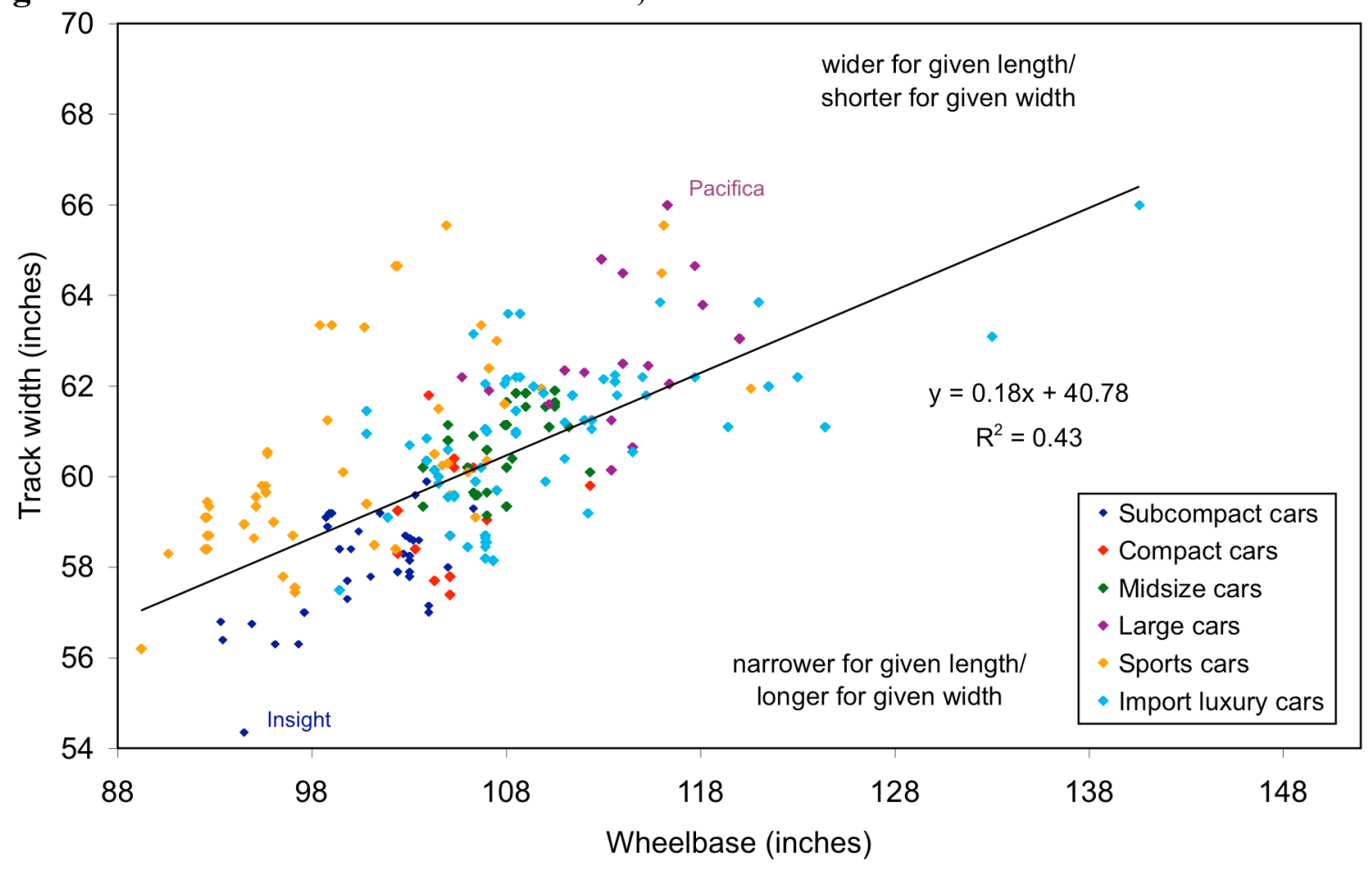


Figure 2-11. Wheelbase and track width, 2005 light truck models

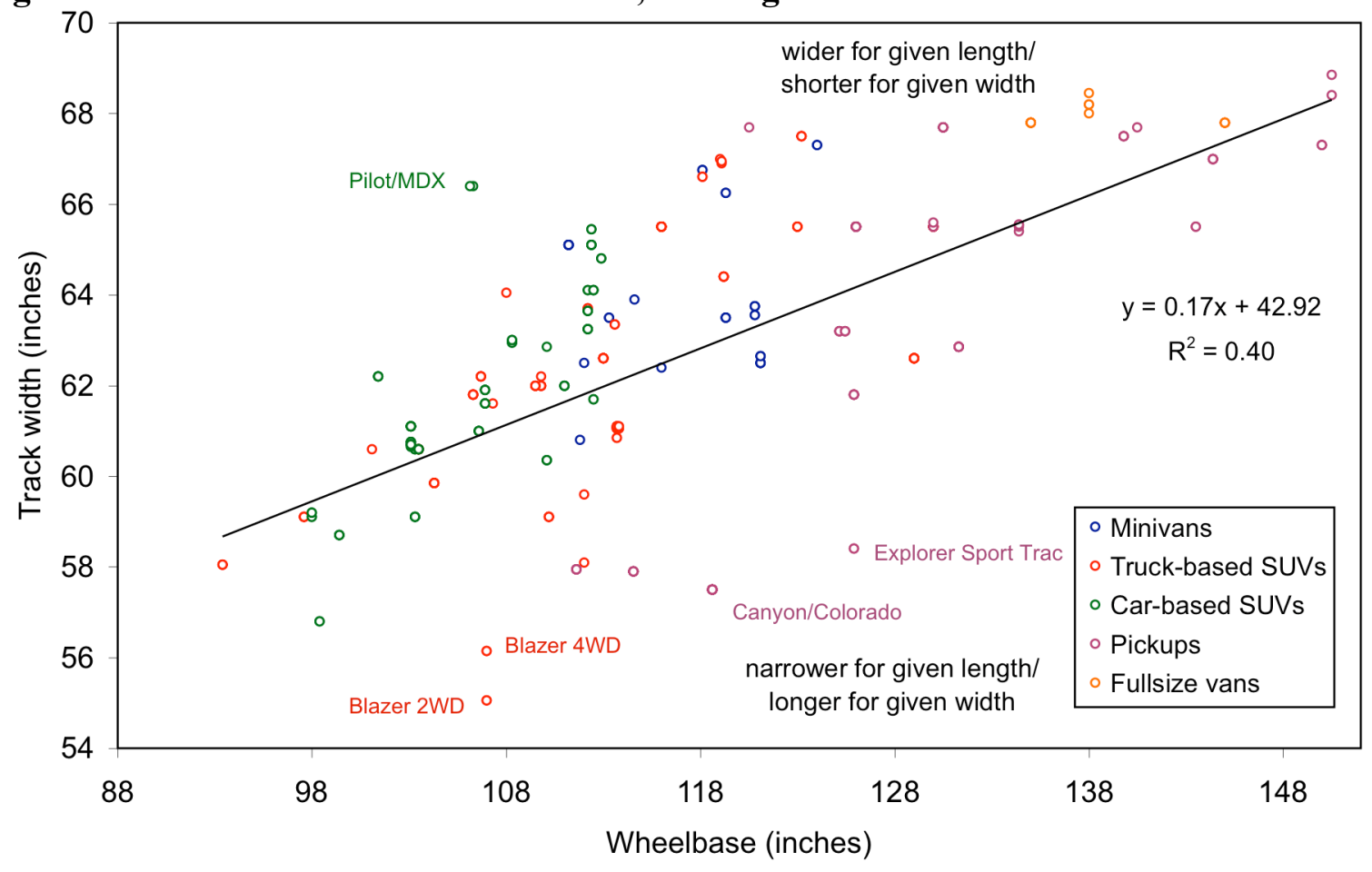

The analysis of 2005 vehicle attribute data, summarized in Table 2-1, indicates that the relationship between vehicle weight and size, at least measured by footprint, is only about 0.63 : not nearly as strong as implied in the NHTSA analysis. The relationship is stronger for cars $(0.60)$ than for light trucks $(0.45)$. The correlation between wheelbase and track width is also not strong, only 0.54 for all light vehicles. Table $2-2$ indicates that the correlations improve somewhat after accounting for the number of vehicle models sold. However, because of limitations in the footprint data provided us, this analysis may be understating the correlation between curb weight and footprint across vehicle models. We hope to obtain more detailed footprint data to study this issue further.

Table 2-1. Summary results of relationship between model year 2005 vehicle weight and size, unweighted

\begin{tabular}{|l|l|l|l|ccccc|}
\hline & & & \multicolumn{4}{|c|}{ Results } \\
\cline { 5 - 8 } Dependent & Independent & Vehicle & Figure & Vehicle & & & \\
variable & variable & type & number & models & Slope & P-value & $\mathrm{R}^{2}$ \\
\hline Footprint (sq ft) & Curb weight & LDV & $2-5$ & 1,079 & 0.007 & $<0.001$ & 0.63 \\
& (lbs) & Cars & $2-6$ & 653 & 0.006 & $<0.001$ & 0.60 \\
& & Trucks & $2-7$ & 426 & 0.007 & $<0.001$ & 0.45 \\
\hline Track width & Wheelbase & LDV & $2-9$ & 1,079 & 0.189 & $<0.001$ & 0.54 \\
(inches) & (inches) & Cars & $2-10$ & 653 & 0.181 & $<0.001$ & 0.43 \\
& & Trucks & $2-11$ & 426 & 0.167 & $<0.001$ & 0.40 \\
\hline
\end{tabular}


Table 2-2. Summary results of relationship between model year 2005 vehicle weight and size, weighted by the number of vehicles sold

\begin{tabular}{|l|l|l|l|cccc|}
\hline & & & \multicolumn{4}{|c|}{ Results } \\
\cline { 5 - 8 } Dependent & \multirow{2}{*}{$\begin{array}{l}\text { Independent } \\
\text { variable }\end{array}$} & Vehicle & Figure & Vehicle & & & \\
variable & type & number & models & Slope & P-value & $\mathrm{R}^{2}$ \\
\hline Footprint (sq ft) & Curb weight & LDV & $2-5$ & 1,079 & 0.007 & $<0.001$ & 0.62 \\
& (lbs) & Cars & $2-6$ & 653 & 0.006 & $<0.001$ & 0.69 \\
& & Trucks & $2-7$ & 426 & 0.008 & $<0.001$ & 0.42 \\
\hline Track width & Wheelbase & LDV & $2-9$ & 1,079 & 0.206 & $<0.001$ & 0.61 \\
(inches) & (inches) & Cars & $2-10$ & 653 & 0.304 & $<0.001$ & 0.62 \\
& & Trucks & $2-11$ & 426 & 0.153 & $<0.001$ & 0.48 \\
\hline
\end{tabular}




\section{Relationship between 2003-07 fatality risk and footprint}

NHTSA chose to base fuel economy standards on a vehicle's footprint in part to reduce the incentive for manufacturers to make vehicles smaller. Previous research indicates that overall fatalities would be reduced if vehicles were made lighter while maintaining their size (wheelbase and track width; van Auken and Zellner, 2002; van Auken et al., 2003). ${ }^{2}$ It is thought that size, particularly crush space, is protective in crashes with another vehicle or stationary object, and that lower, wider, and longer vehicles (i.e. with a lower center of gravity) are less likely to roll over.

In this section we examine the relationship between vehicle footprint and fatality risk, by vehicle make and model. Driver fatality risk is the number of driver fatalities, per million registered vehicle from model years 2003 to 2007. Driver fatalities are from NHTSA's Fatality Analysis Reporting System (FARS) database, while vehicle registrations come from R.L. Polk (Wenzel and Ross, 2005). Risks include both the likelihood that a certain vehicle type or model will be involved in a fatal crash, as well as the vehicle's ability to protect its driver, and the driver's ability to survive, a fatal crash. We calculate risks to drivers of the subject vehicle, as well as the risks those drivers impose on drivers of other vehicles (including motorcycles and medium/heavy-duty vehicles) on the road; pedestrian and bicycle casualties are not included. We only plot risks for models with at least 0.5 million vehicle registration-years; these models have, at a minimum, average annual sales of 37,000 over each of the five model years, and account for $84 \%$ of all registered light vehicles. The Honda Accord had 5 million registration-years over the five-year period, the most of all light-duty vehicles. Because most 3/4- and 1-ton pickups and fullsize vans are exempt from CAFE standards we do not have footprint data for these types of vehicles, and exclude them from our analysis. We also exclude the Crown Victoria from the figures because it has a dramatically high risk to drivers (142) and others (168), due to its frequent use as a police vehicle. Figures 3-1 through 3-3 show FARS fatality risk to drivers versus sales-weighted footprint, by vehicle model. There is virtually no correlation between fatality risk to drivers and vehicle footprint, for either passenger cars or light trucks.

\footnotetext{
${ }^{2}$ Although NHTSA appears to implicitly accept the DRI results that vehicle size is more important than weight to occupant safety, in its official response to DRI comments NHTSA essentially rejected DRI's analysis, and continued to maintain that vehicle weight and size were too closely correlated to analyze independently (Kahane, 2004).
} 
Figure 3-1. Relationship between 2003-07 US fatality risk to drivers and vehicle footprint, by vehicle model

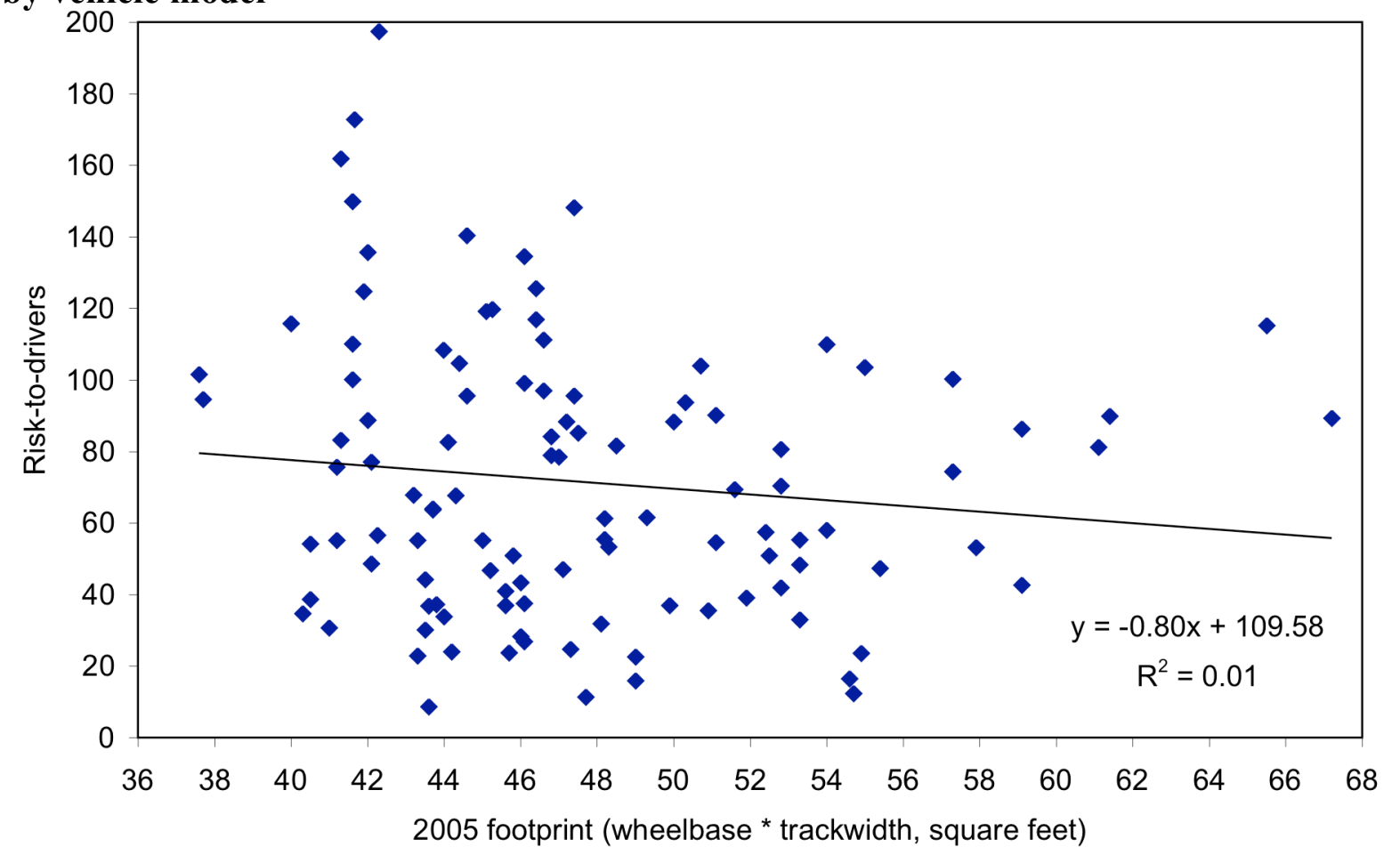

Figure 3-2. Relationship between 2003-07 US fatality risk to drivers and car footprint, by car model

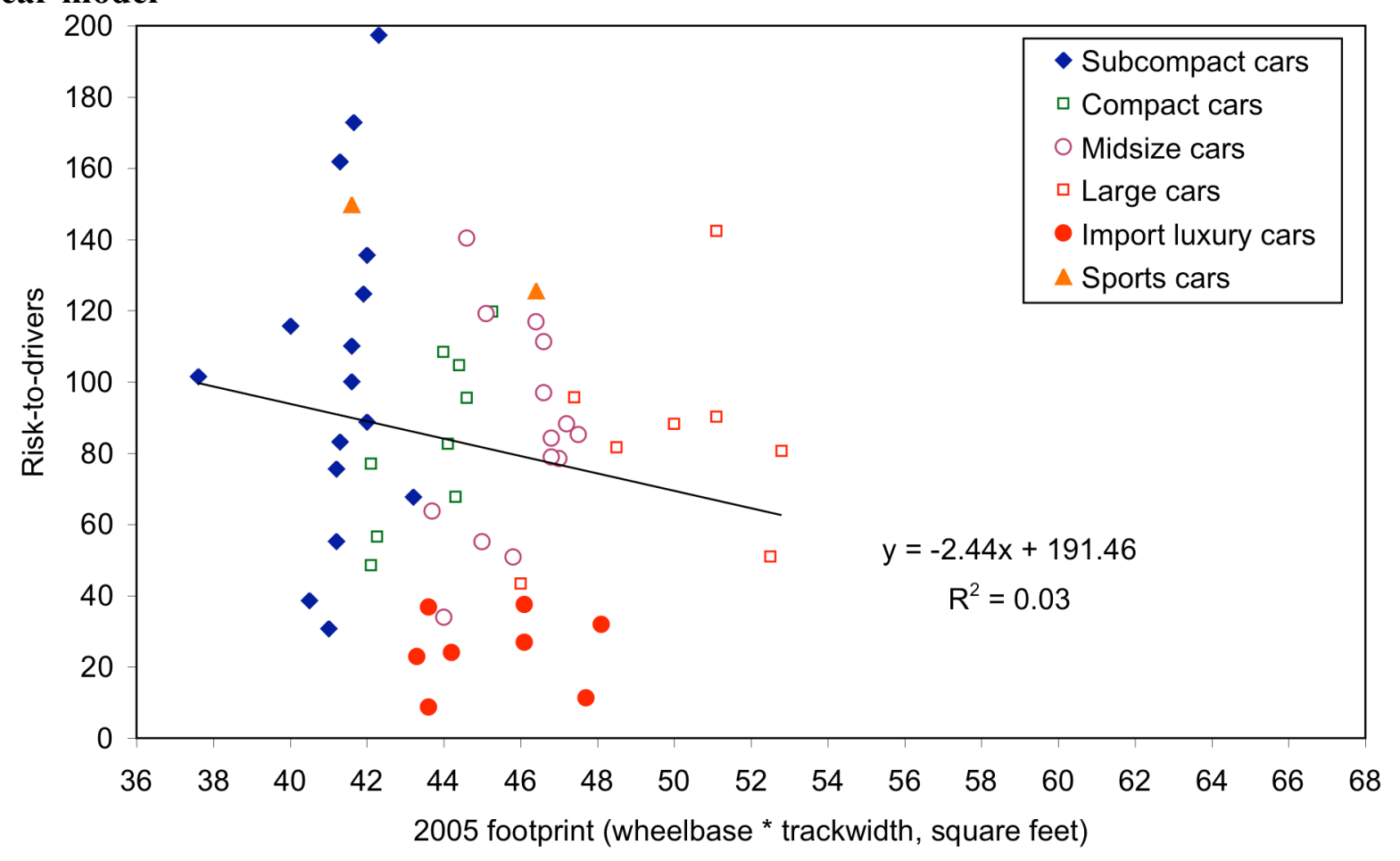


Figure 3-3. Relationship between 2003-07 US fatality risk to drivers and light truck footprint, by light truck model

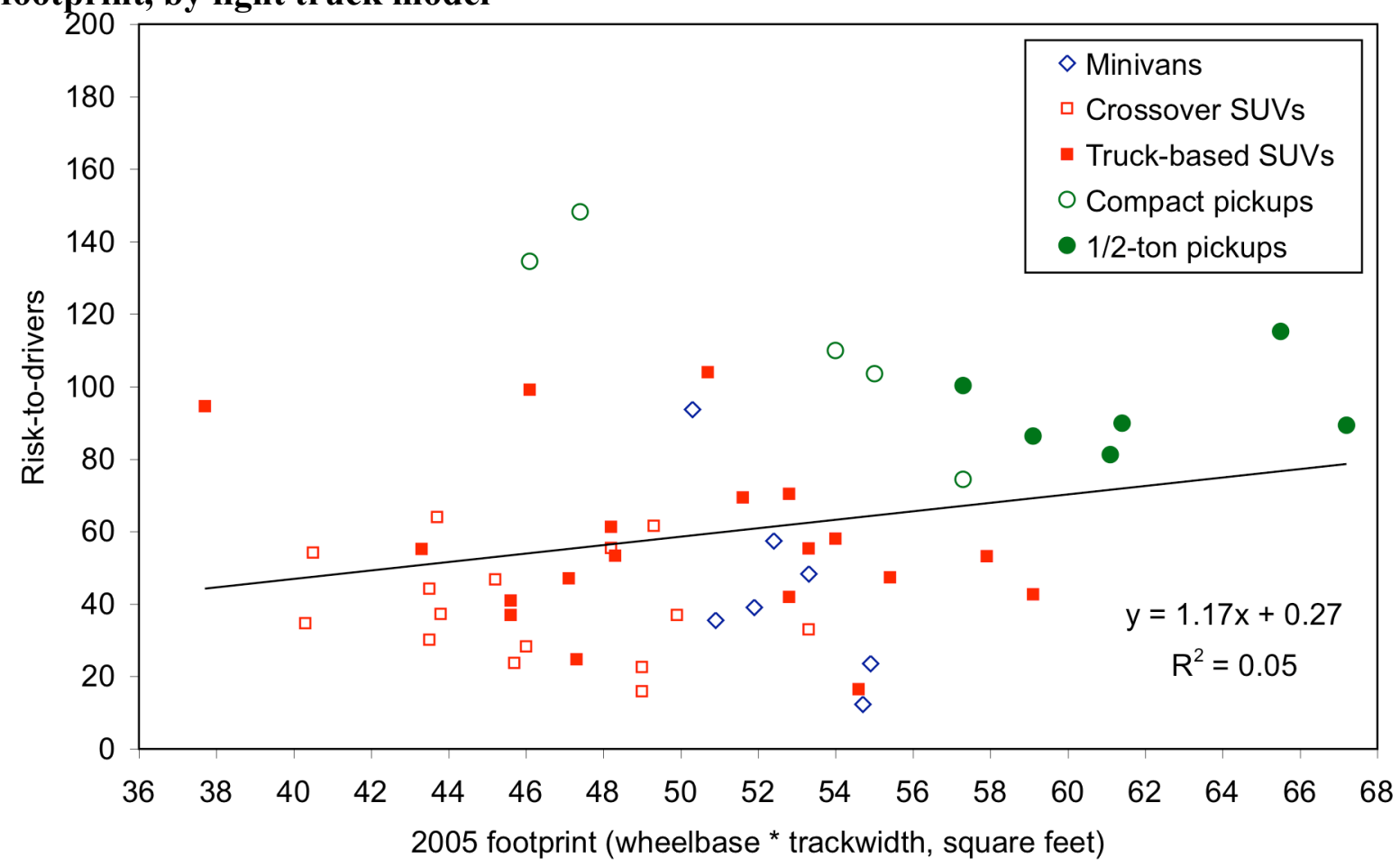

Figures 3-4 through 3-6 show the FARS fatality risk imposed on drivers of other vehicles, versus footprint. Here we see no correlation between risk to others and footprint for cars, and a correlation or 0.33 for light trucks; however, the data indicate that risk imposed by light trucks on drivers of other vehicles increases with increasing footprint. 
Figure 3-4. Relationship between 2003-07 US fatality risk to drivers of other vehicles and vehicle footprint, by vehicle model

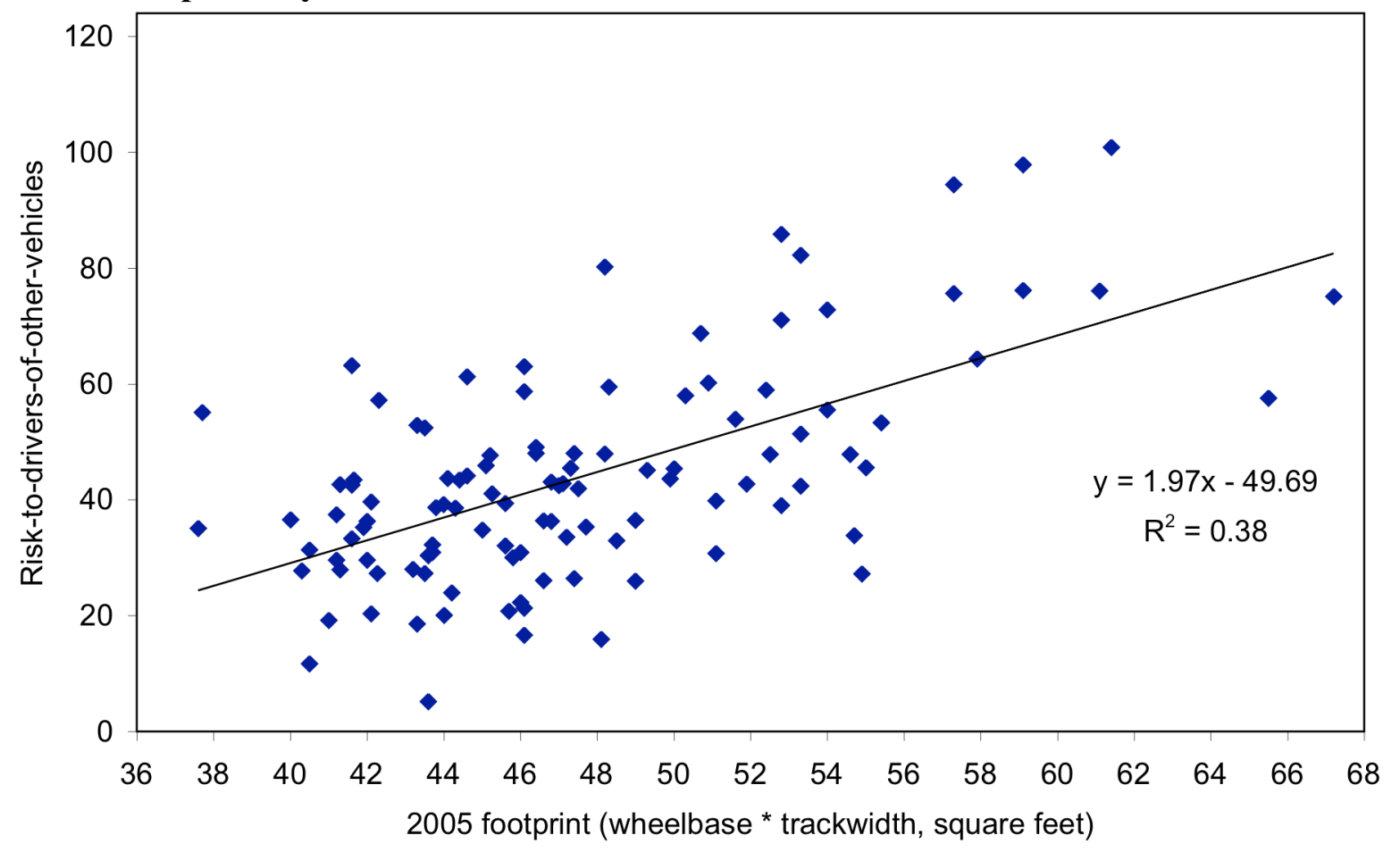

Figure 3-5. Relationship between 2003-07 US fatality risk to drivers of other vehicles and car footprint, by car model

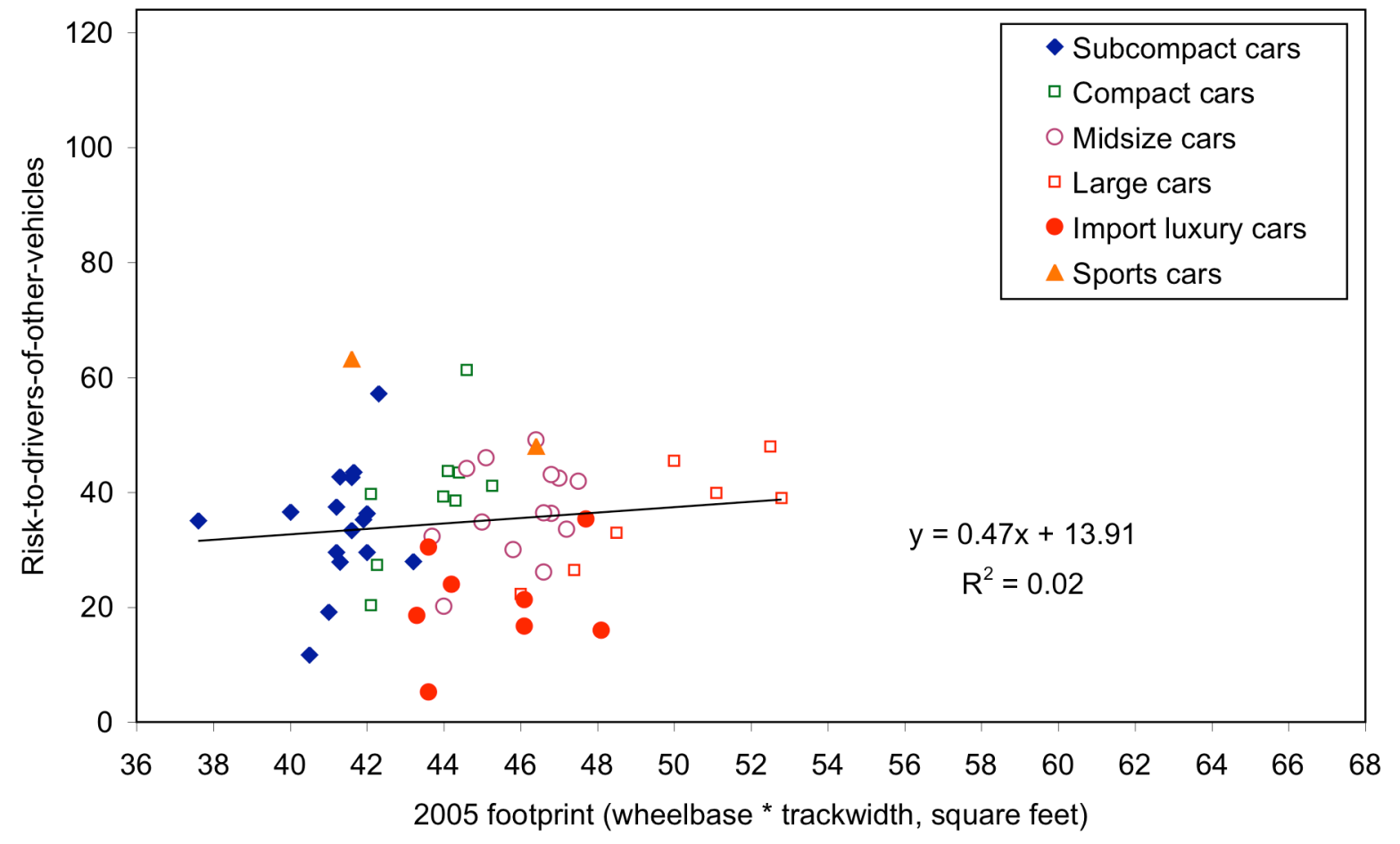


Figure 3-6. Relationship between 2003-07 US fatality risk to drivers of other vehicles and light truck footprint, by light truck model

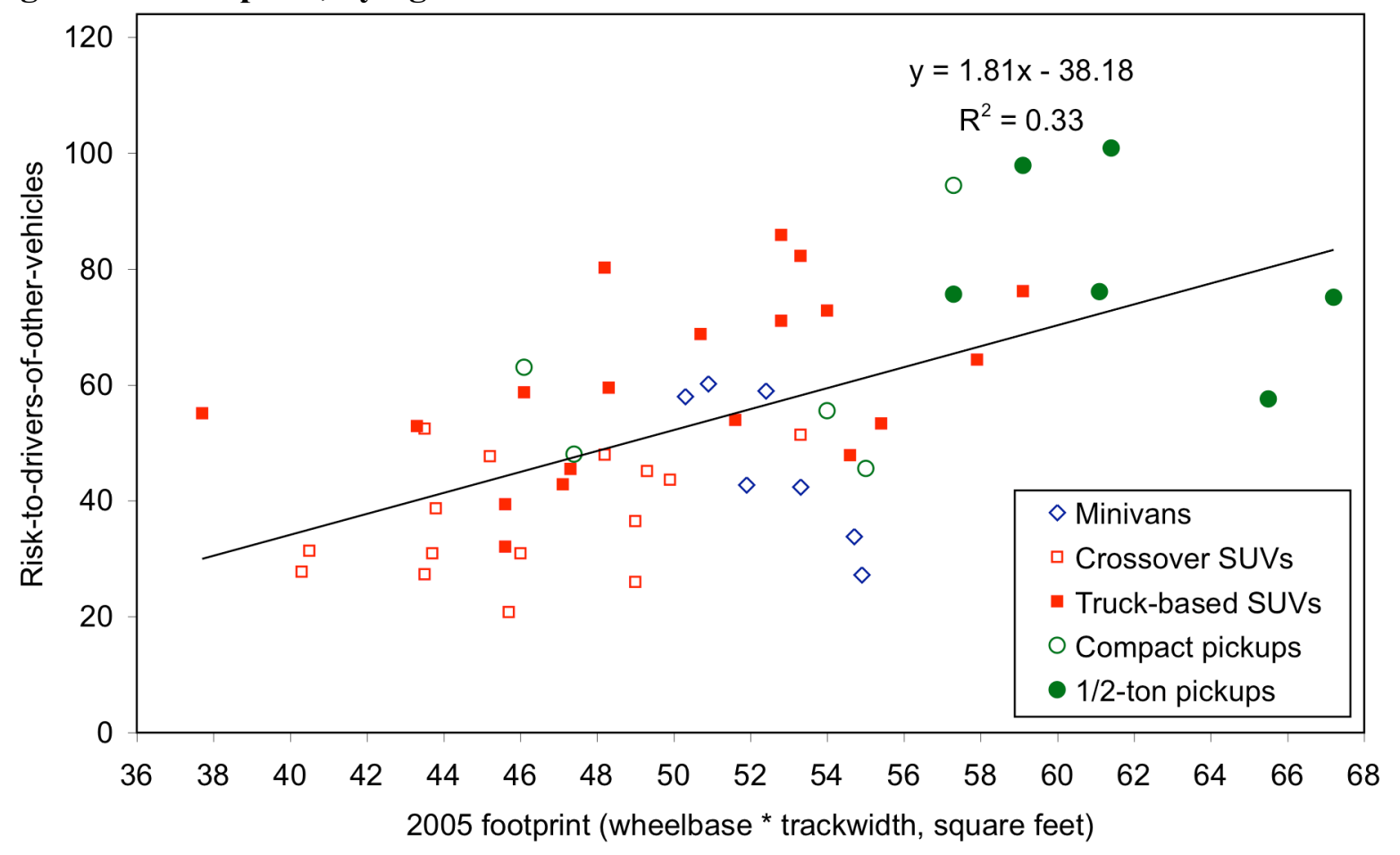

To the extent that wheelbase is correlated with frontal crush space, it should be most protective in frontal crashes, either with another vehicle or a stationary object; similarly, track width may be protective in left (driver) side crashes. However, Figures 3-7 and 3-8 show that there is almost no correlation between wheelbase and fatality risk to drivers in frontal crashes (0.01) and track width and fatality risk to drivers in left side crashes (0.15). 
Figure 3-7. Relationship between 2003-07 US fatality risk to drivers in frontal (nonrollover) crashes and vehicle wheelbase, by vehicle model

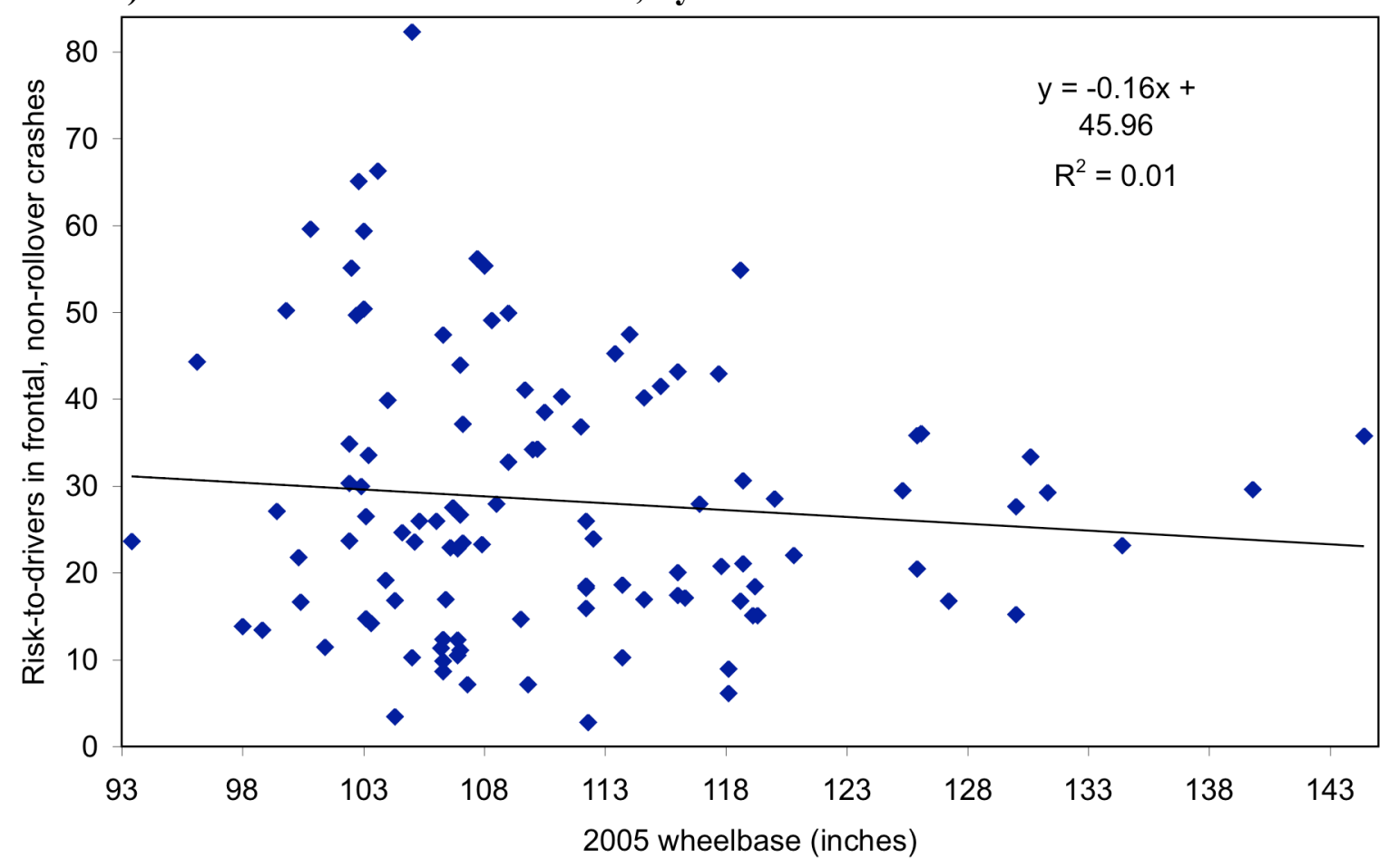

Figure 3-8. Relationship between 2003-07 US fatality risk to drivers in left side (nonrollover) crashes and vehicle track width, by vehicle model

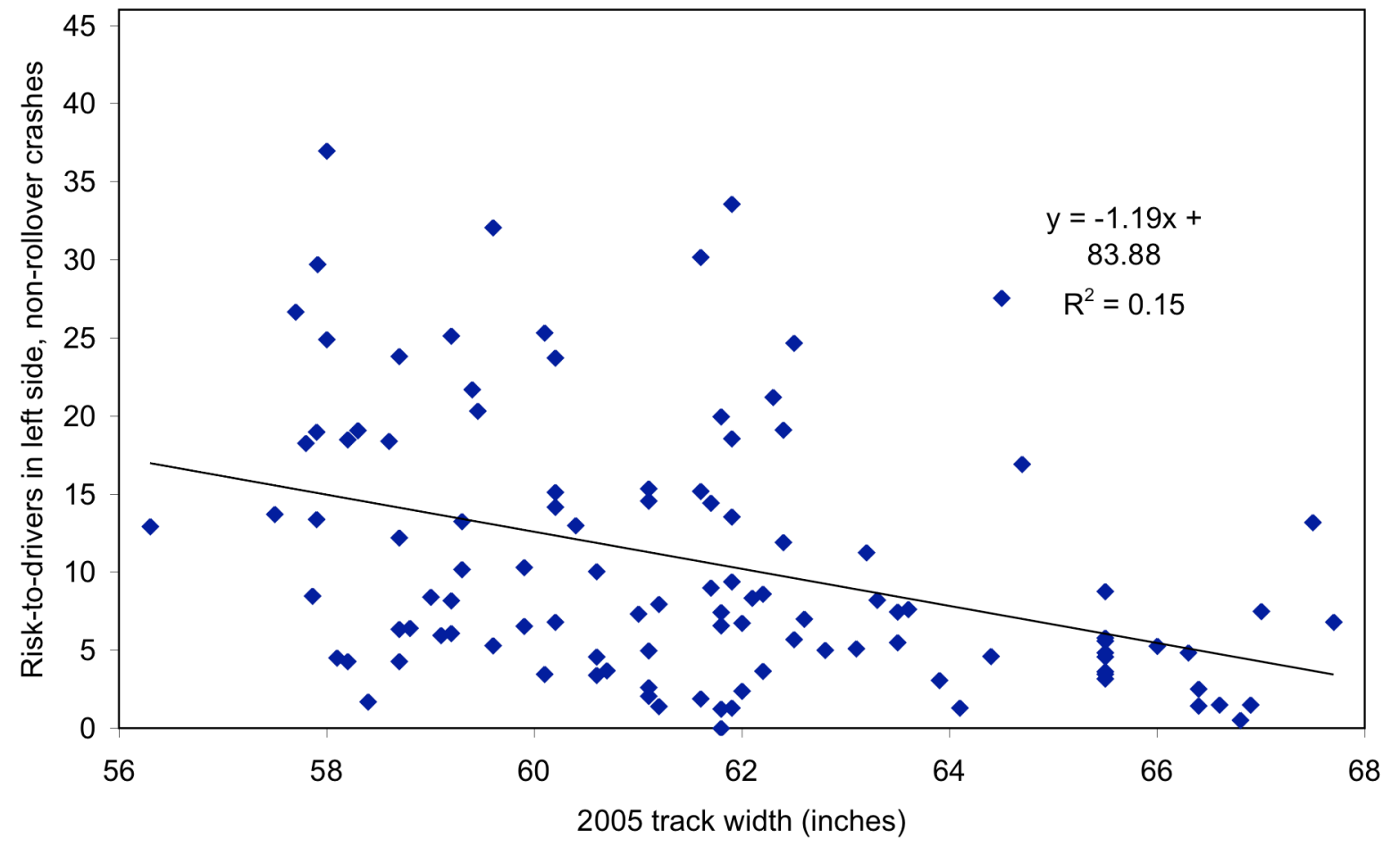


Table 3-1 summarizes the relationship between US fatality risks and vehicle footprint. There is essentially no correlation between fatality risk drivers and footprint, although there is somewhat of a correlation between fatality risk imposed on others and light truck footprint $\left(\mathrm{R}^{2}=0.33\right)$, with risk increasing with increasing footprint. Table 3-2 indicates that weighting the results by the number of model year 2005 sales of vehicle models has little effect on the results.

Table 3-1. Summary results of relationship between vehicle weight/size and casualty risk (excluding crashes involving young male or elderly drivers, and crashes in very rural or urban counties), by vehicle model, unweighted

\begin{tabular}{|c|c|c|c|c|c|c|c|}
\hline \multirow[b]{2}{*}{$\begin{array}{l}\text { Dependent } \\
\text { variable }\end{array}$} & \multirow[b]{2}{*}{$\begin{array}{l}\text { Independent } \\
\text { variable }\end{array}$} & \multirow[b]{2}{*}{$\begin{array}{l}\text { Vehicle } \\
\text { type }\end{array}$} & \multirow[b]{2}{*}{$\begin{array}{l}\text { Figure } \\
\text { number }\end{array}$} & \multicolumn{4}{|c|}{ Results } \\
\hline & & & & $\begin{array}{l}\text { Vehicle } \\
\text { models }\end{array}$ & Slope & P-value & $\mathrm{R}^{2}$ \\
\hline \multirow{3}{*}{$\begin{array}{l}\text { Fatality risk to } \\
\text { drivers }\end{array}$} & \multirow{3}{*}{$\begin{array}{l}\text { Footprint } \\
(\mathrm{sq} \mathrm{ft})\end{array}$} & LDV & $3-1$ & 108 & -0.8 & 0.215 & 0.01 \\
\hline & & Cars & $3-2$ & 56 & -2.4 & 0.174 & 0.01 \\
\hline & & Trucks & $3-3$ & 52 & 1.2 & 0.010 & 0.05 \\
\hline \multirow{3}{*}{$\begin{array}{l}\text { Fatality risk to } \\
\text { drivers of other } \\
\text { vehicles }\end{array}$} & \multirow{3}{*}{$\begin{array}{l}\text { Footprint } \\
(\text { sq ft) }\end{array}$} & LDV & $3-4$ & 108 & 2.0 & $<0.001$ & 0.38 \\
\hline & & Cars & $3-5$ & 56 & 0.5 & 0.357 & 0.02 \\
\hline & & Trucks & $3-6$ & 52 & 1.8 & $<0.001$ & 0.33 \\
\hline $\begin{array}{l}\text { Fatality risk to } \\
\text { drivers in frontal } \\
\text { crashes }\end{array}$ & $\begin{array}{l}\text { Wheelbase } \\
\text { (inches) }\end{array}$ & LDV & $3-7$ & 108 & -0.2 & 0.339 & 0.01 \\
\hline $\begin{array}{l}\text { Fatality risk to } \\
\text { drivers in left } \\
\text { side crashes }\end{array}$ & $\begin{array}{l}\text { Track width } \\
\text { (inches) }\end{array}$ & LDV & $3-8$ & 108 & -1.2 & $<0.001$ & 0.15 \\
\hline
\end{tabular}

Table 3-2. Summary results of relationship between vehicle weight/size and casualty risk (excluding crashes involving young male or elderly drivers, and crashes in very rural or urban counties), by vehicle model, weighted by the number of MY05 vehicles sold

\begin{tabular}{|c|c|c|c|c|c|c|c|}
\hline \multirow[b]{2}{*}{$\begin{array}{l}\text { Dependent } \\
\text { variable }\end{array}$} & \multirow[b]{2}{*}{$\begin{array}{l}\text { Independent } \\
\text { variable }\end{array}$} & \multirow[b]{2}{*}{$\begin{array}{l}\text { Vehicle } \\
\text { type }\end{array}$} & \multirow[b]{2}{*}{$\begin{array}{l}\text { Figure } \\
\text { number }\end{array}$} & \multicolumn{4}{|c|}{ Results } \\
\hline & & & & $\begin{array}{l}\text { Vehicle } \\
\text { models }\end{array}$ & Slope & P-value & $\mathrm{R}^{2}$ \\
\hline \multirow{3}{*}{$\begin{array}{l}\text { Fatality risk to } \\
\text { drivers }\end{array}$} & \multirow{3}{*}{$\begin{array}{l}\text { Footprint } \\
(\mathrm{sq} \mathrm{ft})\end{array}$} & LDV & 3-1 & 108 & -0.5 & 0.347 & 0.01 \\
\hline & & Cars & $3-2$ & 56 & -3.7 & 0.050 & 0.07 \\
\hline & & Trucks & $3-3$ & 52 & 1.5 & 0.015 & 0.11 \\
\hline \multirow{3}{*}{$\begin{array}{l}\text { Fatality risk to } \\
\text { drivers of other } \\
\text { vehicles }\end{array}$} & \multirow{3}{*}{$\begin{array}{l}\text { Footprint } \\
(\text { sq ft) }\end{array}$} & LDV & $3-4$ & 108 & 1.9 & $<0.001$ & 0.47 \\
\hline & & Cars & $3-5$ & 56 & 0.7 & 0.115 & 0.05 \\
\hline & & Trucks & $3-6$ & 52 & 1.7 & $<0.001$ & 0.36 \\
\hline $\begin{array}{l}\text { Fatality risk to } \\
\text { drivers in frontal } \\
\text { crashes }\end{array}$ & $\begin{array}{l}\text { Wheelbase } \\
\text { (inches) }\end{array}$ & LDV & $3-7$ & 108 & -0.1 & 0.537 & 0.04 \\
\hline $\begin{array}{l}\text { Fatality risk to } \\
\text { drivers in left } \\
\text { side crashes }\end{array}$ & $\begin{array}{l}\text { Track width } \\
\text { (inches) }\end{array}$ & LDV & $3-8$ & 108 & -1.5 & $<0.001$ & 0.26 \\
\hline
\end{tabular}




\section{Relationship between 2000-04 casualty risk and footprint}

There are several limitations with the fatality rates per registered vehicle as described above. First, the measure of exposure is the number of registered vehicles of a particular make and model, and not the number of miles that model is driven. Vehicle types and models that are driven more annual miles than average have higher exposure to a potentially fatal crash; adjusting for the amount of miles driven would therefore lower their risk relative to the average vehicle. In particular, pickup trucks tend to be driven more miles than the average vehicle (Wenzel and Ross, 2005; Kahane, 2003); therefore the fatality rates above overstate the risks in pickup trucks.

Second, the fatality risks above do not account for differences in how, and where, particular vehicle types and makes/models are driven, which can also affect their exposure to, and perhaps their crashworthiness in, a potentially fatal crash. In particular, driver age and gender are important driver variables to account for; young males tend to be the riskiest drivers, while the elderly are particularly frail and less able to survive a serious crash. And serious crashes in rural areas tend to be more deadly than those in urban areas, for a variety of reasons: in rural areas travel speeds tend to be higher, and speed limits are not well enforced; roadways are not divided and are not well-lit; guardrails are missing, and large trees are close to roadways; and crashes tend to be further from trauma centers. We found that fatality risks, both to drivers and to drivers of other vehicles, vary substantially by the population density of the county in which the crash occurred, for all vehicle types (Wenzel and Ross, 2005).

We use data on all police-reported crashes to account for the effect vehicle use, driver age/gender, and driving location have on risk. NHTSA collects a sample of US police-reported crashes, as part of its National Automotive Sampling System, General Estimates System (NASS GES); however, although intended to be representative of national crashes, this dataset is quite small. We obtained from NHTSA's State Data System (SDS) data on all police-reported crashes through 2005 in five states (Florida, Illinois, Maryland, Missouri and Pennsylvania) which report the vehicle identification number (VIN) of vehicles, which allows us to determine vehicle model year, type, and make and model. The number of vehicles involved in a crash can act as a proxy of the number of miles a given vehicle type, or model, is driven per year, and is a preferable unit of exposure to a serious crash than the number of registered vehicles. Because there are relatively few fatalities in the five states for which we have crash data, we calculate casualty risks, which are the sum of fatalities and serious or incapacitating injuries. We can account for driver age/gender and driving location effects by excluding from analysis crashes (and casualties) involving young males and the elderly, and occurring in very rural or very urban counties. We analyze casualty risks for model year 2000 to 2004 vehicles; there is a substantial lag time between when crashes occur, when states release their crash databases to NHTSA, and when NHTSA analysts release consistently coded state datasets for public analysis.

The NHTSA and DRI studies used statistical models based on the likelihood that an individual crash would result in a driver fatality. We analyze the casualty rate (driver death or serious injury per 10,000 police-reported crashes) by vehicle make and model, after excluding crashes involving young male and elderly drivers, and in very rural and very urban counties, in order to study the relationship between casualty risk and vehicle dimensions (weight and footprint) by 
vehicle model. This approach allows us to readily see any trends in casualty risk by vehicle model after accounting for driver age and gender, crash location, and other variables. We hope to eventually replicate the NHTSA and DRI analyses of individual crashes using the policereported data summarized here, as described at the end of this section.

We calculated population density deciles by ranking all counties in the five states by their population density (2000 population divided by square miles of land area), and counting the cumulative number of driver casualties. Figure 4-1 shows the cumulative distribution of all driver casualties by county population density. The first 10 percent of casualties (reading up the vertical axis from the origin) occurred in counties with a population density of 60 or less per square mile, the next 10 percent of casualties occurred in counties with a population density of 60 to about 150 per square mile, etc. The largest population density decile includes casualties in counties with a density of 5,000 per square mile or greater (Baltimore, Chicago, St. Louis, and Philadelphia). Figure 4-1. Distribution of drivers of 2000-04 vehicles in state crash data, by population
density of county in which crash occurred

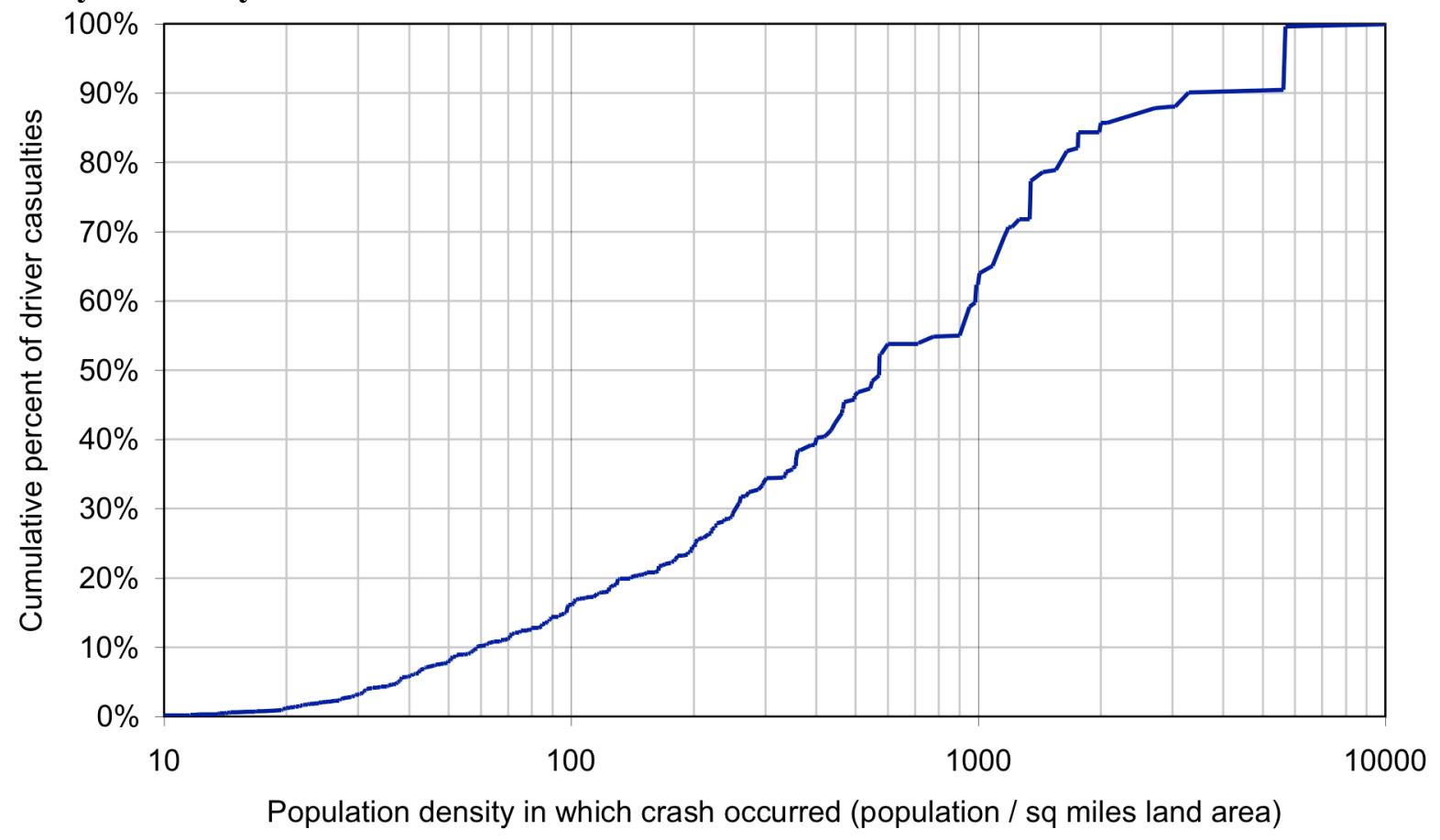

Figure 4-2 shows the casualty risk, excluding young male and elderly drivers, by vehicle type and population density decile. The figure indicates that, for all vehicle types, casualty risk is highest in the two lowest population density deciles (the most rural counties), and lowest in the two highest population density deciles (the most urban counties). Casualty risks are similar in the six middle population density deciles (deciles 3 through 8). Figure 4-3 indicates that a higher fraction of pickup crashes occur in the most rural counties $(22 \%)$, and a lower fraction occur in the most urban counties (21\%), than for other vehicle types. Therefore, we exclude crashes and casualties that occurred in the most rural and most urban counties (density deciles 1, 2, 9, and $10)$, to account for the different locations in which pickups tend to be driven. 
Figure 4-2. Casualty risk for drivers (excluding young males and elderly drivers), by population density decile and vehicle type

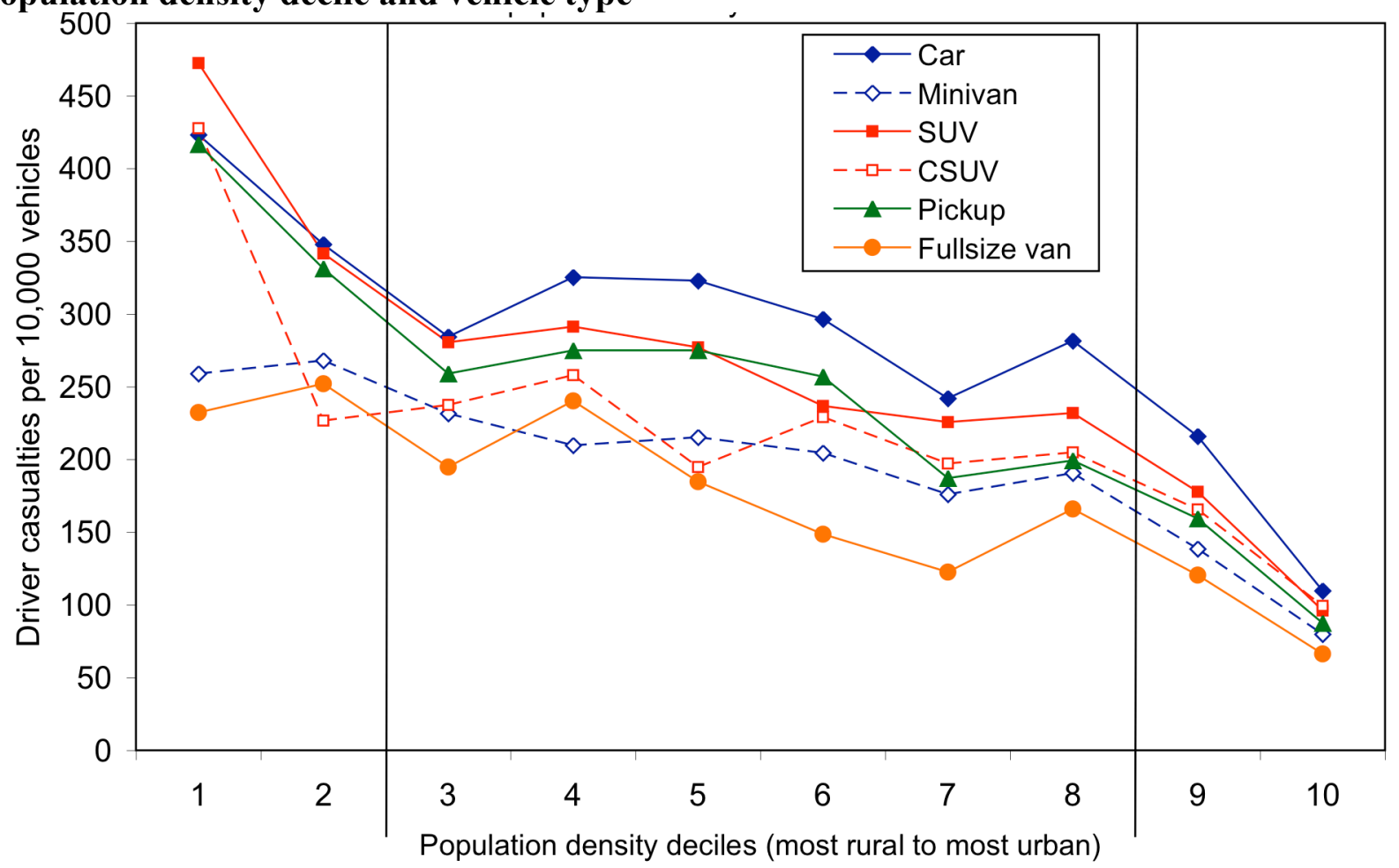

Figure 4-3. Distribution of police-reported crashes, by population density decile and vehicle type

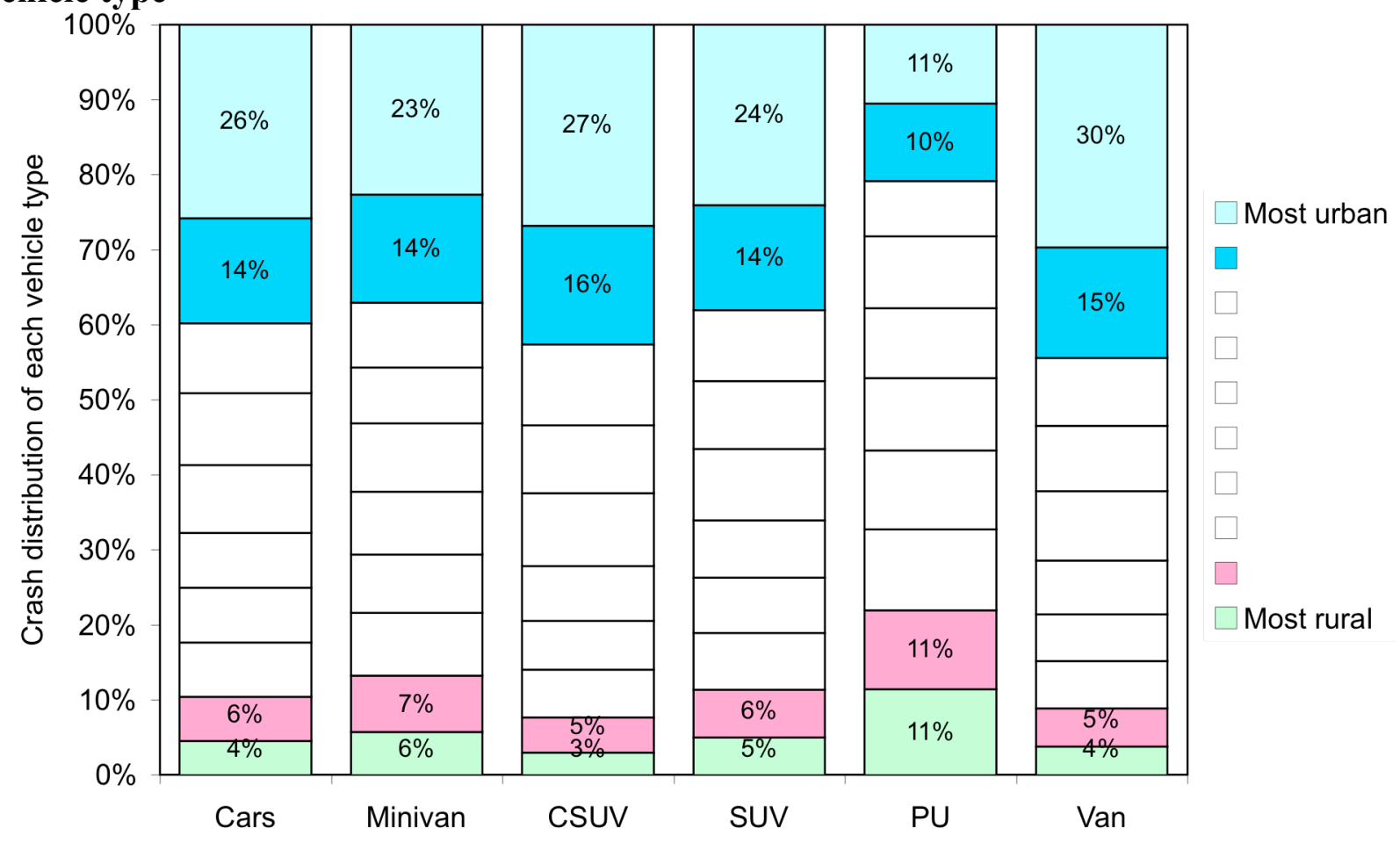

Figures 4-4 and 4-5 compare state casualty risks (filled blue diamonds, left-hand scale) and US 
fatality risks (open blue diamonds, right-hand scale) for model years 2000 to 2004 by vehicle type, both to drivers (Figure 4-4) and to drivers of other vehicles (Figure 4-5). The state casualty risks are for all drivers, including young males and elderly drivers, and all crashes, including those in the most rural and most urban counties. Because the measures of exposure are different (registered vehicles for US fatality risks, vehicles involved in all police-reported crashes for state casualty risks), the absolute values are unimportant; the important comparison is the relative risks among vehicle types between casualty and fatality risk. The scales are adjusted so that the casualty and fatality risks for the most popular vehicle type, midsize cars, are similar. With the exception of sports cars and import luxury cars, the points in Figure 4-4 are arranged left to right by increasing size within each vehicle type.

Figure 4-4. State casualty and US fatality risk for drivers, by vehicle type

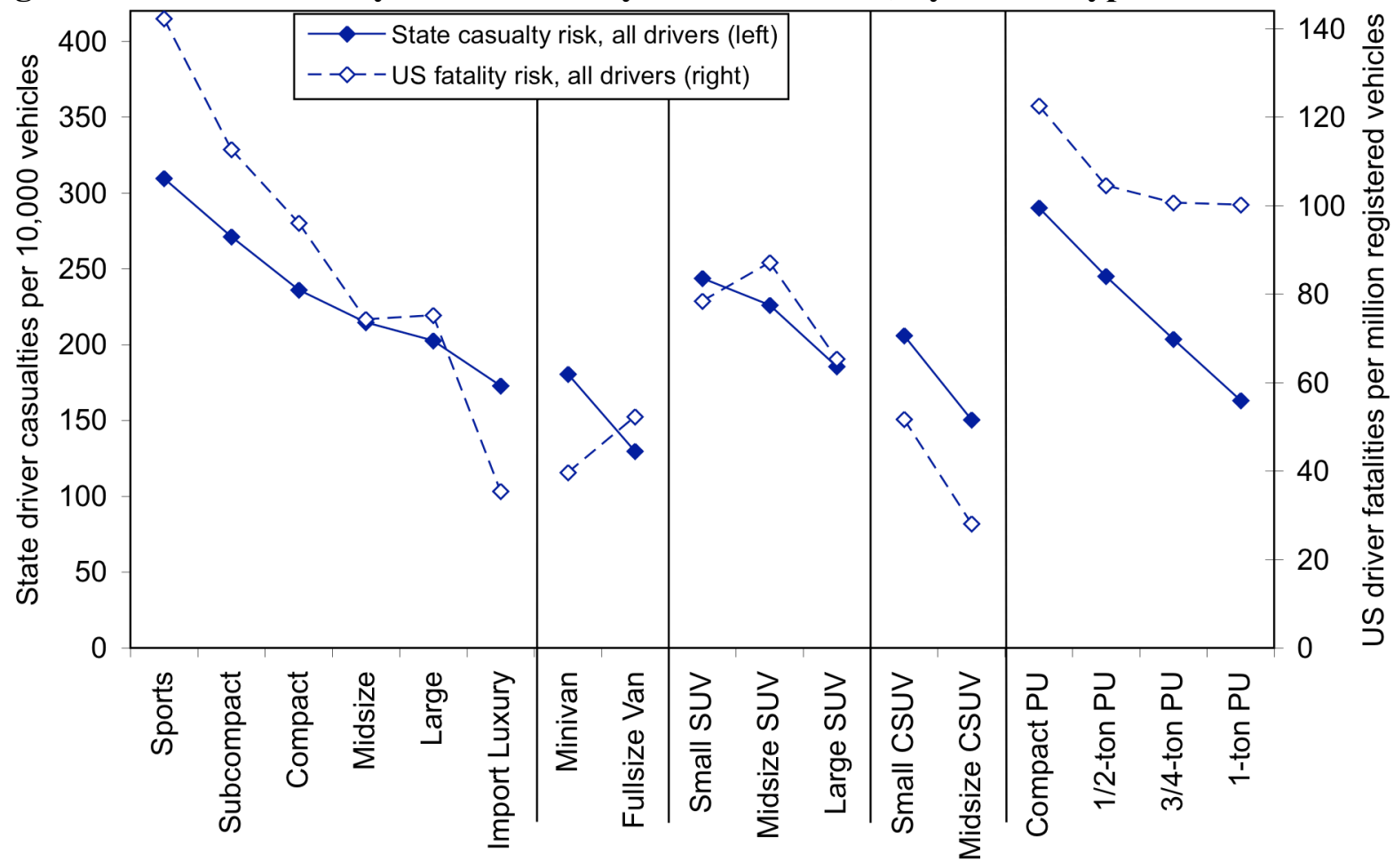

Relative to risks of other vehicles types, Figure 4-4 indicates that state casualty risks for sports cars and pickups, and to a lesser extent subcompact and compact cars, are substantially lower than US fatality risks for those vehicle types. Similarly, note that US fatality risks for import luxury cars, minivans, and crossover SUVs are quite a bit lower, relative to other vehicle types, than their state casualty risks. These differences in US fatality and state casualty risk to drivers may be partially explained by the different measure of exposure used to calculate each type of risk. Pickup trucks tend to be driven more miles each year than midsize cars; therefore using the number of police-reported crashes as the measure of exposure, as is done in calculating the state casualty risks, accounts for the higher mileage pickups are driven, and lowers their casualty risk relative to their fatality risk. On the other hand, import luxury cars are driven fewer miles than midsize cars, which may explain why their state casualty risk increases relative to their fatality risk. However, sports cars are also driven fewer miles than midsize cars, so differences in exposure do not explain their lower casualty risk relative to their fatality risk; and minivans, like 
pickups, are driven substantially more miles than midsize cars, yet their casualty risk is relatively higher than their fatality risk.

Other possible explanations for the differences in casualty and fatality risk for certain types of vehicles are better protection from serious injuries and differences in crash severity (independent of driver or location effects) among vehicle types.

In terms of risk to others, state casualty risks are similar to US fatality risks for most vehicle types, as shown in Figure 4-5, except for 3/4- and 1-ton pickup trucks and fullsize vans, and to a lesser extent truck-based SUVs, which have lower state casualty risks to others than US fatality risks.

Figure 4-5. State casualty and US fatality risk to drivers of other vehicles, by vehicle type

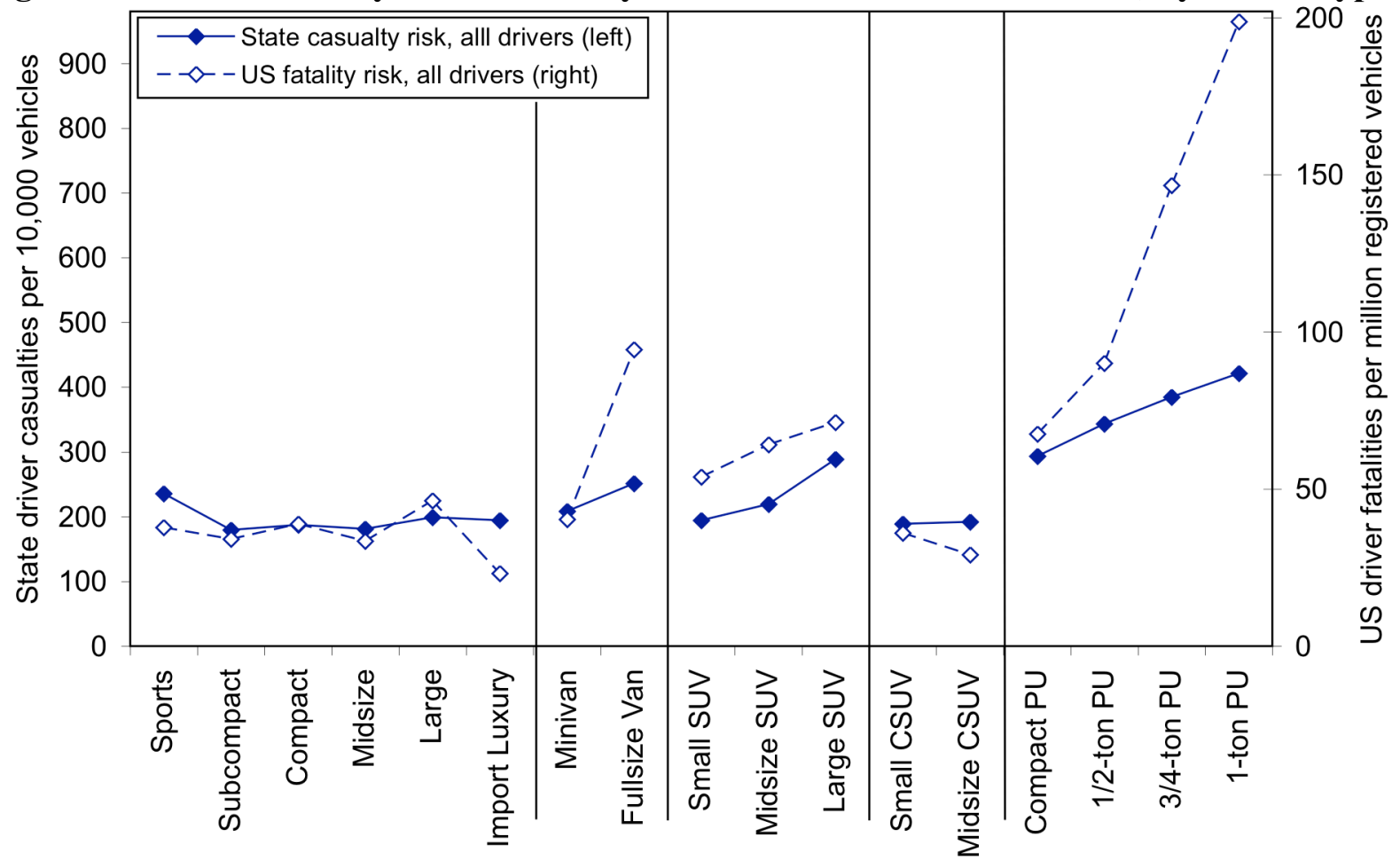

Figures 4-6 and 4-7 show the effect of excluding crashes involving young male and elderly drivers, and crashes in the most rural and most urban counties, on state casualty risks, by vehicle type. Excluding young male and elderly drivers and casualties from the analysis has virtually no effect on the state casualty rates by vehicle type. However, removing crashes that occurred in very rural or very urban counties increases the casualty risks for all vehicles except for casualty risk for drivers of pickup trucks making them more similar to those for other vehicle types. Figure 4-7 indicates that accounting for crash location raises the casualty risk imposed on drivers of other vehicles about equally for all vehicle types. 
Figure 4-6. Casualty risk for drivers accounting for driver age and crash location, by vehicle type

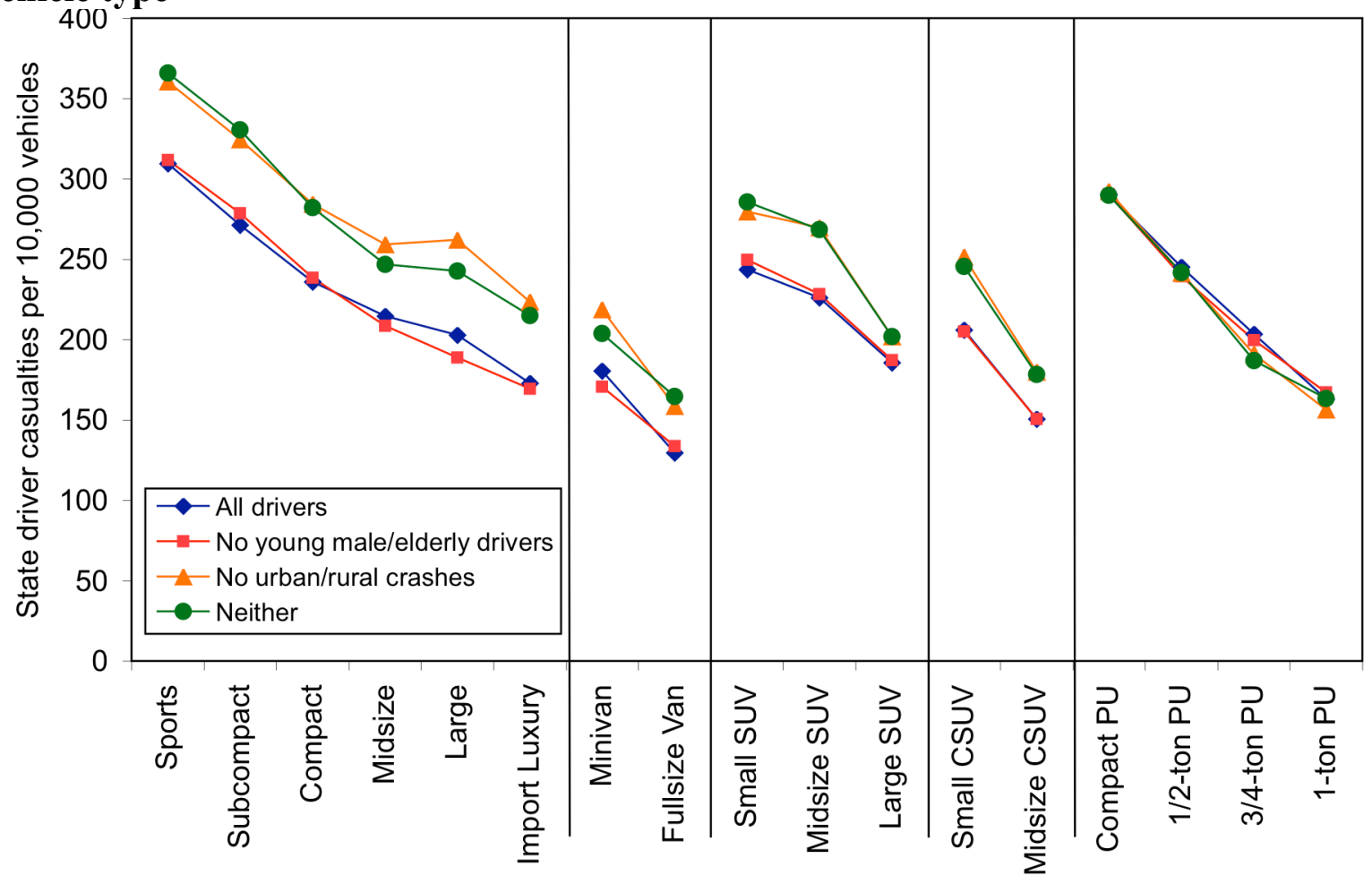

Figure 4-7. Casualty risk to others accounting for driver age and crash location, by vehicle type

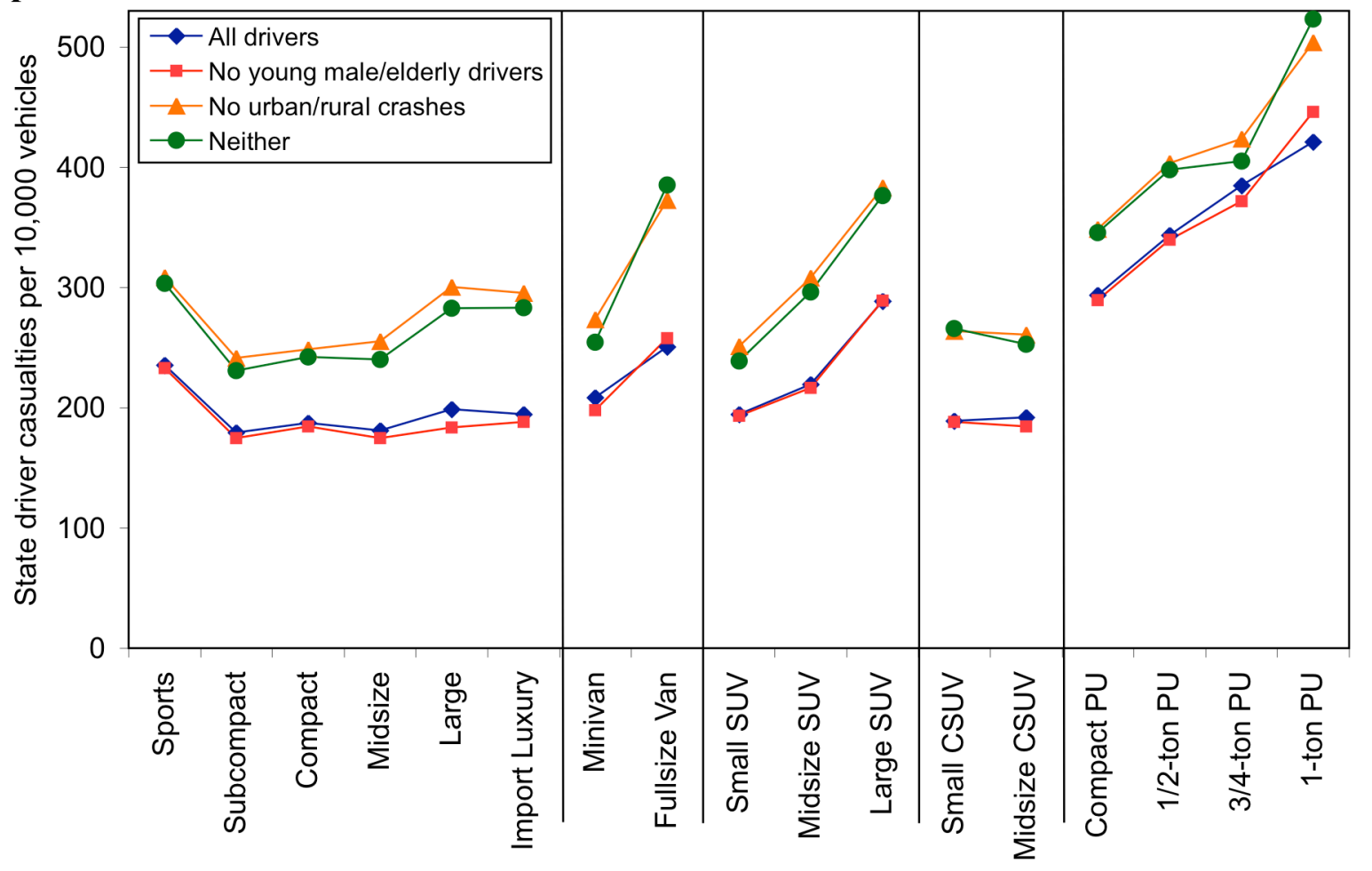


Figure 4-6 suggests that casualty risk to drivers declines with increasing vehicle class, for each vehicle type, while Figure 4-7 suggests that casualty risk to others increases with increasing van, SUV, and pickup class. However, these figures mask the large range in casualty risk by vehicle models: Figures 4-8 through 4-10 show the correlation between casualty risk (after excluding casualties involving young male and elderly drivers, and in urban and rural areas) and vehicle curb weight, for vehicle models. As described above, the earliest vehicle data on vehicle weight, wheelbase and track width provided us are from MY2005, whereas the latest casualty data available from the five states are for MY2000-2004 vehicles. We obtained vehicle weight, wheelbase, and track width from the website of Motortrend magazine for models that were discontinued before 2005. ${ }^{3}$ We calculated simple averages for models that had versions with different measurements. Figures 4-8 through 4-10 include models with at least 1,000 vehicles involved in, or at least 30 serious injuries or fatalities to drivers in, police-reported crashes; these models account for $93 \%$ of all light-duty vehicles involved in police-reported crashes, excluding 3/4- and 1-ton pickups and fullsize vans (the Chevrolet Cavalier was involved in the most crashes, nearly 20,000, and had the most casualties, nearly 700). The figures indicate that casualty risk tends to decrease with increasing vehicle weight, especially for cars; the correlation between adjusted casualty risk and curb weight by vehicle model is 0.31 for all light vehicles, 0.36 for cars and 0.14 for light trucks. The correlations are not improved when the points in each figure are weighted by the number of vehicles involved in crashes.

Figure 4-8. Relationship between casualty risk to drivers and vehicle curb weight, by vehicle model (casualty risk is calculated excluding crashes involving young male or elderly drivers, and crashes in very rural or very urban counties)

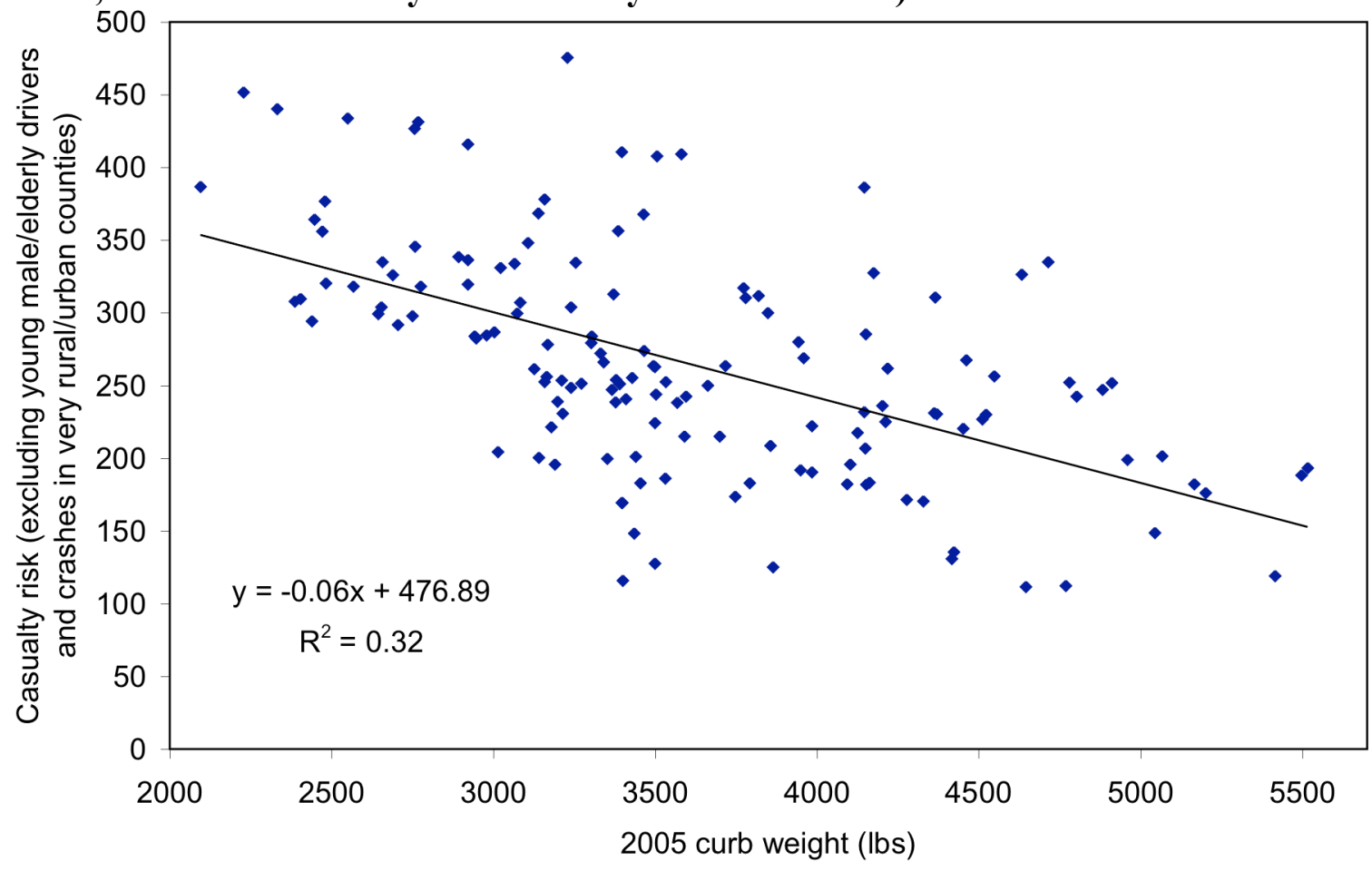

${ }^{3}$ http://www.motortrend.com/used_cars/specifications/index.html 
Figure 4-9. Relationship between casualty risk to drivers and car curb weight, by car model (casualty risk is calculated excluding crashes involving young male or elderly drivers, and crashes in very rural or very urban counties)

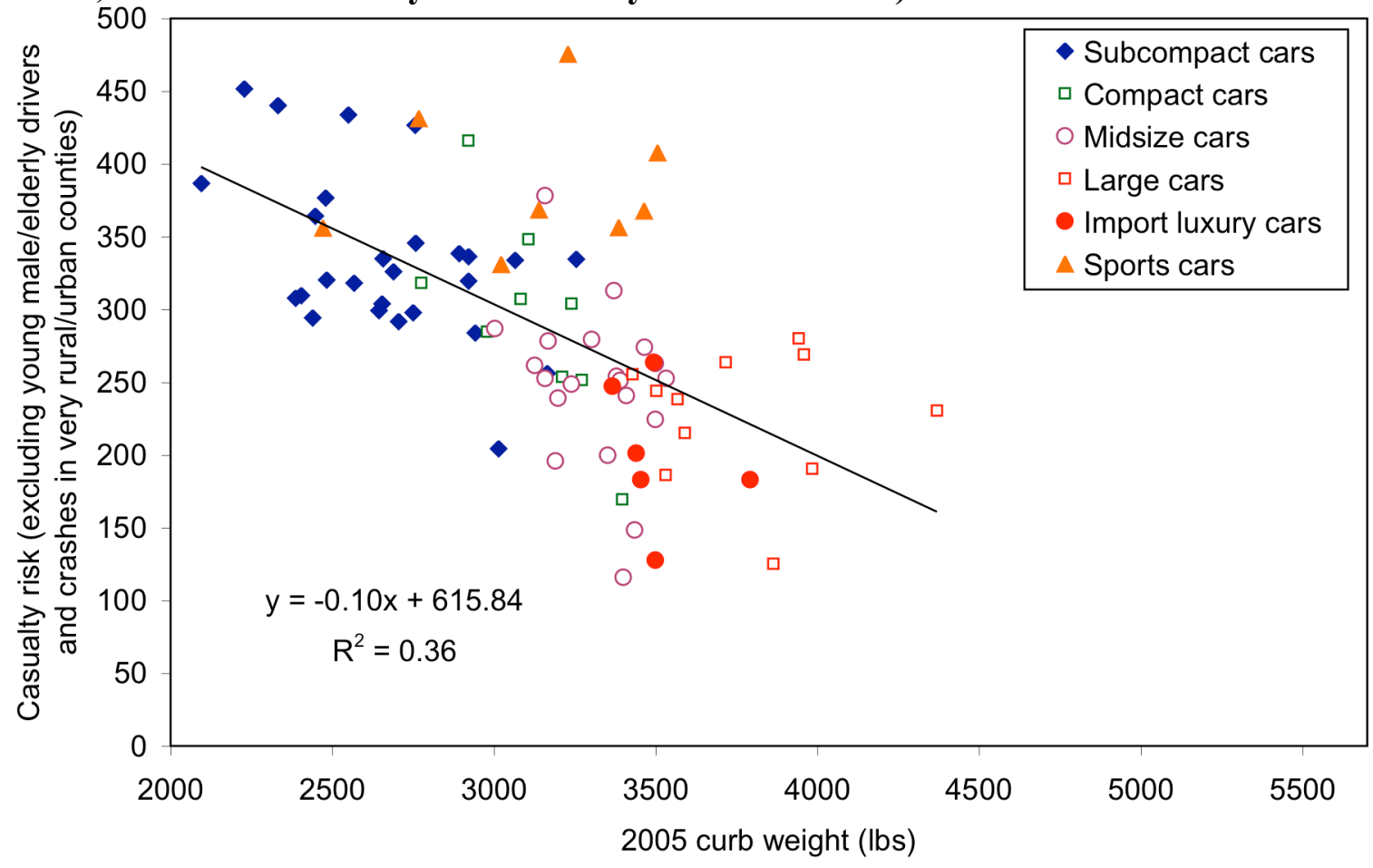

Figure 4-10. Relationship between casualty risk to drivers and light truck curb weight, by light truck model (casualty risk is calculated excluding crashes involving young male or elderly drivers, and crashes in very rural or very urban counties)

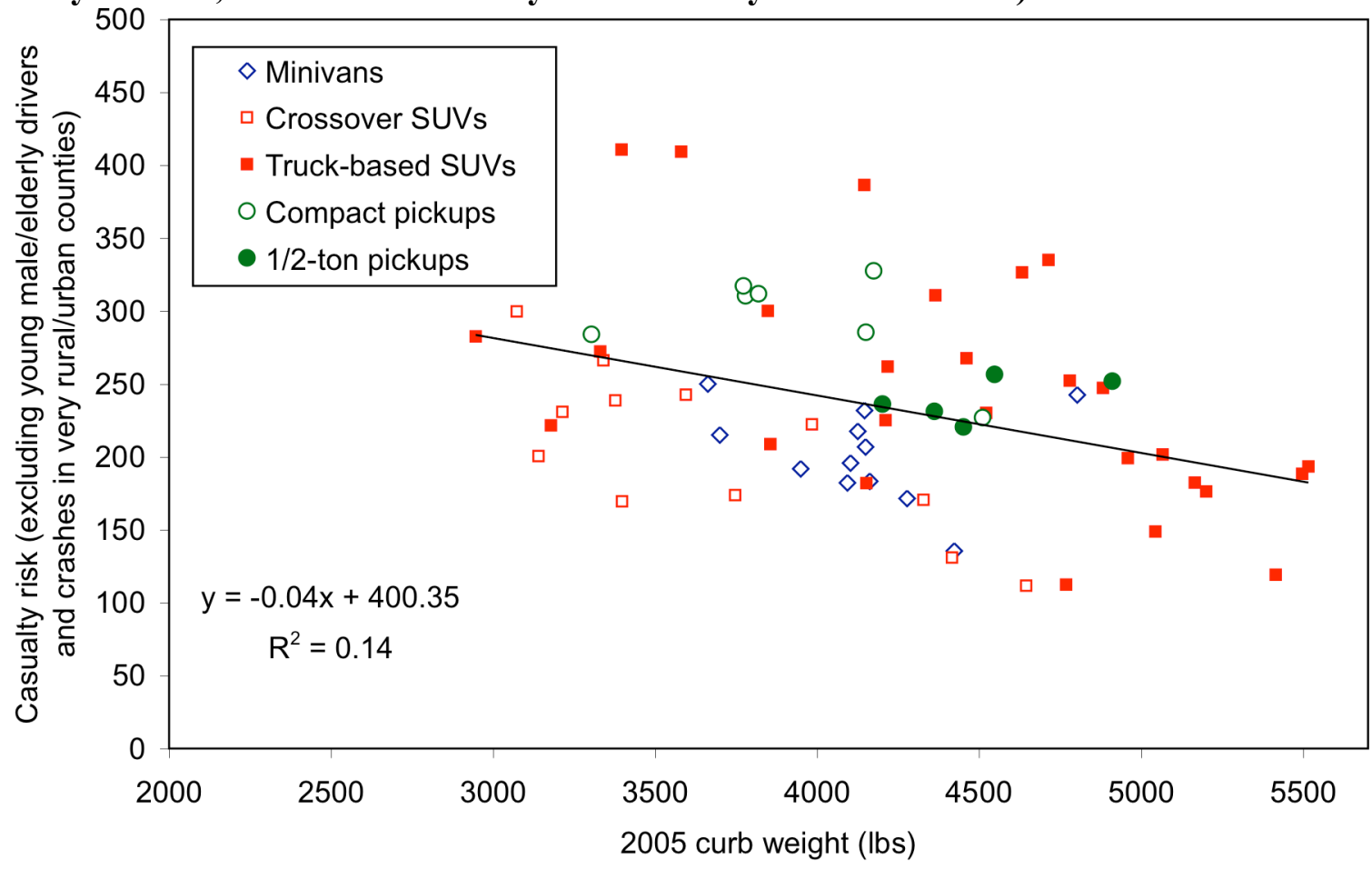


Figures 4-11 through 4-13 show that adjusted casualty risk also tends to decrease with increasing footprint. However, relatively low $\mathrm{R}^{2}$ values indicate again that there is little correlation between adjusted casualty risk and vehicle footprint, for all light vehicles $(0.26)$, cars $(0.37)$, or light trucks $(0.08)$, whether unweighted values or values weighted by the number of vehicles involved in crashes are used.

Figure 4-11. Relationship between casualty risk to drivers and vehicle footprint, by vehicle model (casualty risk is calculated excluding crashes involving young male or elderly drivers, and crashes in very rural or very urban counties)

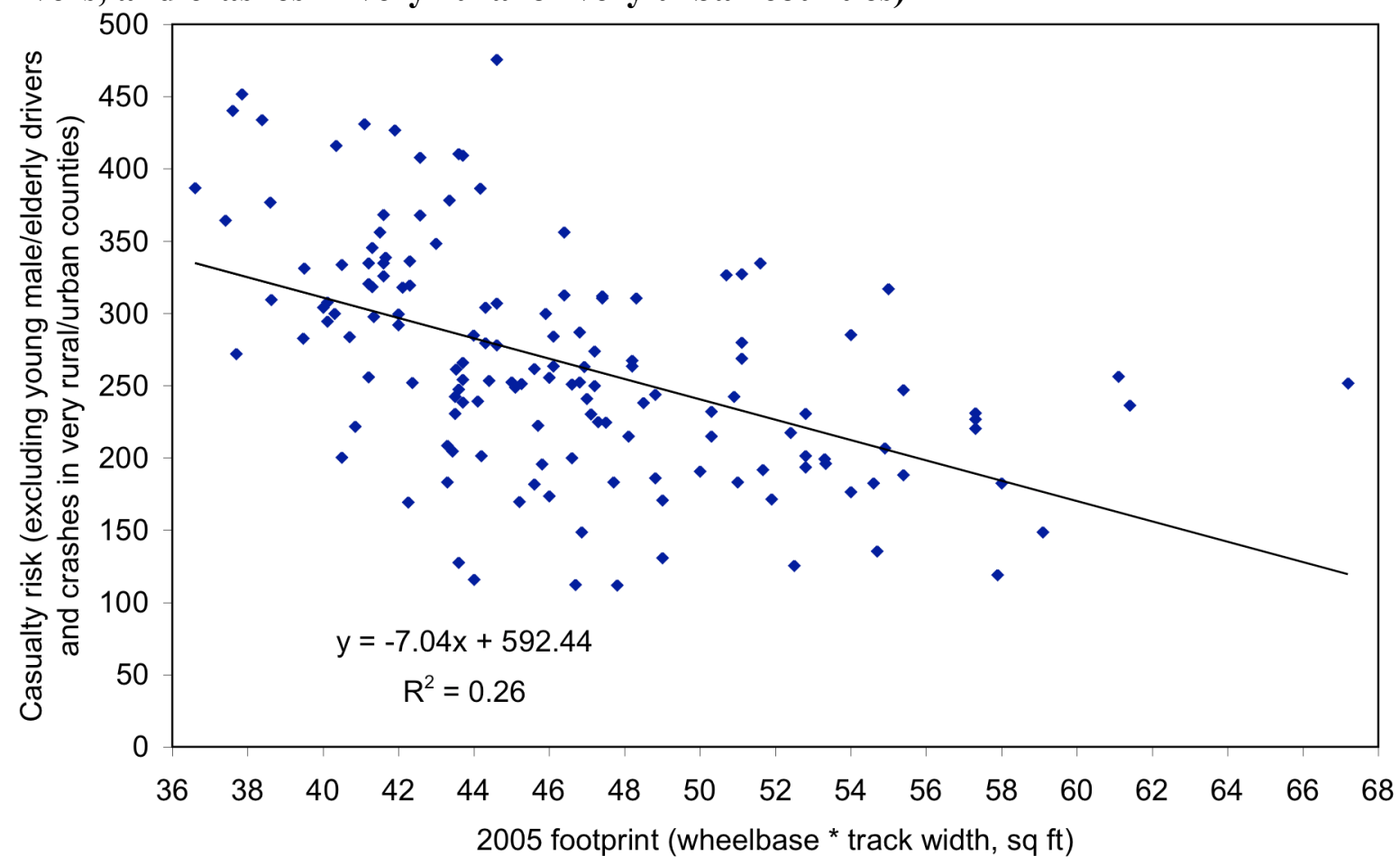


Figure 4-12. Relationship between casualty risk to drivers and car footprint, by car model (casualty risk is calculated excluding crashes involving young male or elderly drivers, and crashes in very rural or very urban counties)

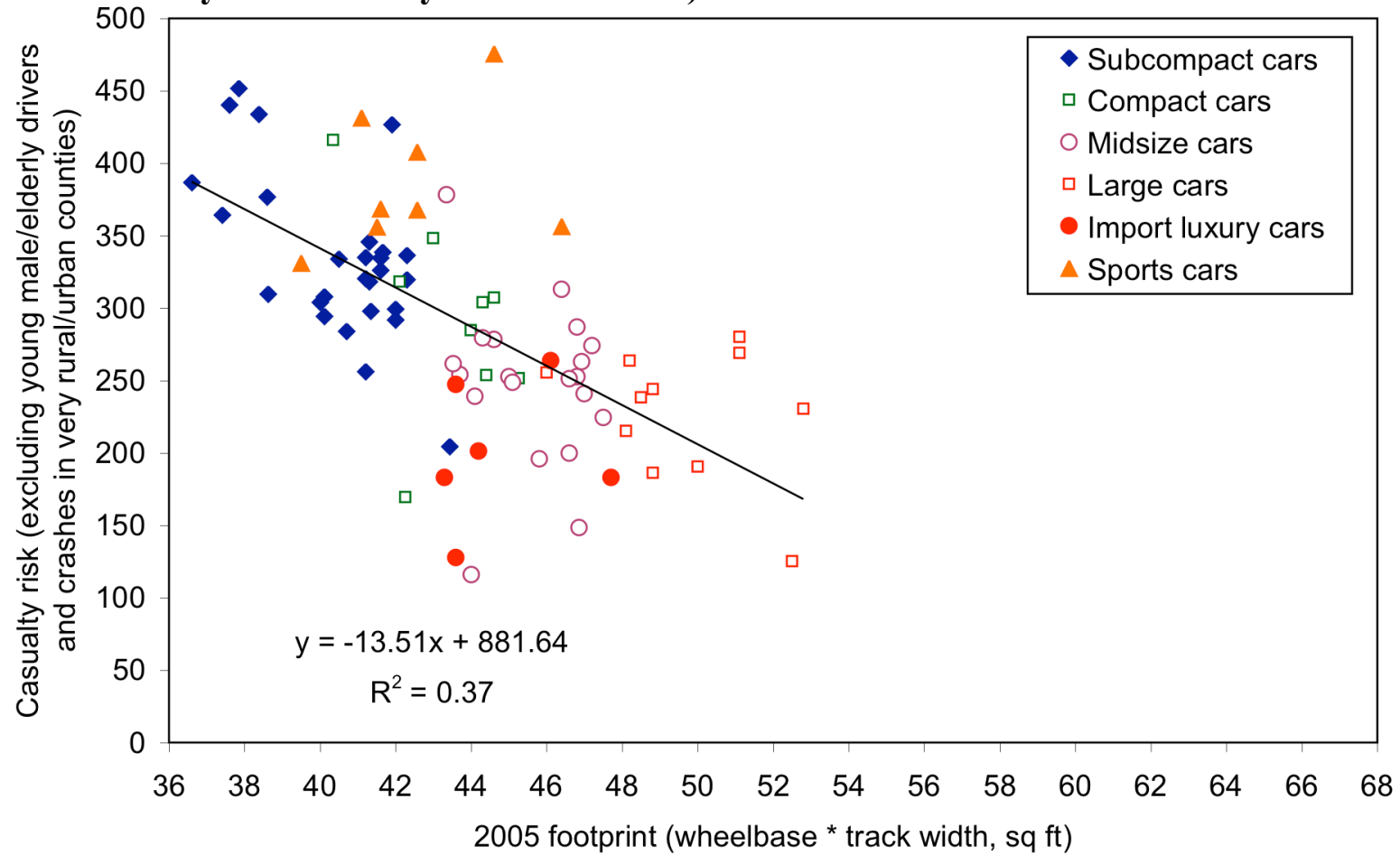

Figure 4-13. Relationship between casualty risk to drivers and light truck footprint, by light truck model (casualty risk is calculated excluding crashes involving young male or elderly drivers, and crashes in very rural or very urban counties)

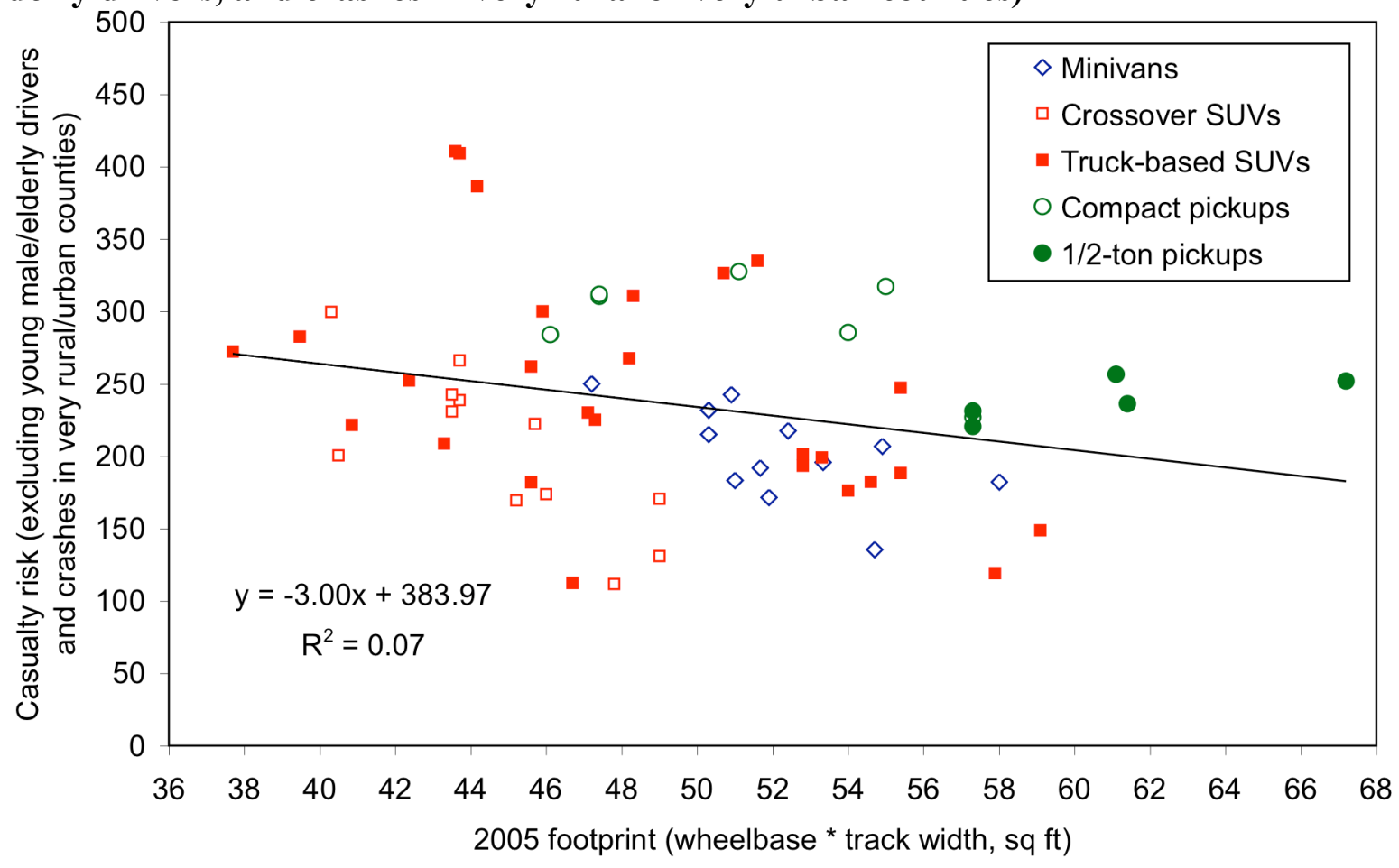


Figures 4-14 and 4-15 show that there also is little correlation between adjusted casualty risk in frontal crashes and wheelbase (0.16) and adjusted casualty risk in left side crashes and track width (0.35). Removing the outlier vehicle models labeled in each figure improves the correlation to only 0.17 in Figure 4-14 and 0.47 in Figure 4-15. (Again, only models involved in at least 1,000, or with at least 30 driver fatalities in, frontal or left side crashes are included; because fewer vehicles are involved in left side crashes than frontal crashes, fewer models are shown in Figure 4-15 than in Figure 4-14.)

Figure 4-14. Relationship between casualty risk to drivers in frontal crashes and vehicle wheelbase, by vehicle model (casualty risk is calculated excluding crashes involving young male or elderly drivers, and crashes in very rural or very urban counties)

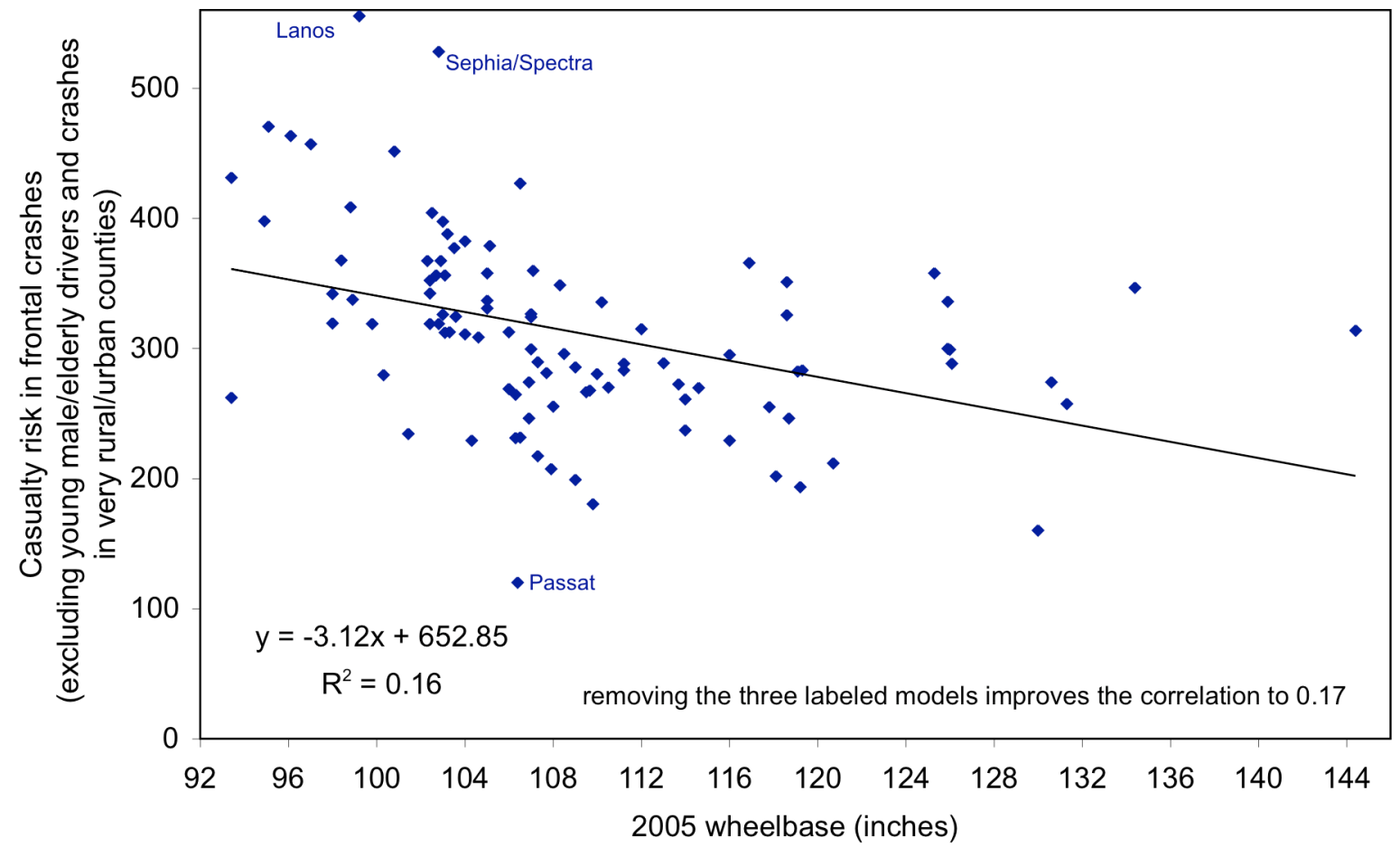


Figure 4-15. Relationship between casualty risk to drivers in left side crashes and vehicle track width, by vehicle model (casualty risk is calculated excluding crashes involving young male or elderly drivers, and crashes in very rural or very urban counties)

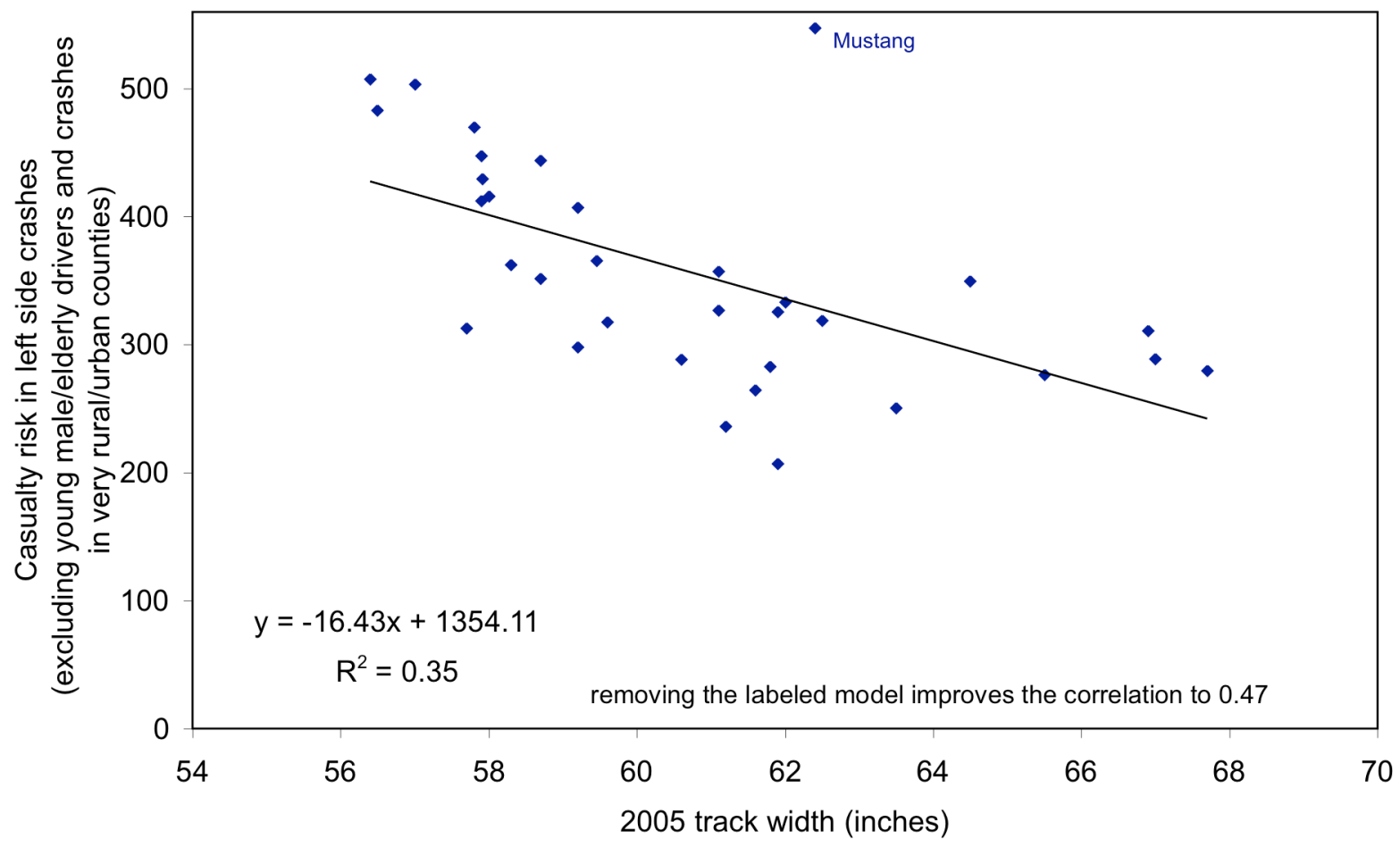

Figures 4-16 through 4-18 show the relationship between adjusted casualty risk to drivers of other vehicles and curb weight, while Figures 4-19 through 4-21 show the relationship with footprint. Although there is not a strong correlation, the risk imposed by light trucks on drivers of other vehicles tends to increase with increasing weight (Figure 4-18) or footprint (Figure 421). 
Figure 4-16. Relationship between casualty risk to drivers of other vehicles and vehicle wheelbase, by vehicle model (casualty risk is calculated excluding crashes involving young male or elderly drivers, and crashes in very rural or very urban counties)

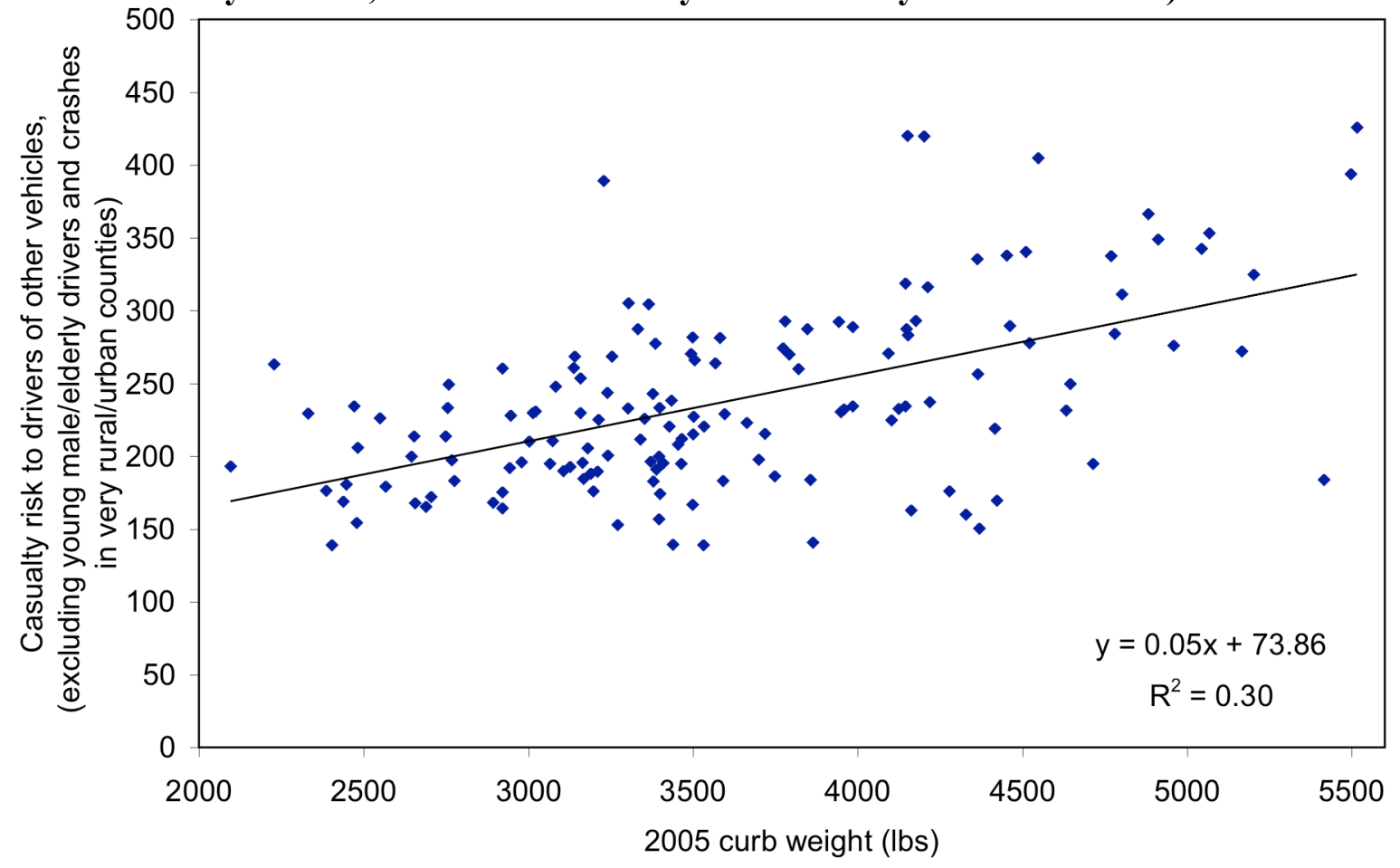

Figure 4-17. Relationship between casualty risk to drivers of other vehicles and car wheelbase, by car model (casualty risk is calculated excluding crashes involving young male or elderly drivers, and crashes in very rural or very urban counties)

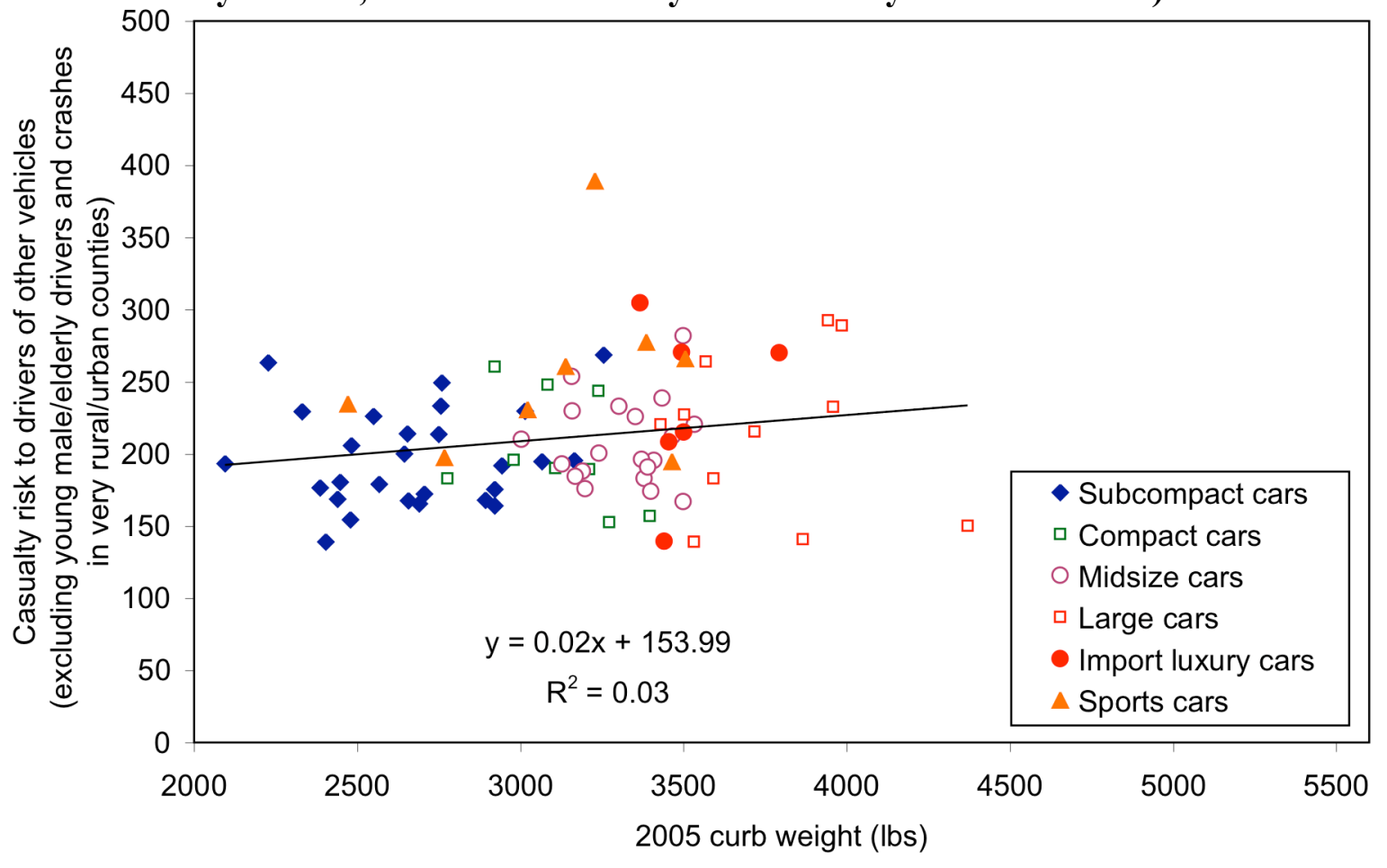


Figure 4-18. Relationship between casualty risk to drivers of other vehicles and light truck wheelbase, by light truck model (casualty risk is calculated excluding crashes involving young male or elderly drivers, and crashes in very rural or very urban counties)

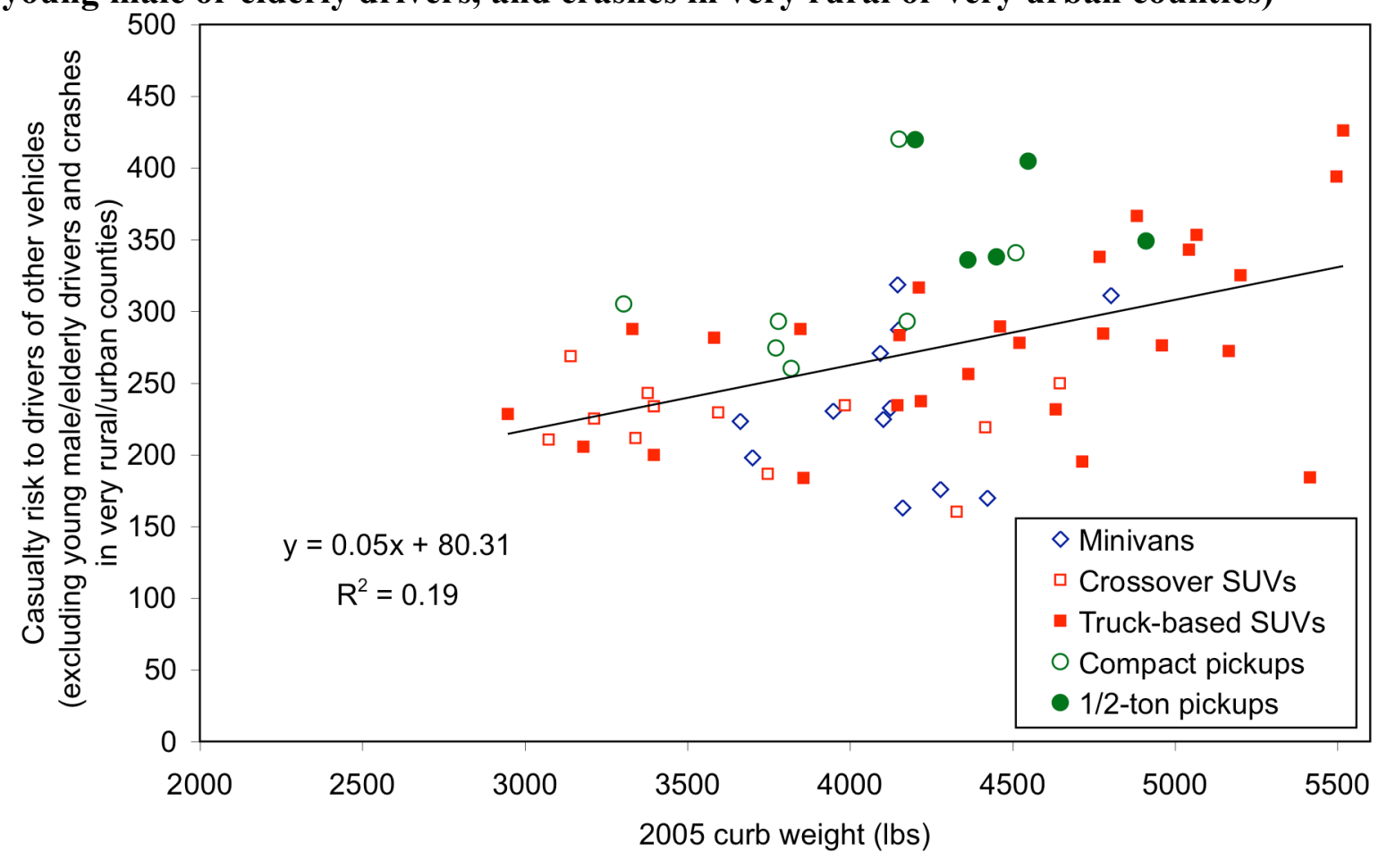


Figure 4-19. Relationship between casualty risk to drivers of other vehicles and vehicle footprint, by vehicle model (casualty risk is calculated excluding crashes involving young male or elderly drivers, and crashes in very rural or very urban counties)

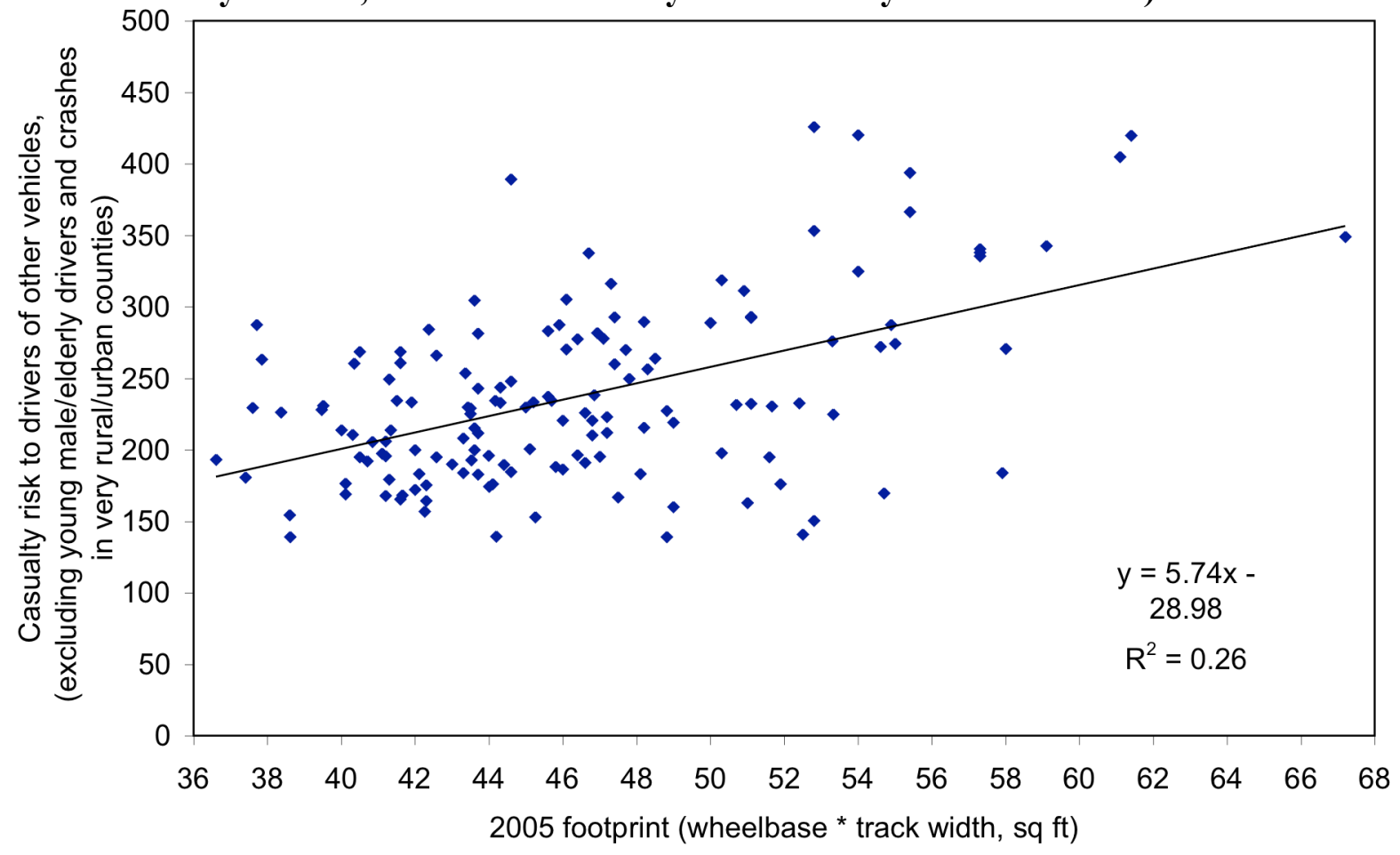

Figure 4-20. Relationship between casualty risk to drivers of other vehicles and car footprint, by car model (casualty risk is calculated excluding crashes involving young male or elderly drivers, and crashes in very rural or very urban counties)

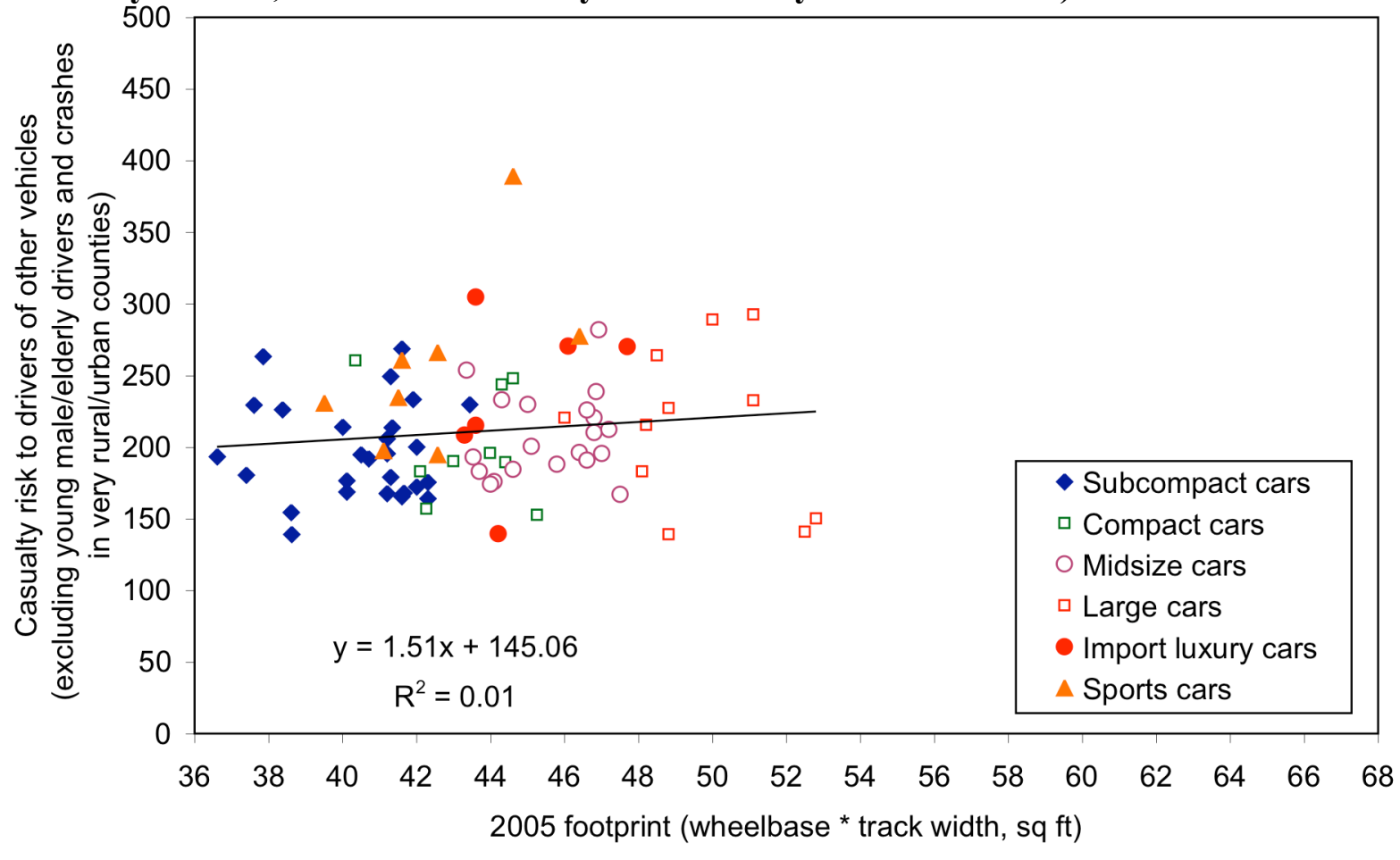


Figure 4-21. Relationship between casualty risk to drivers of other vehicles and light truck footprint, by light truck model (casualty risk is calculated excluding crashes involving young male or elderly drivers, and crashes in very rural or very urban counties)

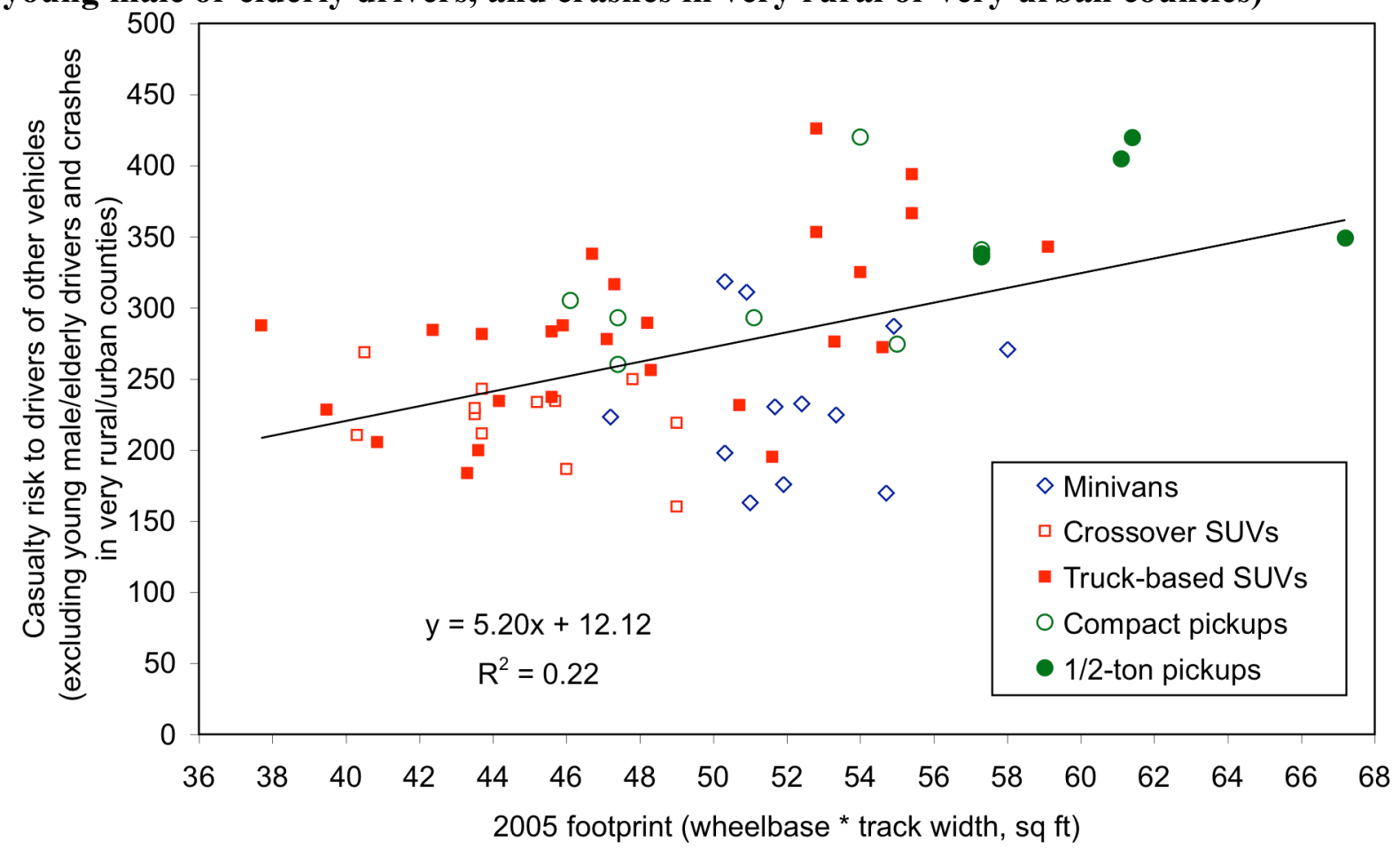

When we weight each vehicle model by the number of registered vehicles, the correlations improve for Figure 4-16 (from 0.23 to 0.40 ) and for Figure 4-18 (from 0.23 to 0.33 ). 
Tables 4-1 and 4-2 summarize the results of the analyses shown in Figures 4-8 through 4-18. Table 4-1 shows the results when each vehicle model is treated equally, whereas Table 4-2 shows the results when each model is weighted by the number of vehicles involved in a policereported crash. The "slope" column in each table indicates the relationship between the dependent variable (adjusted casualty risk) and the independent variable: vehicle weight (in 100 $\mathrm{lb}$ increments), footprint, wheelbase or track width. The negative slope values in the tables indicate that casualty risk to drivers decreases as vehicle weight and size increase; the positive slopes for the last six rows in each table indicate that casualty risk to drivers of other vehicles increases as vehicle footprint increases. The "p-value" column indicates whether the estimated slopes are statistically significant. For the most part, the relationships between casualty risk and vehicle weight or footprint are statistically significant. However, the vehicle measurements explain a relatively small portion of the range in casualty risk by vehicle model, as indicated by the relatively low $\mathrm{R}^{2}$ values in the last column.

Table 4-1. Summary results of relationship between vehicle weight/size and casualty risk (excluding crashes involving young male or elderly drivers, and crashes in very rural or urban counties), by vehicle model, unweighted

\begin{tabular}{|c|c|c|c|c|c|c|c|}
\hline \multirow[b]{2}{*}{$\begin{array}{l}\text { Dependent } \\
\text { variable }\end{array}$} & \multirow[b]{2}{*}{$\begin{array}{l}\text { Independent } \\
\text { variable }\end{array}$} & \multirow[b]{2}{*}{$\begin{array}{l}\text { Vehicle } \\
\text { type }\end{array}$} & \multirow[b]{2}{*}{$\begin{array}{l}\text { Figure } \\
\text { number }\end{array}$} & \multicolumn{4}{|c|}{ Results } \\
\hline & & & & $\begin{array}{l}\text { Vehicle } \\
\text { models }\end{array}$ & Slope & P-value & $\mathrm{R}^{2}$ \\
\hline \multirow{6}{*}{$\begin{array}{l}\text { Casualty risk to } \\
\underline{\text { drivers }}\end{array}$} & Curb weight & LDV & $4-8$ & 144 & -5.5 & $<0.001$ & 0.31 \\
\hline & $(100 \mathrm{lbs})$ & Cars & $4-9$ & 81 & -10.4 & $<0.001$ & 0.36 \\
\hline & & Trucks & $4-10$ & 63 & -3.5 & 0.002 & 0.14 \\
\hline & Footprint & LDV & $4-11$ & 144 & -7.1 & $<0.001$ & 0.26 \\
\hline & $(\mathrm{sq} \mathrm{ft})$ & Cars & $4-12$ & 81 & -13.5 & $<0.001$ & 0.37 \\
\hline & & Trucks & $4-13$ & 63 & -3.1 & 0.025 & 0.08 \\
\hline $\begin{array}{l}\text { Casualty risk to } \\
\text { drivers in frontal } \\
\text { crashes }\end{array}$ & $\begin{array}{l}\text { Wheelbase } \\
\text { (inches) }\end{array}$ & LDV & $4-14$ & 90 & -2.7 & $<0.001$ & 0.13 \\
\hline $\begin{array}{l}\text { Casualty risk to } \\
\text { drivers in left } \\
\text { side crashes }\end{array}$ & $\begin{array}{l}\text { Track width } \\
\text { (inches) }\end{array}$ & LDV & $4-15$ & 30 & -18.3 & $<0.001$ & 0.34 \\
\hline \multirow{6}{*}{$\begin{array}{l}\text { Casualty risk to } \\
\text { drivers of other } \\
\underline{\text { vehicles }}\end{array}$} & Curb weight & LDV & $4-16$ & 144 & 4.6 & $<0.001$ & 0.30 \\
\hline & $(100 \mathrm{lbs})$ & Cars & $4-17$ & 81 & 1.8 & 0.098 & 0.03 \\
\hline & & Trucks & $4-18$ & 63 & 4.6 & $<0.001$ & 0.19 \\
\hline & Footprint & LDV & $4-19$ & 144 & 5.7 & $<0.001$ & 0.26 \\
\hline & $(\mathrm{sq} \mathrm{ft})$ & Cars & $4-20$ & 81 & 1.5 & 0.291 & 0.01 \\
\hline & & Trucks & $4-21$ & 63 & 5.2 & $<0.001$ & 0.22 \\
\hline
\end{tabular}

The results in Table 4-2 are similar to those in Table 4-1, which suggests that weighting casualty risk by the number of each vehicle model involved in police-reported crashes has little effect on the overall results. As mentioned above, weighting risk by the number of vehicles involved does improve the explanatory power of footprint on risk imposed by others, for all light vehicles (from $\mathrm{R}^{2}$ of 0.26 to 0.47 ) and for light trucks (from $\mathrm{R}^{2}$ of 0.22 to 0.33 ) 
Table 4-2. Summary results of relationship between vehicle weight/size and casualty risk (excluding crashes involving young male or elderly drivers, and crashes in very rural or urban counties), by vehicle model, weighted by the number of vehicles of each model involved in police-reported crashes

\begin{tabular}{|c|c|c|c|c|c|c|c|}
\hline \multirow[b]{2}{*}{$\begin{array}{l}\text { Dependent } \\
\text { variable }\end{array}$} & \multirow[b]{2}{*}{$\begin{array}{l}\text { Independent } \\
\text { variable }\end{array}$} & \multirow[b]{2}{*}{$\begin{array}{l}\text { Vehicle } \\
\text { type }\end{array}$} & \multirow[b]{2}{*}{$\begin{array}{l}\text { Figure } \\
\text { number }\end{array}$} & \multicolumn{4}{|c|}{ Results } \\
\hline & & & & $\begin{array}{l}\text { Vehicle } \\
\text { models }\end{array}$ & Slope & P-value & $\mathrm{R}^{2}$ \\
\hline \multirow{6}{*}{$\begin{array}{l}\text { Casualty risk to } \\
\text { drivers }\end{array}$} & \multirow{3}{*}{$\begin{array}{l}\text { Curb weight } \\
(100 \mathrm{lbs})\end{array}$} & LDV & $4-8$ & 144 & -4.6 & $<0.001$ & 0.31 \\
\hline & & Cars & 4-9 & 81 & -8.9 & $<0.001$ & 0.37 \\
\hline & & Trucks & $4-10$ & 63 & -2.8 & 0.002 & 0.09 \\
\hline & \multirow{3}{*}{$\begin{array}{l}\text { Footprint } \\
\text { (sq ft) }\end{array}$} & LDV & $4-11$ & 144 & -4.8 & $<0.001$ & 0.23 \\
\hline & & Cars & $4-12$ & 81 & -11.8 & $<0.001$ & 0.37 \\
\hline & & Trucks & 4-13 & 63 & -1.7 & 0.098 & 0.04 \\
\hline $\begin{array}{l}\text { Casualty risk to } \\
\text { drivers in frontal } \\
\text { crashes }\end{array}$ & $\begin{array}{l}\text { Wheelbase } \\
\text { (inches) }\end{array}$ & LDV & 4-14 & 90 & -2.1 & $<0.001$ & 0.12 \\
\hline $\begin{array}{l}\text { Casualty risk to } \\
\text { drivers in left side } \\
\text { crashes }\end{array}$ & $\begin{array}{l}\text { Track width } \\
\text { (inches) }\end{array}$ & LDV & $4-15$ & 30 & -17.5 & $<0.001$ & 0.36 \\
\hline \multirow{6}{*}{$\begin{array}{l}\text { Casualty risk to } \\
\text { drivers of other } \\
\text { vehicles }\end{array}$} & \multirow{3}{*}{$\begin{array}{l}\text { Curb weight } \\
(100 \mathrm{lbs})\end{array}$} & LDV & $4-16$ & 144 & 5.5 & $<0.001$ & 0.43 \\
\hline & & Cars & $4-17$ & 81 & 2.7 & 0.005 & 0.10 \\
\hline & & Trucks & 4-18 & 63 & 4.8 & 0.001 & 0.17 \\
\hline & \multirow{3}{*}{$\begin{array}{l}\text { Footprint } \\
\text { (sq ft) }\end{array}$} & LDV & $4-19$ & 144 & 6.9 & $<0.001$ & 0.47 \\
\hline & & Cars & $4-20$ & 81 & 3.3 & 0.010 & 0.08 \\
\hline & & Trucks & 4-21 & 63 & 5.6 & $<0.001$ & 0.33 \\
\hline
\end{tabular}


Table 4-3 shows the results of combining curb weight and footprint in the same regression model. Models 1 and 2 suggest that casualty risk to drivers decreases as the weight or footprint of their vehicle increases, and that increasing curb weight by $100 \mathrm{lbs}$ has about the same reduction in casualty risk as increasing footprint by 1 square foot. Weight $\left(\mathrm{R}^{2}=0.31\right)$ explains slightly more of the variation in casualty risk than footprint $(0.26)$; including both weight and footprint negligibly improves the model fit (to 0.32 ), but footprint is not statistically significant (Model 3).

Models 4 through 6 in Table 4-3 introduce dummy variables for six vehicle types (sports cars, import luxury cars, minivans, truck-based SUVs, car-based crossover SUVs, and pickups; other cars are the default vehicle type). Model fit is improved to about 0.55 , with negligible changes in the coefficients depending on whether weight, footprint, or both are used. The coefficients on the type variables are in the expected direction: higher risk than cars in sports cars, pickups, and SUVs, while lower risks than cars in import luxury cars, crossover SUVs, and minivans. The coefficient on minivans is not statistically significant in any of the three models, while the coefficient on SUVs becomes not significant when footprint is used (Model 5).

Table 4-3. Casualty risk to drivers by vehicle model (excluding crashes involving young male or elderly drivers, and crashes in very rural or urban counties)

\begin{tabular}{|c|c|c|c|c|c|c|c|c|c|c|c|c|}
\hline & \multicolumn{2}{|c|}{ Model 1} & \multicolumn{2}{|c|}{ Model 2} & \multicolumn{2}{|c|}{ Model 3} & \multicolumn{2}{|c|}{ Model 4} & \multicolumn{2}{|c|}{ Model 5} & \multicolumn{2}{|c|}{ Model 6} \\
\hline & Est & P val & Est & P val & Est & P val & Est & P val & Est & P val & Est & $\mathrm{P}$ val \\
\hline Intercept & 464 & $<.0001$ & 594 & $<.0001$ & 525 & $<.0001$ & 506 & $<.0001$ & 668 & $<.0001$ & 596 & $<.0001$ \\
\hline $\begin{array}{l}\text { Curb wt } \\
(100 \mathrm{lbs}) \\
\text { Footprint } \\
\text { (sq ft) }\end{array}$ & -5.5 & $<.0001$ & -7.1 & $<.0001$ & $\begin{array}{l}-4.1 \\
-2.4\end{array}$ & $\begin{array}{l}0.001 \\
0.145\end{array}$ & -7.1 & $<.0001$ & -8.7 & $<.0001$ & $\begin{array}{l}-4.6 \\
-3.8 \\
\end{array}$ & $\begin{array}{l}0.003 \\
0.049\end{array}$ \\
\hline $\begin{array}{l}\text { sports } \\
\text { implux } \\
\text { minivan } \\
\text { suv } \\
\text { csuv } \\
\text { pu } \\
\end{array}$ & & & & & & & $\begin{array}{c}102.4 \\
-56.1 \\
-10.6 \\
59.2 \\
-39.2 \\
61.3 \\
\end{array}$ & $\begin{array}{l}<.0001 \\
0.016 \\
0.574 \\
0.001 \\
0.026 \\
0.002 \\
\end{array}$ & $\begin{array}{c}88.7 \\
-77.4 \\
-11.3 \\
0.1 \\
-72.7 \\
84.4 \\
\end{array}$ & $\begin{array}{c}<.0001 \\
0.001 \\
0.560 \\
0.994 \\
<.0001 \\
<.0001 \\
\end{array}$ & $\begin{array}{c}96.5 \\
-63.0 \\
-4.6 \\
41.9 \\
-50.3 \\
77.9 \\
\end{array}$ & $\begin{array}{c}<.0001 \\
0.007 \\
0.807 \\
0.028 \\
0.006 \\
0.000 \\
\end{array}$ \\
\hline Model R2 & & 0.31 & & 0.26 & & 0.32 & & 0.55 & & 0.54 & & 0.56 \\
\hline
\end{tabular}

Table 4-3 indicates that even after excluding young male and elderly drivers, and crashes in rural and urban counties, and accounting for vehicle weight and footprint, sports cars, pickup trucks and truck-based SUVs have higher risk to their drivers $(96,78$, and 42 more casualties per 10,000 drivers, respectively, in Model 6), and import luxury cars and crossover SUVs have lower risk to their drivers (63 and 42 fewer casualties per 10,000 drivers, respectively), than cars. The table also indicates that, when both weight and footprint are included in the same model (Models 3 and 6), vehicle footprint is statistically insignificant. This could be because the CAFE compliance data used in this analysis do not allow footprint to increase with increasing weight for different versions of the same vehicle model, as discussed in Section 1 above. More accurate footprint data for different versions of the same vehicle model are needed to assess whether weight and footprint can be included in the same statistical model. 
Figure 4-22 plots actual casualty risk by vehicle model against casualty risk predicted by Model 6 in Table 4-3, while Figure 4-23 plots the predicted risk as well as the residual risk unexplained by the statistical model. The large degree of scatter of the residual values in Figure 4-23 indicates that using a subset of data that excludes crashes involving young male and elderly drivers, and in very rural and very urban counties, while accounting for vehicle curb weight, footprint, and type, explains only about half of the variability in casualty risk by vehicle model.

Figure 4-22. Actual and predicted casualty risk to drivers by vehicle model, based on vehicle curb weight, footprint, and type (excluding crashes involving young male or elderly drivers, and crashes in very rural or urban counties)

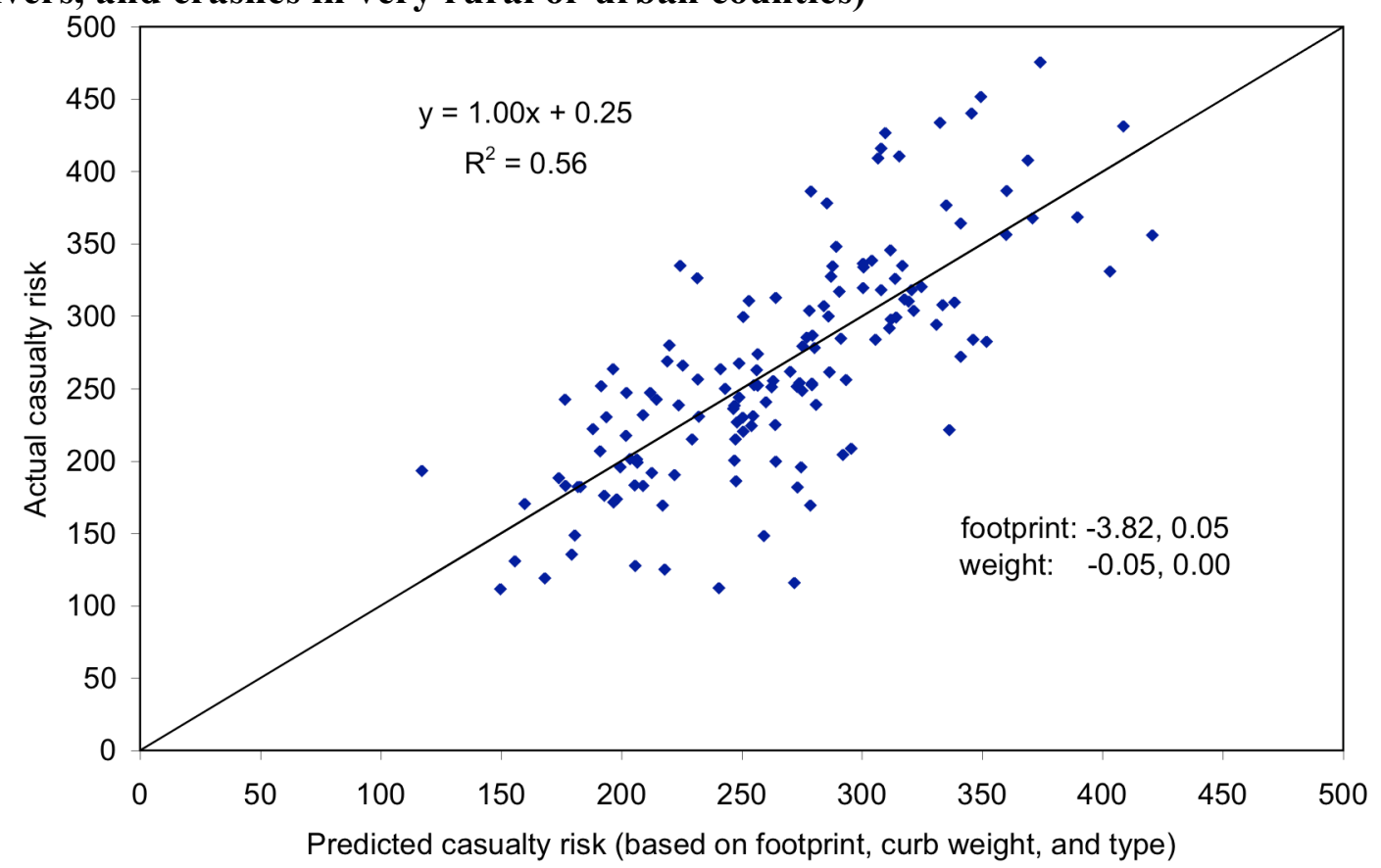


Figure 4-23. Predicted and residual casualty risk to drivers by vehicle model, based on vehicle curb weight, footprint, and type (excluding crashes involving young male or elderly drivers, and crashes in very rural or urban counties)

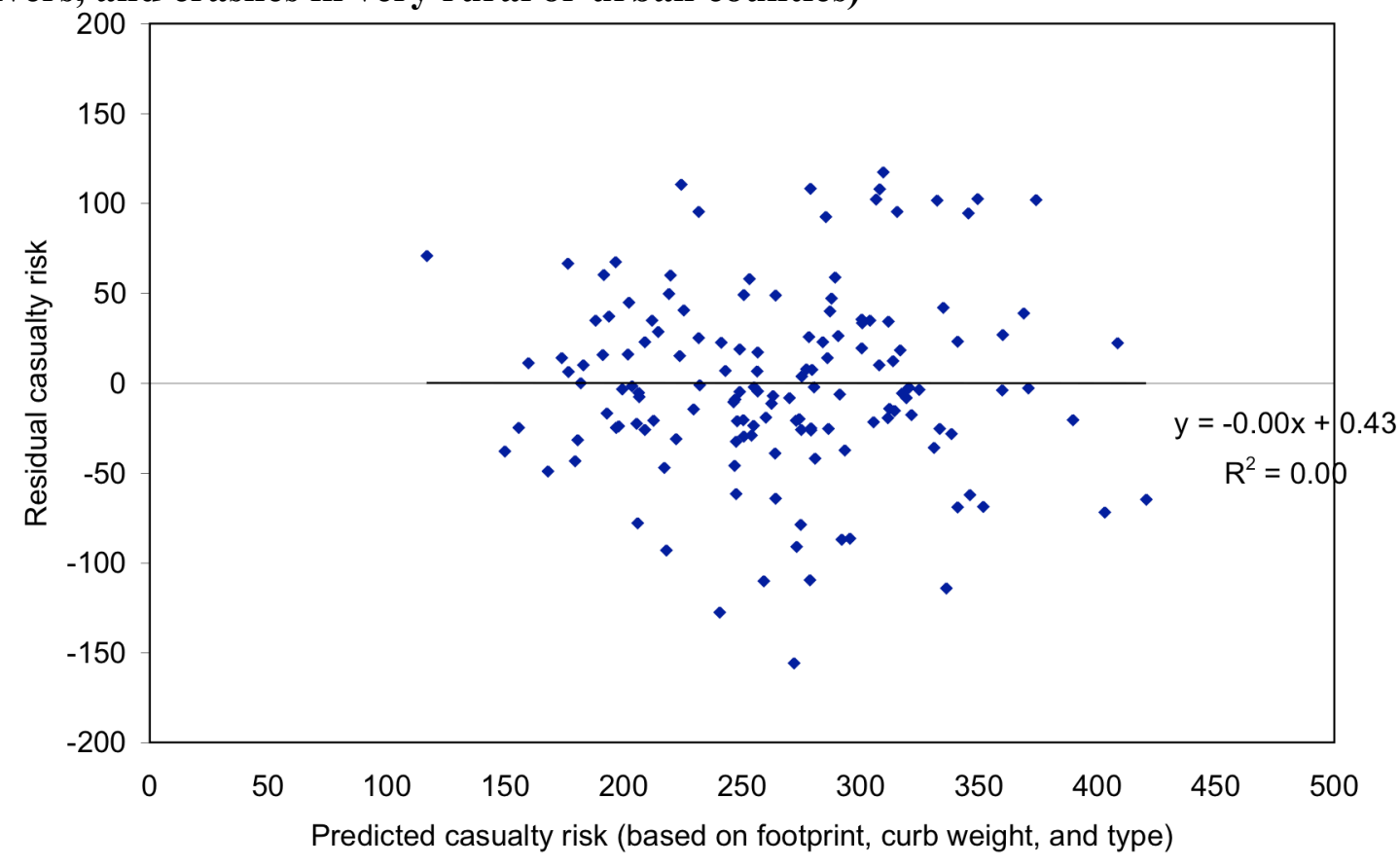

Table 4-4 shows the results for the same six models, this time using casualty risk to drivers of other vehicles as the dependent variable. The coefficients on weight and footprint are all positive, indicating that casualty risk to drivers of other vehicles increases as the weight and/or footprint of the subject vehicle increases; again, the effects of a 100-lb increase in weight on casualty risk to other drivers is about the same as a 1 square foot increase in footprint. Similar to Table 4-3, when variables for vehicle type are added (Models 4 through 6), the size of the coefficient on weight or size is reduced somewhat, and the overall fit of the model improves (from an $\mathrm{R}^{2}$ of about 0.25 to 0.43 ). Although the coefficients on vehicle type often are not statistically significant, the coefficients for sports cars and pickups are consistently large and statistically significant, indicating that these two types of vehicles impose greater risk on drivers of other vehicles than cars. 
Table 4-4. Casualty risk to drivers of other vehicles by vehicle model (excluding crashes involving young male or elderly drivers, and crashes in very rural or urban counties)

\begin{tabular}{|c|c|c|c|c|c|c|c|c|c|c|c|c|}
\hline & \multicolumn{2}{|c|}{ Model 1} & \multicolumn{2}{|c|}{ Model 2} & \multicolumn{2}{|c|}{ Model 3} & \multicolumn{2}{|c|}{ Model 4} & \multicolumn{2}{|c|}{ Model 5} & \multicolumn{2}{|c|}{ Model 6} \\
\hline & Est & P val & Est & P val & Est & P val & Est & P val & Est & P val & Est & P val \\
\hline Intercept & 126 & $<.0001$ & 20 & 0.613 & 65 & 0.124 & 153 & $<.0001$ & 103 & 0.024 & 144 & 0.005 \\
\hline $\begin{array}{l}\text { Curb wt } \\
(100 \mathrm{lbs}) \\
\text { Footprint } \\
\text { (sq ft) }\end{array}$ & 4.1 & $<.0001$ & 5.5 & $<.0001$ & $\begin{array}{l}2.7 \\
2.4\end{array}$ & $\begin{array}{l}0.008 \\
0.088\end{array}$ & 2.9 & 0.000 & 3.2 & 0.002 & $\begin{array}{l}2.6 \\
4.2 \\
\end{array}$ & $\begin{array}{l}0.072 \\
0.820\end{array}$ \\
\hline $\begin{array}{l}\text { sports } \\
\text { implux } \\
\text { minivan } \\
\text { suv } \\
\text { csuv } \\
\text { pu }\end{array}$ & & & & & & & $\begin{array}{l}50.7 \\
27.3 \\
-3.5 \\
27.1 \\
-0.5 \\
97.6\end{array}$ & $\begin{array}{c}0.008 \\
0.207 \\
0.842 \\
0.089 \\
0.977 \\
<.0001\end{array}$ & $\begin{array}{l}55.8 \\
36.3 \\
-0.4 \\
52.8 \\
13.4 \\
92.1 \\
\end{array}$ & $\begin{array}{c}0.004 \\
0.095 \\
0.982 \\
<.0001 \\
0.400 \\
<.0001\end{array}$ & $\begin{array}{c}51.4 \\
28.8 \\
-4.2 \\
29.2 \\
0.7 \\
95.8\end{array}$ & $\begin{array}{c}0.008 \\
0.202 \\
0.816 \\
0.108 \\
0.966 \\
<.0001\end{array}$ \\
\hline Model R2 & & 0.25 & & 0.23 & & 0.27 & & 0.43 & & 0.41 & & 0.43 \\
\hline
\end{tabular}

This initial regression analysis on casualty risk by vehicle model indicates that using a subset of data that excludes young male and elderly drivers, and crashes in very rural and very urban counties, while accounting for vehicle footprint, curb weight, and type, pickups and truck-based SUVs have higher risks to their drivers, and pickups impose higher risks to drivers of other vehicles, than cars. In addition, the models explain only about half of the variability in casualty risk to drivers by vehicle model, and less than half of the variability in risk to drivers of other vehicles

Several steps can be taken to refine the preliminary analysis described here. First, the footprint data used here do not vary for different versions of the same vehicle model. In addition, weight, footprint, and sales data on fullsize (3/4-ton and 1-ton) pickups and vans were not included in the data provided us. We will investigate obtaining more detailed footprint (wheelbase and track width) data, as well as weight and sales data for larger fullsize pickups and vans, from other sources. Because fullsize pickups and vans tend to be larger and heavier than other vehicle types, and impose higher casualty risk on drivers of other vehicles, we expect that including these models will strengthen the relationship of increasing risk to others as subject vehicle weight and/or footprint increases.

Second, the casualty risks in this analysis used all police-reported crashes, including propertydamage only crashes, as the measure of exposure. Under-reporting of minor crashes may bias our results, by state or perhaps vehicle type. Calculating casualty risk by using only serious crashes (defined as those in which at least one vehicle occupant is seriously injured or killed), and not all police-reported crashes, should remove any bias from under-reporting of minor crashes. Casualty risks per serious crash will also give a stronger measure of vehicle crashworthiness than casualty risks per police-reported crash, which include both how well a vehicle protects an occupant given a crash (crashworthiness) as well as how well a vehicle can avoid a serious crash altogether.

Third, because vehicle weight and footprint are fairly well correlated, it may be difficult to distinguish the effect of weight from the effect of footprint, or vice versa. In addition, these two 
variables may account for the effect of other vehicle attributes (such as hood or bumper height; frontal or side stiffness; height of center of gravity; presence of specific safety technologies such as electronic stability controls, side impact airbags, roof strength, seat belt technologies; etc.) on casualty risk by individual vehicle models. To the extent that these other vehicle attributes that directly improve occupant protection are correlated with vehicle weight or footprint, weight or footprint variables in regression models may be picking up the safety benefit of these other vehicle attributes. In an earlier analysis we found that a measure of general quality of vehicle design, resale value, explained more of the variability in fatality risk by vehicle model than vehicle weight. We propose to investigate whether vehicle resale value after several years, from a source such as Kelley's Blue Book, explains more variability in casualty risk than vehicle weight or footprint.

Fourth, rather than building regression models to explain in the range in casualty risks by vehicle model, logistic regression analysis can be used to analyze the probability that a particular vehicle/driver/location combination will result in a driver casualty. Logistic regression analysis allows inclusion of driver age/gender and crash location variables directly in the regression model, rather than excluding crashes involving young males or elderly drivers, and that occurred in very rural or very urban counties, as has been done here. Logistic regression analysis can also account for differences in casualty risk among states. We can also investigate the state crash data to determine if other variables Kahane used (time of day, weather conditions, belt use, etc.) can be included.

Finally, we propose to expand the analyses to other states that report vehicle identification number in their crash data. An expanded dataset will allow more robust analysis of the causes of casualty risk by vehicle model.

\section{Risks in truck-based and car-based SUVs}

Comparison of fatality and casualty risks in conventional truck-based SUVs and newer, carbased crossover SUVs indicates that vehicle weight can be reduced while maintaining size and at least maintaining, if not increasing, occupant safety. In model year 1996, only $2 \%$ of SUV sales were car-based crossover SUVs; by 2005, half of SUVs sold were crossovers. Crossover SUVs are characterized as having unibody construction similar to cars, which eliminates the rigid longitudinal frame rails in truck-based SUVs and pickup trucks that are often deadly to occupants in other vehicles. In addition, crossover SUVs tend to have a lower center of gravity than truck-based SUVs, which makes them less likely to roll over.

Crossovers with the same footprint have about $10 \%$ lower mass, and substantially lower fatality risk, than truck-based SUVs (Table 5-1). Compared to truck-based SUVs, compact crossovers have $36 \%$ lower fatality risk, and midsize crossovers have $49 \%$ lower fatality risk, to their drivers. Small crossovers also impose 31\% lower fatality risk on drivers of other vehicles than small truck-based SUVs, while midsize crossovers impose $37 \%$ lower fatality risk on others than comparable truck-based SUVs. The last two rows of Table 5-1 show similar results after accounting for driver age and crash location, using casualty risks for 2000 to 2004 vehicles from the state crash data, as described above. The exception is casualty risk to others, where compact crossover SUVs impose a $6 \%$ higher casualty risk on others than compact truck-based SUVs. 
However, Table 5-1 indicates that this difference may not be statistically significant, as the 95\% confidence intervals for the risks by compact SUVs and compact crossover SUVs overlap.

Table 5-1. Comparison of footprint, curb weight and risk, for SUVs and crossover SUVs

\begin{tabular}{|l|cc||cc|}
\hline Item & $\begin{array}{c}\text { Compact } \\
\text { SUV }\end{array}$ & $\begin{array}{c}\text { Midsize } \\
\text { SUV }\end{array}$ & $\begin{array}{c}\text { Compact } \\
\text { Crossover SUV }\end{array}$ & $\begin{array}{c}\text { Midsize } \\
\text { Crossover SUV }\end{array}$ \\
\hline Footprint (sq ft)* & 42 & 49 & 43 & 49 \\
Curb weight (lbs)* & 3672 & 4500 & $3359(-313)$ & $4081(-419)$ \\
2003-07 fatality risk to drivers & $69 \pm 9$ & $63 \pm 4$ & $44 \pm 4(-36 \%)$ & $32 \pm 3(-49 \%)$ \\
2003-07 fatality risk to others & $52 \pm 8$ & $59 \pm 4$ & $36 \pm 4(-31 \%)$ & $37 \pm 4(-37 \%)$ \\
2000-04 casualty risk to drivers & $286 \pm 25$ & $268 \pm 12$ & $245 \pm 21(-14 \%)$ & $178 \pm 23(-34 \%)$ \\
2000-04 casualty risk to others & $216 \pm 27$ & $270 \pm 15$ & $229 \pm 24(+6 \%)$ & $218 \pm 30(-19 \%)$ \\
\hline
\end{tabular}

* Sales-weighted averages for MY05 models

Of course it is likely that factors other than weight reduction account for the lower risks in crossover SUVs; for example, unibody construction, lower bumpers, and less rigid fronts make crossovers more compatible with cars than truck-based SUVs. NHTSA research indicates that light truck bumper height and frontal stiffness are dangerous to car occupants, even after accounting for light truck weight (Kahane 20003); and lower height and center of gravity, stronger roofs, and perhaps early adoption of electronic stability controls may account for the lower rollover fatalities in crossover SUVs. The experience of crossover SUVs indicates that other vehicle attributes may be as important, if not more important, than vehicle weight or footprint in terms of occupant safety.

\section{Conclusions}

This report summarizes our analysis of the relationship between vehicle weight, footprint and risk. Our analysis indicates that there is a relatively weak relationship between footprint and casualty risk to drivers of individual vehicle models, either for cars or light trucks. There is a wide range in casualty risk for vehicle models of the same type and footprint, even after accounting for miles driven, driver age and gender, and crash location. Similarly, there is little relationship between vehicle wheelbase and casualty risk in frontal crashes, or track width and risk in left side crashes. The relationship between footprint and casualty risk imposed on drivers of other vehicles is also relatively weak, although the risks imposed by light trucks tend to increase as their footprint increases. Because the current CAFE standards are based on the footprint of individual vehicles, we focus our conclusions on the relationship between footprint and risk. However, our analysis leads us to similar conclusions regarding the relationship between vehicle weight and risk.

Based on our study, a fuel economy standard that discourages vehicles with smaller footprint, or lower weight, will not necessarily reduce casualties, and will not be as effective in reducing fuel consumption and associated greenhouse gas emissions as a single stringent standard applied across all vehicle sizes. In fact, there is evidence that manufacturers' redesign of traditional truck-based SUVs into car-based crossover SUVs has resulted in lighter vehicles of the same size, with reduced risks both to their drivers and to the drivers of other vehicles. A single stringent fuel economy standard would discourage the continued use of light trucks (with low 
fuel economy) as essentially substitutes for cars, and encourage greater use of lighter and smaller vehicles. Details of vehicle design, which can be improved through direct safety regulations, will have a greater effect on occupant safety than fuel economy standards that are structured to maintain vehicle size or weight.

\section{References}

Kahane, C.J., 2003. Vehicle weight, fatality risk and crash compatibility of model year 1991-99 passenger cars and light trucks. NHTSA DOT HS 809 662. U.S. Department of Transportation, National Highway Traffic Safety Administration, Washington, D.C.

Kahane, C.J., 2004. Response to docket comments on NHTSA technical report "Vehicle weight, fatality risk and crash compatibility of model year 1991-99 passenger cars and light trucks". Submission to docket no. NHTSA-2003-16318. U.S. Department of Transportation, National Highway Traffic Safety Administration, Washington, D.C.

Van Auken, R.M., Zellner, J.W., 2002. An assessment of the effects of vehicle weight on fatality risk in model year 1985-98 passenger cars and 1985-97 light trucks. DRI-TR02-02. Dynamic Research, Inc., Torrance, California.

Van Auken, R.M., Zellner, J.W., Boughton, J.P., Brubacher, J.M., 2003. A further assessment of the effects of vehicle weight and size parameters on fatality risk in model year 1985-98 passenger cars and 1985-97 light trucks. DRI-TR03-01. Dynamic Research, Inc., Torrance, California

Van Auken, R.M., Zellner, J.W., 2005a. An assessment of the effects of vehicle weight and size on fatality risk in 1985 to 1998 model year passenger cars and 1985 to 1997 model year light trucks and vans. SAE Technical Paper Series, 2005-01-1354. Society of Automotive Engineers, Warrendale, PA.

Van Auken, R.M., Zellner, J.W., 2005b. Supplemental results on the independent effects of curb weight, wheelbase, and track on fatality risk in 1985-1998 model year passenger cars and 19861997 model year LTVs. DRI-TR05-01. Dynamic Research, Inc., Torrance, California.

Wenzel, Thomas P., and Marc Ross, 2005. "The effects of vehicle model and driver behavior on risk." Accident Analysis and Prevention, 37:479-494. LBNL-55417 